\title{
Control of Interfacial Dust Cake to Improve Efficiency of Moving Bed Granular Filters
}

Final Technical Report

\author{
U.S. Department of Energy \\ Contract No. DE-FG26-99FT40588 \\ Prepared by \\ Robert C. Brown and Gerald M. Colver \\ Center for Sustainable Environmental Technologies \\ Iowa State University \\ 286 Metals Development Building \\ Ames, IA 50011
}

October 31, 2002 


\section{TABLE OF CONTENTS}

LIST OF TABLES

LIST OF FIGURES

ABSTRACT

CHAPTER 1. INTRODUCTION 1

CHAPTER 2. BACKGROUND 3

2.1 History of moving bed granular filters (MBGF) 3

2.2 Theory of filtration 6

2.3 Effect of operating conditions 11

$\begin{array}{ll}2.4 \text { Shortcomings of previous work } & 13\end{array}$

2.5 Innovations introduced by this research 14

CHAPTER 3. EXPERIMENTAL APPARATUS AND METHODS 16

3.1. Cold-flow apparatus for filter and instrumentation 16

3.2. Simulating high pressure, high temperature conditions 20

3.3. Statistical methods 22

3.3.1. Central composite design 23

3.3.2. Data collection 26

3.3.3. Statistical analysis $\quad 29$

CHAPTER 4. RESULTS AND DISCUSSION 32

$\begin{array}{lll}4.1 & \text { Atmospheric tests } & 32\end{array}$

4.1.1 APD as a function of operating condition variables 33

4.1.2 Average efficiency (AE) as a function of GF and DL 40

4.1.3 Residual analysis for APD model 44 
4.1.4 Residual analysis for AE model $\quad 47$

4.1.5 F-test for APD and AE models 49

$\begin{array}{llr}4.2 & \text { Similitude tests } & 50\end{array}$

4.2.1 Similitude tests on $4 \mathrm{~mm}$ granules $\quad 50$

4.2.2 Comparison between $2 \mathrm{~mm}$ and $4 \mathrm{~mm}$ granules 59

4.3 Miscellaneous trials $\quad 64$

4.3.1 Effect of operating pressure 64

4.3.2 Effect of superficial velocity 66

$\begin{array}{lll}\text { 4.3.3 } & \text { Occurrence of dust cake } & 73\end{array}$

$\begin{array}{ll}\text { CHAPTER 5. CONCLUSIONS } & 75\end{array}$

$\begin{array}{ll}\text { REFERENCES } & 78\end{array}$

APPENDIX A. ISOKINETIC SAMPLING VELOCITY CALCULATION 81

APPENDIX B. PARTICLE SIZE ANALYSIS $\quad 84$

APPENDIX C. FILTER BODY MECHANICAL DRAWING AND PHOTO 86

APPENDIX D. PARTICLE CONCENTRATION CALCULATION 88

APPENDIX E. SUPERFICIAL VELOCITY CALCULATION 89

APPENDIX F. APD FULL-QUADRATIC MODEL 91

APPENDIXG. AE FULL-QUADRATIC MODEL 92

APPENDIX H. APPENDIX H. CONTOUR PLOTS GENERATION 93

APPENDIX I. UNCERTAINTY ANALYSIS FOR EFFICIENCY 97

APPENDIX J: STATISTICAL REGRESSION ANALYSIS 98

APPENDIX K: CALCULATIONS OF MINIMUM FLUIDIZATION VELOCITIES 104 


\section{LIST OF TABLES}

Table $3.1 \quad$ Operating conditions of prototype and model filters

Table 3.2 Predictors and their coded variables

Table 3.3 Central composite design settings and data

Table 4.1 Average pressure drop obtained from each run

Table 4.2 A forward-stepped APD model

Table 4.3 Average efficiency obtained from each run

Table 4.4 A forward-stepped AE model

Table 4.5 Test matrix used to investigate the effect of dust-to-granule ratio on filter efficiency

Table 4.6 Experimental conditions and dimensionless numbers for four similitude experiments

Table 4.7 Filter collection efficiency against time for different dustto-granule ratios

Table 4.8 Experimental conditions and dimensionless numbers for comparisons between $4 \mathrm{~mm}$ and $2 \mathrm{~mm}$ granules

Table $4.9 \quad$ Filter efficiency vs. time for $4 \mathrm{~mm}$ and $2 \mathrm{~mm}$ granules

Table 4.10 Comparison of experimental conditions and dimensionless numbers for high and low pressure tests

Table 4.11 Filter efficiency vs. time for high and low pressure tests

Table 4.12 Experimental conditions and dimensionless numbers for experiments with high and low superficial velocities

Table 4.13 Filter collection efficiency vs. time for high and low superficial velocities 
Table B.1 Particle mean diameter calculation $\quad 84$

Table B.2 Various particle mean diameters calculations 85

Table F.1 Regression Analysis of a full-quadratic APD model $\quad 91$

Table G.1 Regression analysis of a full-quadratic AE model 92

Table H.1 Mathcad commands for superficial velocity calculation 95

Table H.2 Mathcad commands for AE model. 96

Table K.1 Minimum fluidization velocities for $4 \mathrm{~mm}$ and $2 \mathrm{~mm}$ granules

under 23 psig and 5 psig pressure 104 


\section{LIST OF FIGURES}

$\begin{array}{lll}\text { Figure 2.1 Various types of granular bed filters } & 4\end{array}$

$\begin{array}{lll}\text { Figure 2.2 Counter-current flow of gas and granules } & 15\end{array}$

$\begin{array}{lll}\text { Figure 3.1 } & \text { MBGF cold flow facility } & 17\end{array}$

$\begin{array}{lll}\text { Figure 3.2 MBGF cold flow facility via Pro Engineer } & 18\end{array}$

$\begin{array}{lll}\text { Figure 3.3 Internal design of the filter body } & 20\end{array}$

Figure 4.1 Contour plot of APD with respect to GF, DL, and VL at $0.16 \mathrm{~m} / \mathrm{s} \quad 37$

Figure 4.2 Contour plot of APD with respect to GF, DL, and VL at $0.18 \mathrm{~m} / \mathrm{s} \quad 38$

Figure 4.3 Contour plot of APD with respect to GF, DL, and VL at $0.20 \mathrm{~m} / \mathrm{s}$

Figure 4.4 Contour plot of APD with respect to GF, DL, and VL at $0.22 \mathrm{~m} / \mathrm{s} \quad 40$

Figure 4.5 Contour plot of AE versus GF and DL 44

$\begin{array}{lll}\text { Figure 4.6 Residual APD versus APD } & 45\end{array}$

$\begin{array}{lll}\text { Figure } 4.7 & \text { Residual APD versus GF } & 45\end{array}$

$\begin{array}{lll}\text { Figure } 4.8 & \text { Residual APD versus VL } & 46\end{array}$

$\begin{array}{lll}\text { Figure } 4.9 & \text { Residual APD versus DL } & 46\end{array}$

$\begin{array}{lll}\text { Figure 4.10 Normal quantile plot for APD model } & 47\end{array}$

$\begin{array}{lll}\text { Figure 4.11 Residual AE versus AE } & 47\end{array}$

$\begin{array}{lll}\text { Figure 4.12 Residual AE versus GF } & 48\end{array}$

$\begin{array}{lll}\text { Figure 4.13 Residual AE versus DL } & 48\end{array}$

Figure 4.14 Normal quantile plot for AE model 49

Figure 4.15 Inlet ash concentration vs. time for several dust-to granule ratios 55

Figure 4.16 Outlet ash concentration vs. time for several dust-to-granule ratios 56 
Figure 4.17 Filter efficiency vs. time for several dust-to-granule ratios

Figure 4.18 Pressure drop vs. time for several dust-to-granule ratios

Figure 4.19 Zone resulting the pressure drop across the bed

Figure 4.20 Filter efficiency vs. time for experiment with $4 \mathrm{~mm}$ and $2 \mathrm{~mm}$ granules 60

Figure 4.21 Pressure drop vs. time for $4 \mathrm{~mm}$ and $2 \mathrm{~mm}$ granules

Figure 4.22 Designations of regions A, B and C in filter body described in text

Figure 4.23 Filter efficiency vs. time for high and low pressure tests

Figure 4.24 Pressure drop vs. time for high and low pressure tests

Figure 4.25 Filter efficiency vs. time for high and low superficial velocities

Figure 4.26 Pressure drop vs. time for high low superficial velocities

Figure 4.27 Boroscopic examination of granules for dust cake (dust-to-granule ratio $=9.8 \%$ ) (a) Dust cake evident at interfacial region (b) Little evidence of dust just below the interfacial region.

Figure C.1 Mechanical drawing of the filter body 86

$\begin{array}{lll}\text { Figure C.2 Photo of the filter body } & 87\end{array}$

Figure E.1 Dimensions for superficial velocity calculation $\quad 90$

Figure J.1 Fit of efficiency versus time with mass dust ratio 99

$\begin{array}{lll}\text { Figure J.2 Fit of efficiency by dust-to-granule ratio } & 100\end{array}$

Figure J.3 Fit of efficiency versus time for $4 \mathrm{~mm}$ and $2 \mathrm{~mm}$ granule experiments 100

$\begin{array}{lll}\text { Figure J.4 Fit of efficiency versus granule size } & 101\end{array}$

Figure J.5 Fit of efficiency versus time for high and low pressure experiments 101

$\begin{array}{lll}\text { Figure J.6 Fit of efficiency versus pressure } & 102\end{array}$

Figure J.7 Fit of efficiency versus time for high and low superficial velocities 103

$\begin{array}{lll}\text { Figure J.8 } & \text { Fit of efficiency versus superficial velocity } & 103\end{array}$ 


\section{Executive Summary}

The goal of this research is to improve the performance of moving bed granular filters for gas cleaning at high temperatures and pressures. A second objective is to better understand dust capture interfacial phenomena and cake formation in moving bed filters. Granular bed filters are attractive in advanced coal-fired power cycles because they employ low-cost refractory particles as filter media and offer the prospect for constant pressure drop when operated as a moving bed. An important process is the removal of fine particles from high-temperature and high-pressure gas streams to satisfy gas turbine fuel quality requirements. The experimental bed configuration used in the present study utilizes a cold flow, axially symmetric, counter-current flow to simulate a filter operating at high temperatures $(1088 \mathrm{~K})$ and elevated pressures (10 atmospheres). The granular filter is evaluated in two separate performance studies: (1) optimization of particle collection efficiency and bed pressure drop in a factorial study at near-atmospheric operating pressures through appropriate use of granular bed materials, particle sizes, and feed rates; and (2) high temperature and high pressure model simulation conducted at above-atmospheric pressures and room temperature utilizing dust and granular flow rates, granular size, system pressure, and superficial velocity.

The factorial study involves a composite design of 16 near-atmospheric tests, while the model simulation study is comprised of 7 above-atmospheric tests. The simulation data are correlated in terms of the density ratio and dimensionless parameters Stokes, Reynolds, Froude, and interception numbers. Similarity rules are validated in tests at four different mass dust ratios (fly ash capture rate/granular flow rate) and show nearly constant collection efficiencies $(\sim 99.5 \pm 0.3 \%)$ for operating pressures of $160 \mathrm{kPa}$ gage $(23.2 \mathrm{psig})$ at room temperature $(20 \mathrm{C})$, which simulates the hydrodynamic conditions expected for typical gasification streams (1088 K, 10 atmospheres).

A special design feature of our moving granular bed is the establishments of quasisteady dust capture at the interface and within the bed with the avoidance of periodic variation in efficiency and pressure drop inherent in most barrier filters. Another feature of this filter is the natural conical shape of the bed itself that helps to compensate for the 
increase in pressure drop resulting from captured particles. Other noteworthy hydrodynamic features include the use of cyclonic action at the inlet to the bed, counter-current flow of air and granular material, and straightening fins that prevent filter cake scouring leading to high efficiency (near $100 \%$ with standard deviation of $0.00113 \%$ ) and low pressure drop $(0.689$ $\mathrm{kPa}$ and below) operation of the bed.

An important outcome from the near-atmospheric pressure studies are relationships developed using central composite design between the independent variables, superficial velocity $(0.16-0.22 \mathrm{~m} / \mathrm{s})$, dust feed rate $(0.08-0.74 \mathrm{~kg} / \mathrm{hr})$, and granular flow rate $(3.32-15.4$ $\mathrm{kg} / \mathrm{hr}$ ). These operating equations provide contour plots for bed conditions that simultaneously satisfy low-pressure drop and high particle collection efficiency. Within the operating range of independent variables tested, superficial velocity is found not to be significant in predicting particle collection efficiency for the near-atmospheric studies; however, superficial velocity was found to be important for the bed pressure drop for both the composite design and simulation studies. Both granular flow rate and the dust feed rate are found to be significant factors, affecting both pressure drop and collection efficiency of the bed. Under similar hydrodynamic conditions, the larger $4 \mathrm{~mm}$ glass bead granules provide higher collection efficiency compared to $2 \mathrm{~mm}$ beads. The effect of increasing system pressure is to increase the collection efficiency. 


\begin{abstract}
The goal of this research is to improve the performance of moving bed granular filters for gas cleaning at high temperatures and pressures. A second objective is to better understand dust capture interfacial phenomena and cake formation in moving bed filters. The experimental bed tested in the present study has several unique design features configured as cold flow, axially symmetric, counter-current flow to simulate a filter operating at high temperatures $(1088 \mathrm{~K})$ and elevated pressures (10 atmospheres). The granular filter is evaluated in two separate performance studies: (1) optimization of particle collection efficiency and bed pressure drop in a factorial study at near-atmospheric operating pressures through appropriate use of granular bed materials, particle sizes, and feed rates; and (2) high temperature and high pressure model simulation conducted at above-atmospheric pressures and room temperature utilizing dust and granular flow rates, granular size, system pressure, and superficial velocity. The factorial study involves a composite design of 16 nearatmospheric tests, while the model simulation study is comprised of 7 above-atmospheric tests. Similarity rules were validated in tests at four different mass dust ratios and showed nearly constant collection efficiencies $(\sim 99.5 \pm 0.3 \%)$ for operating pressures of $160 \mathrm{kPa}$ gage (23.2 psig) at room temperature $(20 \mathrm{C})$, which simulates the hydrodynamic conditions expected for typical gasification streams (1088 K, 10 atmospheres). An important outcome from the near-atmospheric pressure studies are relationships developed using central composite design between the independent variables, superficial velocity $(0.16-0.22 \mathrm{~m} / \mathrm{s})$, dust feed rate $(0.08-0.74 \mathrm{~kg} / \mathrm{hr})$, and granular flow rate $(3.32-15.4 \mathrm{~kg} / \mathrm{hr})$. These operating equations were optimized in contour plots for bed conditions that simultaneously satisfy lowpressure drop and high particle collection efficiency.
\end{abstract}




\section{Introduction}

The goal of this research is to improve the performance of moving bed granular filters for hot gas clean-up. Advanced coal-fired power cycles under development by the U.S. Department of Energy include pressurized fluidized bed combustion and integrated gasification/ combined cycles based on gas turbines and fuel cells. All of these advanced cycles are premised on the efficient removal of fine particles from high temperature, high pressure (HTHP) gas streams (National Resource Council, 1995). Several methods are available for removing particles from gas streams including cyclone separators, barrier filters, electrostatic separators, scrubbers, acoustical or thermal agglomeration, and granular bed filters.

Recent analyses suggest that ceramic candle barrier filters and granular bed filters are the most promising approaches to hot-gas clean-up for advanced coal conversion technologies (Wilson \& Haas, 1994; Staubly et al. 1994). Granular bed filters are attractive for hot gas filtration because they employ low-cost refractory granules as filter media (Kuo et al., 1998a).

The formation of dust cake at the filter interface is a key factor in high efficiency performance of both types of filter. However, we believe moving bed granulars offer a unique opportunity to establish an optimal thickness to the dust cake that can be maintained under steady or quasi-steady operating conditions. The advantage of a steady-state dust cake is avoidance of periodic variation in efficiency and pressure drop inherent in most barrier filters.

A cold flow moving bed granular filter was constructed to achieve the above-mentioned goals. The moving bed granular filter built was tested with a maximum dust loading of $0.8 \mathrm{~kg}$ of ash/hr. This filter incorporates new design features such as cyclonic inlet, counter-current flow of gas and granules, and flow straightening fins with the objective to achieve low pressure drop 
and high efficiency. In addition, the apparatus was also used to study the effect of air velocity (superficial velocity), dust loading, and granular flow rate on the performance of filtration in terms of pressure drop and efficiency via statistical design of experiment and analysis. 


\section{Background}

\subsection{History of moving bed granular filters (MBGF)}

Operation of fixed bed granular filters is illustrated in Fig. 2.1a. A dirty gas stream flows downward through a bed of granules, which intercepts dust particles carried by the gas. Pressure drop across the bed increases as the voids between granules become clogged with dust.

Eventually filtration has to be interrupted to allow the bed to be cleaned, which is accomplished with a reverse flow or pulse of gas through the bed. For a co-current configuration, particulate laden gas travels in the same direction as the downward flowing granules. Additional detail for this configuration can be found in Kalinowski and Leith's paper (1982). In the counter-current configuration, particulate laden gas moves in a direction opposite of granule flow. Guillory (1982) and Moresco and Cooper (1981) used this type of MBGF.

The first patent for a fixed bed granular filter dates to the late nineteenth century (Wilder, 1896). Sittig (1977) documents a wide variety of applications for fixed granular bed filters in the first half of the twentieth century. More recent applications include control radioactive particle emissions (Juvinall et al., 1970), dust removal from industrial gas (Engelbrecht, 1965), and fume control from open-hearth furnaces (Thring and Strauss, 1963). Miyamoto and Bohn (1974) noted that collection efficiency was initially low but increased sharply as the particulate load in the bed increased.

Squires and his coworkers (Squires \& Pfeffer, 1970) were among the first to consider the use of fixed granular beds for control of fly ash emissions. A louvered panel arrangement held 16-30 mesh sand. Reported collection efficiencies were as high as 99.8\%. They also noted formation of dust cake at the entrance surface of the bed, which eventually increased pressure drop to unacceptable levels. 

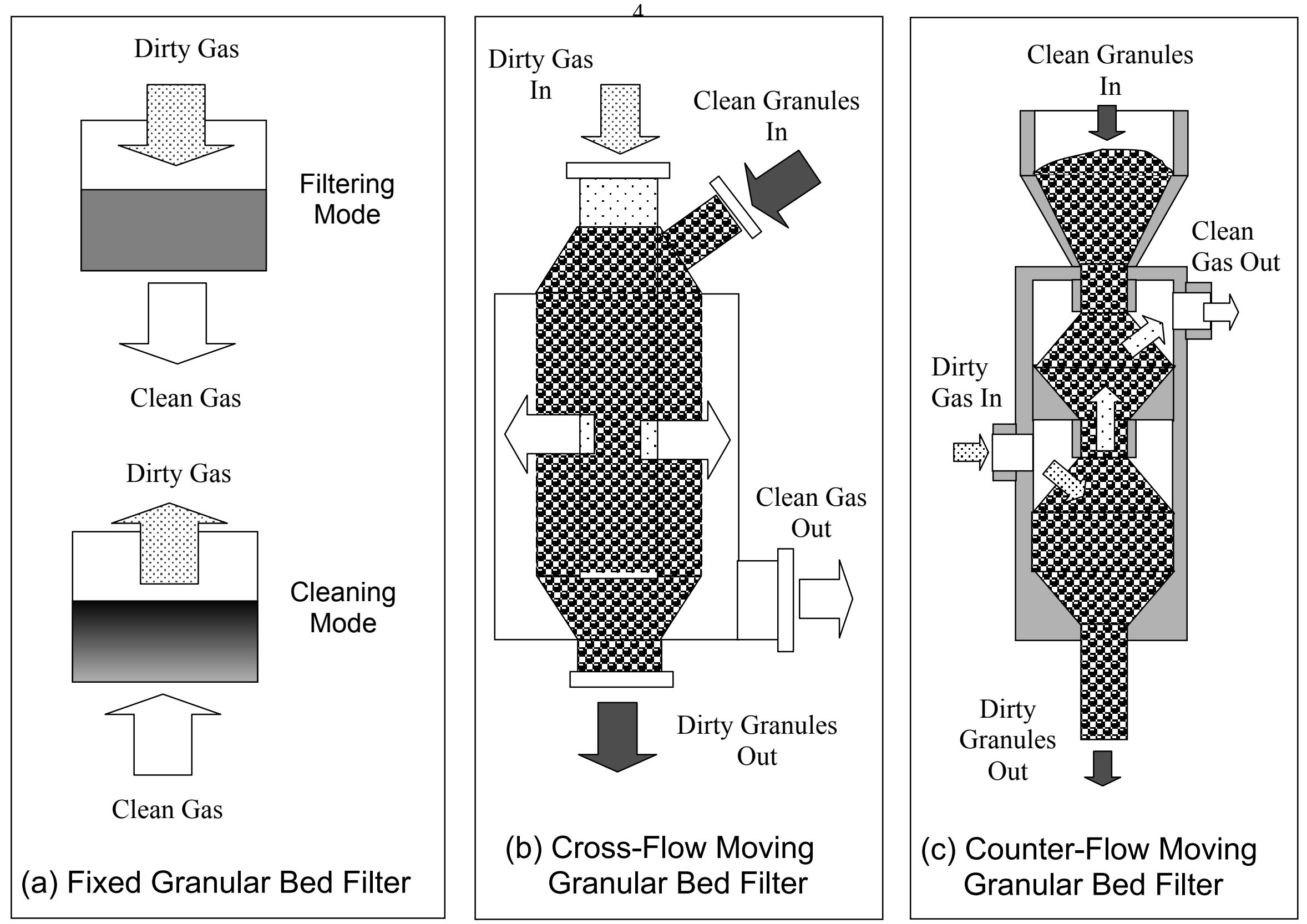

Fig. 2.1. Various types of granular bed filters 
Subsequent passage of the Clean Air Act Amendments of 1970 encouraged further development of granular bed filters for coal-fired power systems. Argonne National Laboratory launched a program in the late 1970's to develop a fixed bed granular filter for pressurized fluidized bed combustion systems (Swift et al., 1978). About the same time the U.S. Environmental Protection Agency (EPA) sponsored fixed bed granular filter tests at Exxon (Nutkis et al., 1981). The Department of Energy supported work at Westinghouse (Lippert et al., 1981) on the same filter design as evaluated by Exxon. For superficial velocities at the filter elements less than $0.4 \mathrm{~m} / \mathrm{s}$ collection efficiency was essentially $100 \%$. Significantly, the researchers attributed these outstanding results to the formation of a dust cake at the surface of the beds, a result confirmed by tests with Plexiglas models operated at ambient conditions. It was hypothesized that dust bridges the gaps between individual media granules and the collection mechanism shifts from interception deep within the bed to impaction at the freeboard-bed interface.

The pressure drop of fixed granular beds rapidly increases as contaminant builds up on the bed. Cleaning usually entails reverse flow of gas similar to the process for cleaning barrier filters. As a result, filter operation is intermittent and entrainment of filter granules can be a serious problem. Heavy dust loadings requiring frequent media regeneration favor the use of moving bed granular filters.

The use of moving beds dates back to the 1940's (Hall and Munday, 1946). Some of the earliest designs employed cross-flow configurations, illustrated in Fig. 2.1b. Granular media flows downward by the action of gravity through a section enclosed by screens or louvers. Gas flows horizontally from a dirty gas plenum through the vertically flowing granules, which intercept the particles, and exits into a clean gas plenum. Tsubaki and Tien 
(1988) used a cross-flow design in their experimental study as did Otani, Miyajima, and Emi (1990) in their cold flow filter.

Several decades later, Combustion Power Company developed a screenless moving bed filter to avoid plugging problems (Saxena et al., 1985). The resulting design appears to be the first parallel flow moving bed granular filter. A central gas pipe injects gas downward into the center of a hopper-shaped granular bed. The gas turns 180 degrees to flow upward through the downward flowing solids; thus, this is a counter-current flow design. Some of the literature published on this filter suggests that most of the dust capture occurs in a zone very close to the injection point of gas into the bed. Delft University of Technology carried

out a series of experiments in a counterflow moving bed filter similar to that for Combustion Power Company but employed a simpler feed system for the granular media (Zevenhoven et al., 1992).

\subsection{Theory of filtration}

Performance of particulate filters are often expressed in terms of the particle collection efficiency, $\eta$

$$
\eta=1-\frac{\text { mass } \text { of } \text { dust exiting }}{\text { mass of dust entering }}
$$

Collection efficiency of a moving granule bed filter is a function of the granule size, superficial velocity at the filter face, velocity of the granules, and the properties of the gas and dust (Saxena et al., 1985). For a clean filter, collection efficiency is also a function of bed depth. As previously discussed, the presence of dust cake not only increases collection 
efficiency but may shift collection to an essentially surface phenomenon. However, virtually no experimental information is available on the effect of dust cake on filtration mechanisms.

For high performance filters, efficiency is more conveniently expressed as the penetration, $\mathrm{P}$ :

$$
P=1-\eta
$$

which simply indicates the fraction of dust completely penetrating the filter

The theory of granular bed filtration is essentially that of barrier filters. In principle, several separation mechanisms can contribute:

- Inertial impaction - a dust particle is too large to follow a curved streamline around a granule and its inertia carries it into the granule.

- Diffusion-Brownian motion of a dust particle superimposed on the bulk flow of the gas brings the particle into collision with a granule.

- Gravity - dust particles settle from the gas flow under the action of gravity.

- Interception - a dust particle following a streamline close to a granule slides into the granule.

- Electrostatic attraction - dust particles carrying an electrostatic charge will be attracted to the granules.

For granular beds, with granules on the order of $1 \mathrm{~mm}$ and dust particles finer than $50 \mu \mathrm{m}$ or so, inertial impaction is generally considered to be the most important filtration mechanism. In this case the Stokes number, St, controls the collection mechanism (Gal et al., 1985):

$$
S t=\frac{\rho_{p} d_{p}^{2} U C_{s}}{9 \mu d_{g}}
$$


where $\mathrm{C}_{\mathrm{s}}$ is the Cunningham's correction factor for molecular slip, $\rho_{\mathrm{p}}$ is the dust particle density, $d_{p}$ is the dust particle diameter, $\mu$ is the fluid viscosity, $d_{g}$ is the granule diameter, and $\mathrm{U}$ is the superficial velocity at the filter face. Generally, the collection efficiency exceeds $90 \%$ for a granular bed when $\mathrm{St}>0.01$, which corresponds to particles larger than a few microns.

For very small particles, Brownian diffusion can play an important role. The Peclet number, Pe, controls the collection mechanism in this circumstance (Fuchs, 1989):

$$
P e=\frac{3 \pi \mu d_{p} U d_{g}}{C_{s} k T}
$$

where $\mathrm{k}$ is the Boltzman constant and $\mathrm{T}$ is the absolute temperature. Collection efficiency of a granular bed filter efficiency will exceed $90 \%$ for $\mathrm{Pe}<1000$, which corresponds to particles smaller than $0.1 \mu \mathrm{m}$.

For large particles, gravity effects can become important. The appropriate dimensionless parameter is the Grashof number, Gr:

$$
G r=\frac{\rho_{p} d_{p}^{2} g C_{s}}{18 \mu U}
$$

where $\mathrm{g}$ is the gravitational constant. Gravitational settling can be neglected for particles smaller than $100 \mu \mathrm{m}$. However, if flow through a filter begins to stall, gravitational settling can quickly become important. 
Collection by interception, which is a geometrical effect, is directly proportional to the size ratio $d_{p} / d_{g}$ and can be neglected if this ratio is less than 0.001 . Electrostatic charging of dust and granules arises naturally in flowing solids; the magnitude of this effect depends on electrical properties of the gas and granules. Although electrostatic forces are expected to be small at elevated temperatures, it is an effect that should be accounted for in an experimental program.

Operation of granular beds at high temperature and pressure are expected to decrease the efficiency of their performance (Peukert and Loffler, 1991). Although diffusional separation improves, increasing gas viscosity at elevated temperatures reduces the effectiveness of inertial separation.

Systematic efforts to model granular bed filters are relatively rare in the literature. Guillory (1978) and Moresco and Cooper (1981) have posed models in terms of such filter characteristics as filter depth, dust concentration, gas flow rate, and granular media flow rate. Dimensional analyses have been applied by Geffken et al. (1979) and Wigton (1978) to obtain semi-empirical expressions for collection efficiency in terms of the Stokes, Peclet, and Grashof numbers, although the range of these numbers was not necessarily applicable to hot gas clean-up conditions.

The work of Goren (1979) is notable for its generalized approach to analyzing experimental data. First, monodispersed, electrically neutral particles of potassium biphthalate were used to simulate dust particles without electrostatic effects complicating interpretation of results. Second, collection efficiencies for individual media granules were calculated from the raw data, which is more useful than data on overall filter efficiencies in designing filters. 
Individual granule collection efficiencies, $\eta_{\mathrm{g}}$, were determined from data on bed penetration, $\mathrm{P}$, using the relationship:

$$
\eta_{g}=\frac{2 d_{g} \ln P}{3(1-\varepsilon) H}
$$

where $\varepsilon$ is the bed voidage and $\mathrm{H}$ is the bed height. Goren derived expressions for $\eta_{\mathrm{g}}$ corresponding to three distinct operating regimes:

$$
\begin{array}{ll}
\text { Inertial impaction dominant: } & \eta_{g}=1270 S t^{9 / 4} \\
\text { Brownian diffusion dominant: } & \eta_{g}=232 P e^{-2 / 3} \\
\text { Gravitational settling dominant: } & \eta_{g}=0.97 G r^{3 / 4}
\end{array}
$$

This important study has three shortcomings. First, the experiments were performed at ambient conditions; the relationships for $\eta_{\mathrm{g}}$ do not encompass the range of dimensionless numbers to be encountered by commercial hot-gas clean-up systems. Second, experiments were performed in fixed granular beds, which does not capture the dynamics of moving bed granular filters of interest to the present study. Third, the experiments were performed with clean granular media; the important role of dust cake in achieving high collection efficiencies is overlooked.

The research by Gal et. al. (1985) is notable for predicting filtration efficiency of a granular bed with inertial effects dominant. The efficiency was found to be a function of a modified Stokes number.

$$
S t^{\prime}=S t\left(1+\frac{1.75 \operatorname{Re}}{150(1-\varepsilon)}\right)
$$


where $\mathrm{Re}$ is the Reynolds number based on granular diameter and $\varepsilon$ is the void fraction in the bed.

Various researchers, including Gutfinger and Tardos (1979), Tien (1989), Gutfinger et al. (1991), and Brown (1997) have explored mechanistic models. However, these models address only the initial stages of particle deposition, when media granules can be assumed to be free of dust. Mechanistic models have not been developed to the point where they can account for the role of dust cake on filter performance.

\subsection{Effect of operating parameters}

Some of the parameters that determine the performance of a granular bed filter are: superficial velocity, granular flow rate, the ratio of dust flow rate to granular flow rate, granule size, and bed depth.

Superficial velocity is defined as the actual volumetric flow rates through a filter divided by the cross-sectional area of the filtration zone. In studies on fixed beds of glass fibers, Blasewitz et al. (1955) discovered that efficiency dropped with increasing superficial velocity. On the other hand in studies carried out at Combustion Power Company Moresco et al. (1981) developed a correlation for penetration showing that high Stokes number and high superficial velocity increases filtration efficiency. In later studies at Combustion Power Company, Guillory (1982) reported that pressure drop was insensitive to velocity.

Kalinowski and Leith (1982) regressed an empirical equation from a $2^{4}$ full factorial design of experiment. Their result showed a drop in efficiency as superficial gas velocity increased. Tsubaki and Tien (1988) found that as superficial gas velocity increased, the efficiency also increased. Peukert and Loffler (1990) determined that lower superficial gas velocity both improved filtration efficiency and decreased pressure drop. Yang et al. (1992) concluded 
that higher superficial gas velocity caused higher-pressure drop and lower dust collection efficiency. Wu et. al. (1998)found that for their counter-flow moving bed filter, increasing superficial velocity increased filter efficiency when small (0.65 $\mathrm{mm}$ dia.) granules where used as filter media, whereas an opposite effect was observed for larger granules $(1.65 \mathrm{~mm}$ dia.). These contradictory results may reflect differences in the design of the filters being tested by different researchers.

As for granular flow rate, both Kalinowski and Leith (1982) and Otani et al. (1990) found that filter efficiency decreased as granular flow rate increased. In contrast, Guillory (1982) found granular flow rate did not have significant effect on pressure drop, while Tsubaki and Tien (1988) found that granular flow rate did not have a significant effect on filtration efficiency. Yang et al. (1992) studied the effect of granular flow rate on both filtration efficiency and pressure drop and found little effect in either case. Wu et al. (1998) found that for their counter-flow moving bed filter, decreasing granular flow rate had the effect of increasing the efficiency.

Kalinowski and Leith (1982) investigated the effect of the ratio of dust feed rate to granular flow rate on filter performance. They concluded that filtration efficiency dropped as this ratio increased. They also reported that granule size does not affect the filtration efficiency and claimed that efficiency increased with decreasing bed depth.. Peukert and Loffler (1990) found that using finer granule improved collection efficiency.

A few studies examined the effect of temperature on filtration efficiency. In tests with fixed beds, Peukert and Loffler found that efficiency fell from $99.97 \%$ at room temperature to $99.8 \%$ at $400 \mathrm{C}$ and to $98.6 \%$ at $800 \mathrm{C}$. On the other hand, they observed that over extended periods of time, high temperatures favored the formation of dust cake, which 
ultimately improved collection efficiency. At Delft University of Technology, the Netherlands, Zevenhoven et al. performed tests on a screenless moving bed granular filter developed by Combustion Power Company. At a system pressure of 5 bar (abs) they found the filtration efficiency varied from $89 \%$ to $97 \%$ at an inlet concentration of $1.04-1.05 \mathrm{~g} / \mathrm{m} 3$,

a flow rate of $150 \mathrm{~m} 3 / \mathrm{h}$, and a temperature of about $600 \mathrm{C}$. At a pressure of $7 \mathrm{bar}(\mathrm{abs})$ and at about $650 \mathrm{C}$, the efficiency was around $93-98 \%$ at an inlet concentration of $1.3-1.5 \mathrm{~g} / \mathrm{m} 3$ and at a flow rate of $400 \mathrm{~m} 3 / \mathrm{h}$.

Previous researchers have rarely discussed the effect of upstream deposition on the collection efficiency of granular bed filters. Jung and Tien (1991) correlated collection efficiency to dust concentration; however, this work was limited to fixed bed filters. Kalinowski and Leith (1982) noted that the efficiency of a cross-flow moving bed filter initially increased with time, which they attributed to the formation of intergranular dust deposits.

\subsection{Shortcomings of previous work}

Previous research offers considerable anecdotal evidence that dust cake formation is extremely important in achieving high collection efficiency for granular bed filters. However, experimental and theoretical studies of this interfacial phenomenon are almost totally absent in the published literature. Further hampering the usefulness of existing experimental data to the design of commercial moving bed granular filters are the conditions under which most of the data was obtained. Usually no attempt was made to simulate the hydrodynamic conditions of hot gas clean-up. Thus, this data correlated in terms of such dimensionless parameters as Stokes number, Peclet number, and Grashof number, gives results outside the operating range expected for commercial filters. Furthermore, the complications presented 
by a moving bed of granules were ignored in most of these investigations. Methods for maintaining steady state dust cake to achieve high collection efficiency in moving bed granular filters are unexplored.

\subsection{Innovations introduced by this research}

Based on observations by other researchers that formation of a dust cake is important to efficient dust collection for fixed bed granular filters, we have developed a new concept for a moving bed granular filter that makes use of this property of dust cakes. The goal is to establish a quasi-steady dust cake that is continuously renewed on the upstream side of the dust cake and swept away on the downstream side. A unique design feature of our filter is the buildup of dust near the gas-bed interface of the filter to improve particle capture efficiency while the natural conical shape of the bed itself helps to compensate for the increase in pressure drop resulting from the captured particles. An inner cone placed in the bed itself improves the control of granular flow.

The design, illustrated in Fig. $2.1 \mathrm{c}$, has two interfacial zones: one in the engagement section of the filter and the other in the disengagement section. Granular media spilling out

of a centrally located dipleg forms the engagement zone. The disengagement section, located immediately above the engagement section, is similarly formed from a second dipleg. The purpose of these zones is to form large surface areas for gas to flow into and out of the granular media, which keeps pressure drop as low as possible. The interfacial area of the engagement zone is where the dust cake is formed. The lower edge of the filter cake is continuously dispersed by the downward flow of granular while the upper interface is continuously covered by a fresh layer of granular material cascading from the dipleg above the interface. In this fashion, the dust cake establishes a steady state thickness, which is 
controlled to give high collection efficiency and low pressure drop. Figure 2.2 shows the internal design of the moving bed granular filter. Air enters the filter through a tangential inlet giving a cyclonic motion to the airflow that reduces pressure drop across the bed as the momentum of the airflow is substantially conserved.. This cyclonic airflow flows downward through flow straightening fins to meet the granular bed. The evenly spaced fins ensure a uniform flow and reduce the disturbance to a dust cake.

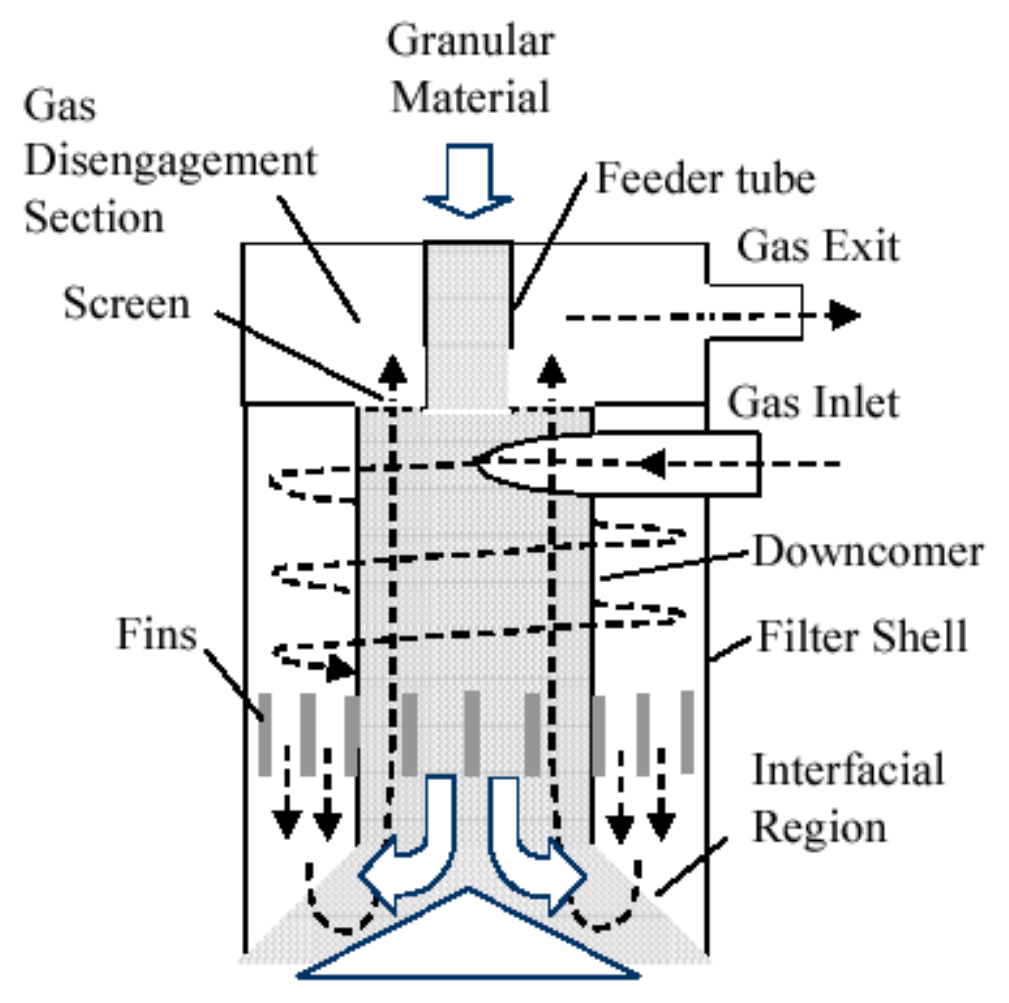

Figure 2.2 Counter-current flow of gas and granules 


\section{EXPERIMENTAL APPARATUS AND PROCEDURES}

\subsection{Cold-flow apparatus for filter and instrumentation}

The research was performed in a 0.3 meter diameter moving bed granular filter. A schematic diagram of the apparatus is shown in Figure 3.1. A three dimensional drawing is shown in Figure 3.2. An additional photo and drawing of the bed are shown in Appendix C. The facility is fully instrumented using computer data acquisition.

Fresh granular material is fed in at the top of the bed with dirty granular material removed from the bottom of the bed. Fly ash laden air enters the bed filter through a $0.114 \mathrm{~m}$ (4.5 in) diameter inlet feed pipe $2.134 \mathrm{~m}$ (84 in) in length while cleaned air exits from the top of the bed (counter-flow to the granular material flow) through a pipe of similar length and diameter. The airflow rate and system pressure are controlled by two 1.27 -centimeter ( $1 / 2$ inch) ball valves located at the inlet and exits of the system. A STP Dwyer rotameter (range: 0-0.0165 STP $\mathrm{m} / \mathrm{s})$ with pressure gauge $(0-689 \mathrm{kPa})$ monitored clean air flow rate into the system. The $0.302 \mathrm{~m}$ (11.9-in) id aluminum bed housing together with the system piping components are designed to handle pressures up to 206.8-241 kPa gage (30-35 psig), suitable for similitude (cold flow) studies. An auger feed controls the flow rate of fly ash from a vibrated reservoir located upstream and just at the entrance to the inlet feed pipe. The fly ash feeder was placed in a pressure vessel at the operating system pressure to facilitate feeding (Fig. 3.1). The dirty gas passes through the filter and exits to a fume hood. 


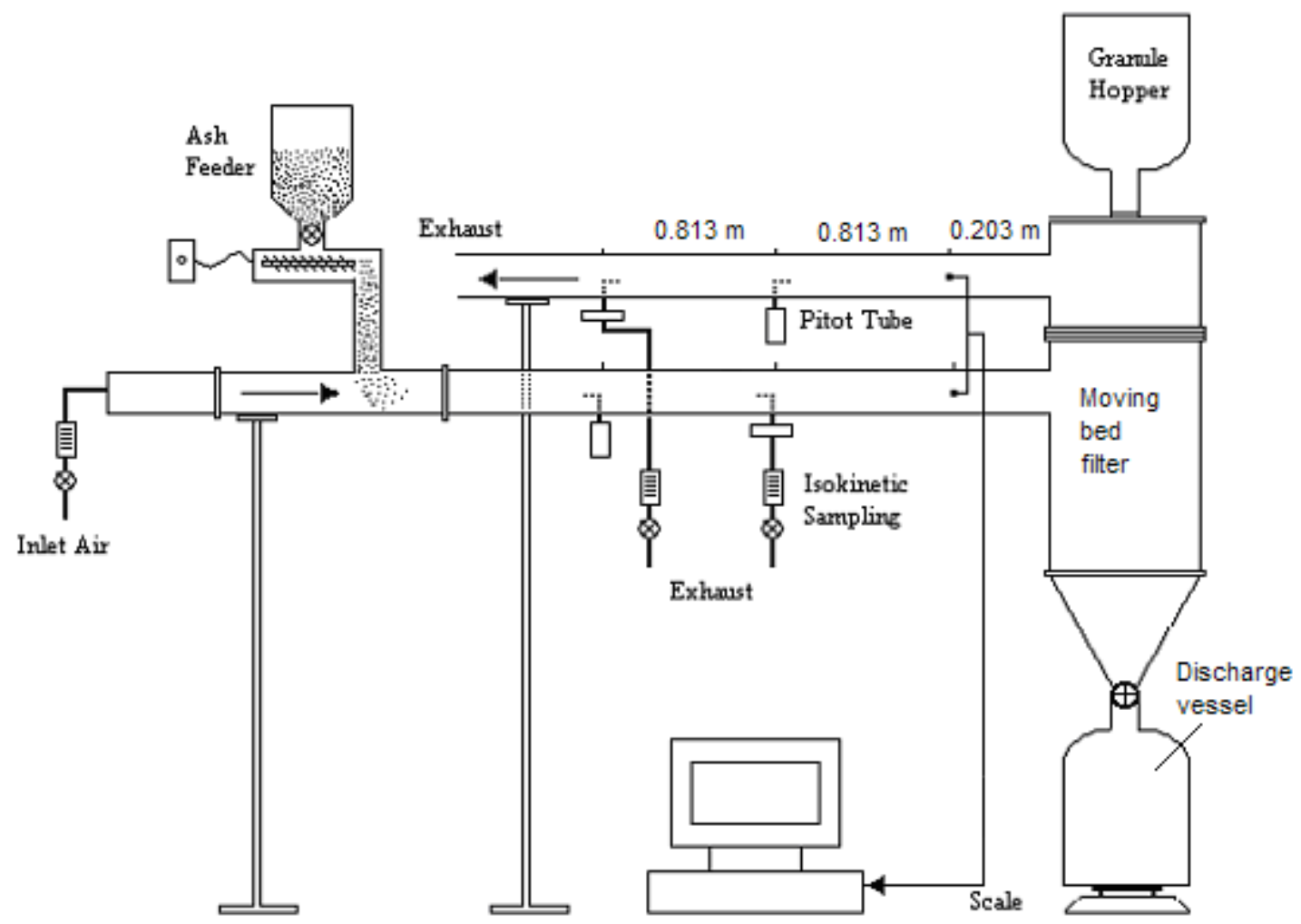

Figure 3.1. MBGF Cold Flow Facility

Pitot tubes are placed in the centerlines of both the inlet and outlet ducts to enable air velocity and volumetric flow rate calculations. Real time air velocity and volumetric flow rate can be recorded via the aid of a data acquisition system (Keithley: STA-08 PGA and DAC BOARD). A sampling frequency of $1 \mathrm{~Hz}$ via DAC was used throughout the entire set of experiments. A sample isokinetic calculation is given in Appendix A. A particle size analysis of the flyash used in our experiments is given in Appendix B. Appendix D gives a sample calculation for particle concentration. 


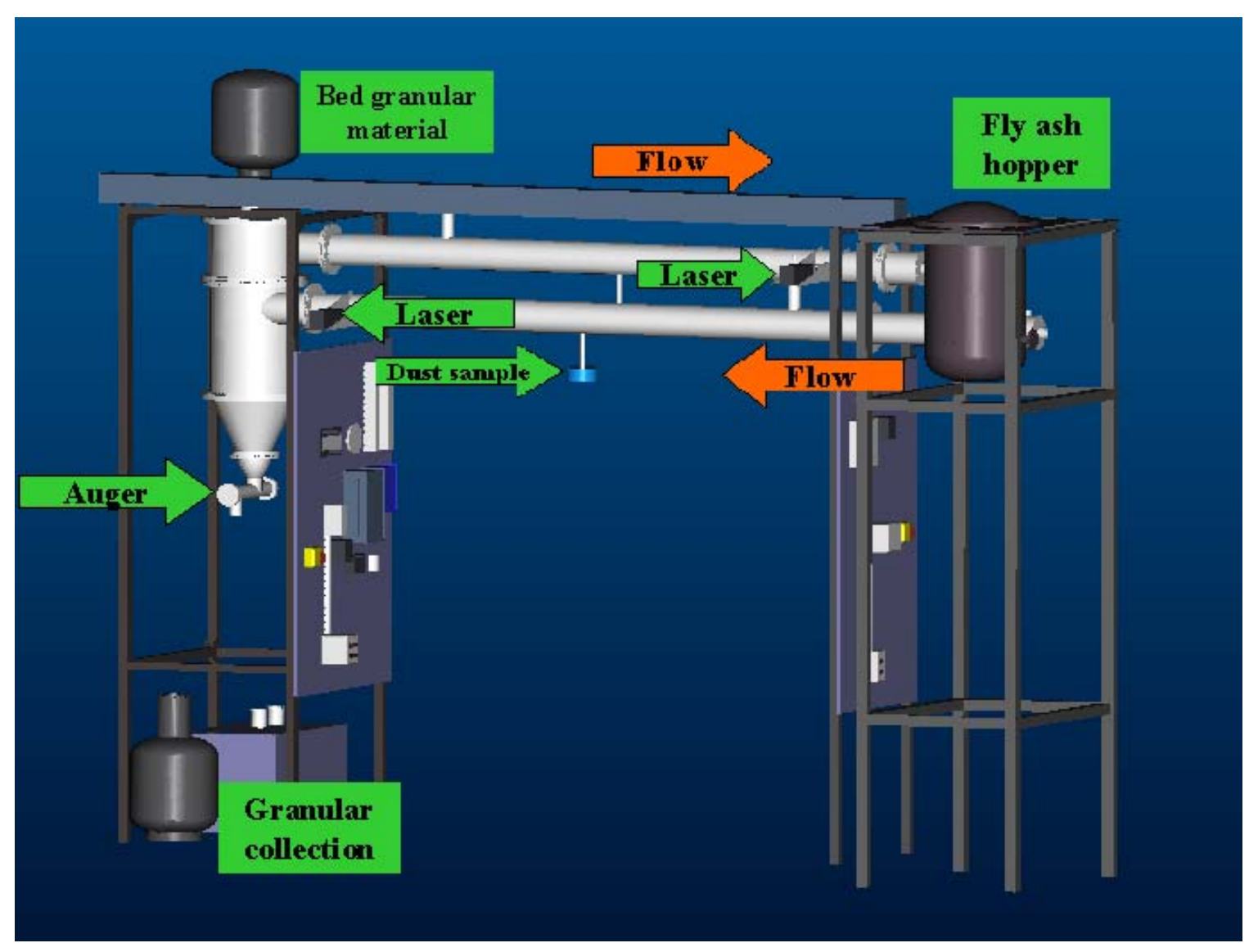

Figure 3.2. MBGF Cold Flow Facility via Pro Engineer

Isokinetic sampling probes are installed at the centerlines of both inlet and outlet ducts to determine ash concentrations (air velocity is determined by the pitot tubes). EPA recommends that the sampling probes are placed at least eight duct diameter apart and downstream of pitot tubes. The outside diameter and wall thickness for the sampling probes are $3.97 \mathrm{~mm}$ (5/32 inch) and $0.889 \mathrm{~mm}$ (35/1000 inch) respectively. Each sampling probe feeds the sampled flyash to a $47 \mathrm{~mm}$ membrane filter with the air feed rate measured by a rotameter located downstream of a controlling valve.

Lasers and photocells are placed immediately outside the filter in both inlet and outlet ducts monitored particle concentration of fly ash. However, long-term drift proved to be a problem so that only qualitative results were obtained. Spherical glass beads from Jaygo, Inc. 
are used as the filter media. The filter media are fed in, prior to each run, from a storage vessel located above the filter via a downcomer.

The bed filter media flow rate is controlled by a motor having a built in variable speed controller. The motor drives an auger and withdraws beads to a collection tank placed below the filter while air flows upward through the bed and disengages the bed where the granules are the cleanest. This mechanism ensures that re-entrainment is minimized.

It was found that fluidization in the bed could lead to dust re-entrainment (W.C. Yang et al., 1992) from the bed so that it is desirable to operate the bed below fluidization conditions everywhere in the bed. A large mesh screen placed at the disengagement section of the bed prevented granules from leaving the bed.

Both the ash feeder and the bead flow auger were calibrated prior to the experiments. However, it was found that the calibrated ash feed rate could vary from the actual rate during run conditions. The actual amount of ash entering the filter is determined by measuring the mass difference before and after a run. A correction to the filtered fly ash was made by subtracting the ash deposited in the inlet duct (assuming negligible deposition in the outlet duct due to high efficiencies obtained). The average ash feed rate is obtained by dividing the corrected mass difference in the hopper by the total run time in hours:

Actual rate of ash enters $=$

(ash in feeder before)-(ash in feeder after)-(ash left in duct)

total number of hours run

It was found that the calibrated bead rate was in close agreement with the actual bead flow rate. 


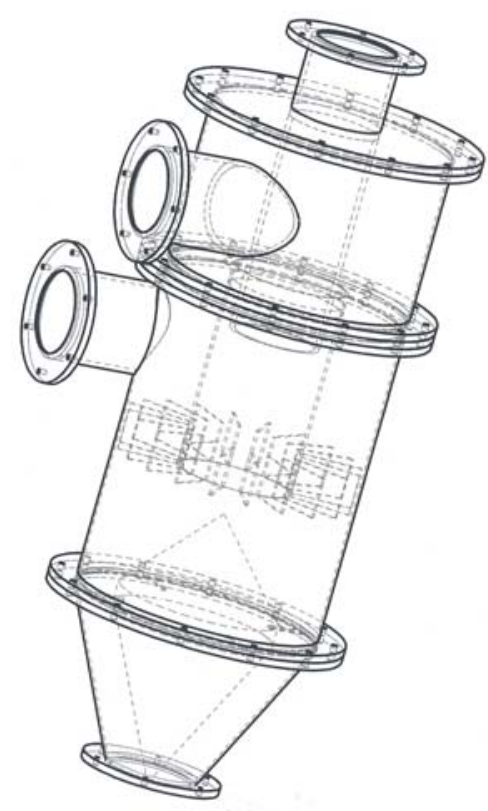

Figure 3.3. Internal design of the filter body

To assist granular flow in the bed and reduce the quantity of material in the bed, a "double-cone" baffle fabricated from wood is placed in the bed just beneath the straightening fins (Figure 3.4). The cone angle was made at the angle of repose $\left(52^{\circ}\right)$ of the glass beads.

\subsection{Simulating high pressure, high temperature conditions}

Similitude analysis is based on dimensionless parameters to describe filter performance (Freidlander, 1977). For inertial impaction filters, collection efficiency can be expressed as:

$$
\eta=f(S t, \operatorname{Re}, R)
$$


where $\mathrm{Re}$ is the Reynolds number based on granule diameter $\left(\rho_{\mathrm{f}} \mathrm{Ud} \mathrm{d}_{\mathrm{g}} / \mu\right)$ and $\mathrm{R}$ is the interception number defined as the ratio $\mathrm{d}_{\mathrm{p}} / \mathrm{d}_{\mathrm{g}}$. For Brownian diffusion, Peclet number, Pe, is substituted for Stokes number. For gravitational settling Grashof number is substituted for Stokes number. The following analysis is performed for the case of inertial impaction controlling filter performance, but similar arguments can be made for the other two cases.

For moving bed granular filters, we must also include hydrodynamic behavior of the granular media, which requires the introduction of the ratio of granule density to fluid density, $\rho_{\mathrm{g}} / \rho_{\mathrm{f}}$, and the Froude number, Fr (Glicksman, 1993):

$$
F r=\frac{U^{2}}{g \cdot d_{g}}
$$

Consider two geometrically similar moving bed granular filters operating in the inertial impaction regime. The hydrodynamic behavior and, hence, the particle collection efficiency of these filters will be identical if their dimensionless variables $\mathrm{St}, \mathrm{Re}, \mathrm{R}$, and $\mathrm{Fr}$ are equal. Let subscripts 1 and 2 distinguish the physical properties of these two filters. Algebraic manipulation of the above dimensionless variables yields property relationships convenient for establishing hydrodynamic similarity between the filters:

$$
\frac{\rho_{p 1}}{\rho_{p 2}}=\frac{\rho_{g 1}}{\rho_{g 2}}=\frac{\rho_{f 1}}{\rho_{f 2}} \quad \frac{U_{1}}{U_{2}}=\left(\frac{v_{1}}{v_{2}}\right)^{\frac{1}{3}} \quad \frac{d_{p 1}}{d_{p 2}}=\frac{d_{g 1}}{d_{g 2}}=\left(\frac{v_{1}}{v_{2}}\right)^{\frac{2}{3}}
$$

where $v=\mu / \rho_{\mathrm{f}}$ (kinematic viscosity of the fluid).

A typical moving bed granular filter operates at $850 \mathrm{C}$ and $1000 \mathrm{kPa}$ with gas flow velocities near $0.27 \mathrm{~m} / \mathrm{s}$, bed granules approximately $7.3 \mathrm{~mm}$ diameter, fly ash particles with density of $2400 \mathrm{~kg} / \mathrm{m}^{3}$ and fly ash particle diameters averaging $21 \mu \mathrm{m}$. From the above 
relationships one finds that a cold-flow model can achieve hydrodynamic similitude with a high temperature, high-pressure prototype $(\mathrm{St}=0.1, \mathrm{Re}=136, \mathrm{R}=0.0029, \mathrm{Fr}=1.02)$. Indeed, an especially simple situation arises if a cold flow model operating at $300 \mathrm{~K}$ is pressurized to $160 \mathrm{kPa}$ gage (23.2 psig). Under these circumstances, the gas densities in the hot-flow prototype and cold-flow model are the same and similitude is achieved with the same density of dust particles and the same density of bed granules in the two beds.

However, the diameter of dust particles and bed granules in the cold-flow model will have to be about half the size of those in a high temperature, high pressure prototype. Table 3.1 summarizes the parameters for both prototype and similitude models.

\subsection{Statistical methods}

An empirical correlation explains a process in the form of an equation fit to actual data. In this method, an equation was regressed from the data collected for each response variable. Response variables are the desired parameters on the left hand side of the equations regressed, while predictors are the independent variables appear on the right hand side.

Pressure drop and efficiency are the two response variables in this study, while superficial velocity, dust loading, and granular flow rate are the predictors. The steps to obtain an empirical correlation follow from a design of experiment (DOE), the graphical representation of the data, and appropriate statistical analysis. 
Table 3.1 Operating conditions of prototype and model filters

\begin{tabular}{|c|c|c|}
\hline & Prototype & Model \\
\hline Air pressure & $898.67 \mathrm{kPa}$ gage (130.34 psig) & $159.67 \mathrm{kPa}$ gage (23.16 psig) \\
\hline Air temperature & $850 \mathrm{C}$ & $20 \mathrm{C}$ \\
\hline Air density $\rho_{g}$ & $3.10 \mathrm{~kg} / \mathrm{m}^{3}$ & $3.10 \mathrm{~kg} / \mathrm{m}^{3}$ \\
\hline Air viscosity $\mu$ & $4.48 \mathrm{E}-5 \mathrm{~kg} / \mathrm{m}-\mathrm{s}$ & $1.83 \mathrm{E}-5 \mathrm{~kg} / \mathrm{m}-\mathrm{s}$ \\
\hline Ash diameter $d_{p}$ & $20.86 \mathrm{um}$ & $11.46 \mathrm{um}$ \\
\hline Ash density $\rho_{p}$ & $2400 \mathrm{~kg} / \mathrm{m}^{3}$ & $2400 \mathrm{~kg} / \mathrm{m}^{3}$ \\
\hline Granule density $\rho_{g}$ & $2450 \mathrm{~kg} / \mathrm{m}^{3}$ & $2450 \mathrm{~kg} / \mathrm{m}^{3}$ \\
\hline Granule diameter $\mathrm{d}_{\mathrm{g}}$ & $7.28 \mathrm{~mm}$ & $4 \mathrm{~mm}$ \\
\hline Superficial velocity U & $0.27 \mathrm{~m} / \mathrm{s}$ & $0.20 \mathrm{~m} / \mathrm{s}$ \\
\hline$S t=\frac{\rho_{p} \cdot d_{p}^{2} \cdot U \cdot C_{s}}{9 \cdot \mu \cdot d_{g}}$ & 0.1 & 0.1 \\
\hline $\operatorname{Re}=\frac{\rho_{f} \cdot U \cdot d_{g}}{\mu}$ & 135.92 & 135.92 \\
\hline$R=\frac{d_{p}}{d_{g}}$ & 0.0029 & 0.0029 \\
\hline$R_{r h o}=\frac{\rho_{g}}{\rho_{f}}$ & 790.32 & 790.32 \\
\hline$F r=\frac{U^{2}}{g \cdot d_{g}}$ & 1.02 & 1.02 \\
\hline
\end{tabular}

\subsubsection{Central composite design}

A statistical design of experiment (DOE) method called central composite design was used to formulate a set of experiments in order to the relationships between predictors and optimum operating conditions for the performance of the moving bed granular filter. The important concept in DOE is to be able to turn each predictor's "knob" to a specified level or operating value for each run. Calibrated values of dust loading (DL) and granular flow rate (GF) are 
used to "set" each predictor at a specific level. However, controlling superficial velocity is troublesome as it depends on the actual air velocity inside the bed, which depends on inlet bed pressure (see Appendix E). Thus, the rotameter setting (RS) is chosen to (indirectly) "set" superficial velocity at different levels.

The major steps in designing a set of experiments via central composite design are (Vardeman, 1999):

1. Generate a two level full or partial factorial design

2. Add some replication of center points (preferably greater than 1)

3. Add two star points for each independent variable

This study examines three predictors and uses two center points; thus, central composite design results in a total of 16 different sets of process conditions. In order to generate a two level full factorial design, low and high levels for each predictors were selected as follow: granular flow rate $(8.6-16.24 \mathrm{~kg} / \mathrm{hr})$, rotameter setting $\left(0.0071-0.0094 \mathrm{STP} \mathrm{m}^{3} / \mathrm{s},[15-20\right.$ SCFM]), and dust loading $(0.28-0.84 \mathrm{~kg} / \mathrm{hr})$. These lows and highs were selected based on the capability of the filter system.

A coded variable equation is used to determine center and star points:

Coded variable $=\frac{(\text { set values }- \text { mean of predictor })}{s}$

where the mean of predictor is the average of all set values for each predictor, and $\mathrm{s}$ is defined as:

$$
\mathrm{s}=\frac{1}{2} \times(\text { high }- \text { low })
$$


Central composite design always generates a total of five different levels for each predictor. The central point coded variable values are always zero, and the coded variable values for star points are calculated using Equation 3.3:

$$
\mathrm{A}= \pm\left(2^{\mathrm{k}}\right)^{1 / 4}
$$

where $\mathrm{k}$ is three corresponding to the number independent of variables.

Each predictor's set value can be obtained by manipulating Equation 3.1 to solve for GF, RS, and DL as indicated in Table 3.2. Table 3.3 shows the designed experiments obtained using Equation 3.1 - 3.3 and the corresponding response variables' data collected.

\section{Table 3.2. Predictors and their coded variables}

\begin{tabular}{|l|c|c|}
\hline Factor & $\frac{\text { Variable symbol }}{\text { Coded Variable }}$ \\
\hline Granular Flow Rate & GF & $x_{1}=\frac{G F-12.42}{3.82}$ where $x_{1}$ is in $\mathrm{kg} / \mathrm{hr}$ \\
\hline${ }^{1}$ Rotameter Setting & $\mathrm{RS}$ & $x_{2}=\frac{R S-17.5}{2.5}$ where $x_{2}$ is in SCFM \\
\hline Dust Feed Rate & $\mathrm{DL}$ & $x_{3}=\frac{D L-0.56}{0.28}$ where $x_{3}$ is in $\mathrm{kg} / \mathrm{hr}$ \\
\hline
\end{tabular}

With the operating conditions determined, experiments were carried out to collect results for both average pressure drop and average efficiency measured over the duration of each experiment. Finally, a regression method was utilized to find one regressed model for

\footnotetext{
${ }^{1}$ Appendix E shows calculations of superficial velocity (VL) from rotameter setting (RS) specified in each run.
} 
each response variable. This model was useful in optimizing and developing contour plots of filter performance.

\subsubsection{Data Collection}

The total runtime for each run is the time required to fill up the discharge vessel or about $35 \mathrm{~kg}$. The pressure drop across the filter bed and particle collection efficiency are the important response variables collected in this study. An average pressure drop (APD) over each run was used in the statistical analysis utilizing the data acquisition system at a sampling of $1 \mathrm{~Hz}$. Although the efficiency was sampled at intervals of 30 minutes, an average efficiency (AE) was also measured over longer periods of time (e.g. 2 hours). The original "set" of values for each predictor were adjusted in tests to actual values being "measured."

As indicated above, central composite design gives a total of sixteen runs. The order of experiment performed was chosen randomly with the help of a random number generator in MS Excel for a discrete uniform distribution (Ragsdale, 1998):

$$
\text { Integer }(n * \operatorname{RAND}())+\mathrm{a}
$$

where $\mathrm{n}$ is the highest discrete number in the set $(=16)$; and a is the lowest discrete number in the set, which is 1 in our study. RAND() is the random number generator in MS Excel ranging between 0.0 and 1.0. The chronological order by using Equation 3.4 in this research is: $5,2,4,7,1,6,8,3,12,14,13,10,16,15,9$, and 11 .

As an example, for Run \#1, the granular flow rate (GF), rotameter setting (RS), and dust feed rate (DL) were set at $8.6 \mathrm{~kg} / \mathrm{hr}, 15 \mathrm{SCFM}$, and $0.28 \mathrm{~kg} / \mathrm{hr}$ respectively. Operating values for granular flow rate (GF) and dust feed rate (DL) used in each run were determined 
from calibration curves. However, measured values of GF's and DL's during each run were typically different from the calibration values, particularly for the dust feed rate. It is believed that a scouring effect may have contributed to additional ash removal at higher air flow rates.

Similarly, in the central composite design Table 3.2, air velocity into the filter was set at different values using a rotameter. However, the actual superficial velocity (VL) passing through the filtering zone differed with different granular flow and dust feed rates.

The measured value of each predictor was obtained following each run. Actual granular flow rate and dust feed rate were obtained by dividing measured values before and after a run using Equation [3.1]. Detailed calculations are found in Appendix E. 


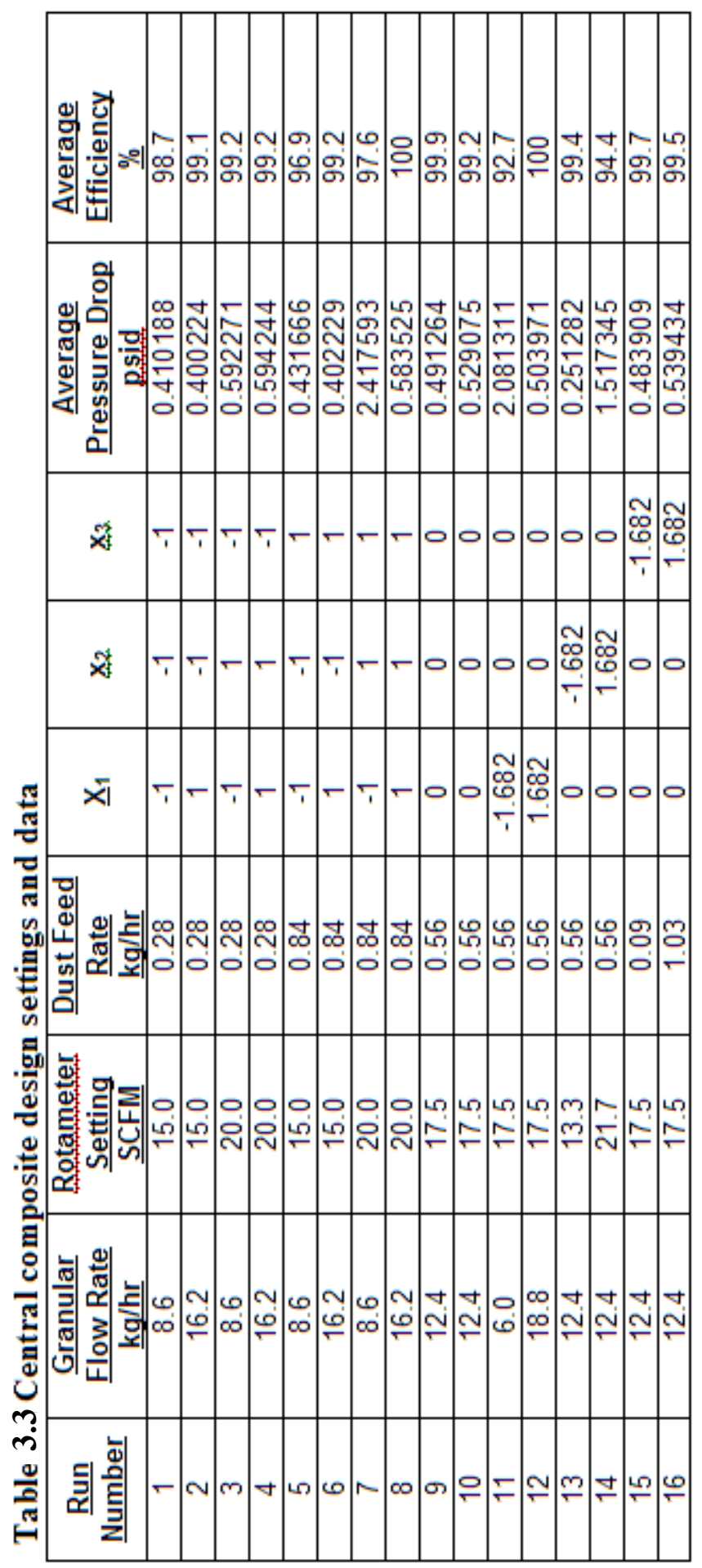




\subsubsection{Statistical Analysis}

For each response variable, the results obtained in Table 3.2 were regressed to form a full quadratic equation. Individual effects (single, square, or crossed) in the regressed full quadratic equation were checked against a p-value of 0.05. A p-value greater than 0.05 indicates lack of evidence to claim insignificant effect in that equation, while a p-value less than 0.05 indicates the particular effect is significant in predicting the response variable. Besides looking the significance tests on each effect, $\mathrm{R}^{2}$ and adjusted $\mathrm{R}^{2}$ are also important in determining whether a good fit of data occurs. Another important regression diagnostic is a residual plot for each response variable and each independent variable that appear in the predicting equation. Before using the regressed equation, it was checked to determine if the random error normal distribution assumption was valid, a requirement in regression analysis. A regressed equation is only valid if it passes the normal distribution test. If the regressed full quadratic equation is determined not to be suitable in predicting response variable, a forward-stepped method of regression can be used. Then, the F-test is used to determine if a full or reduced (forward-stepped) model is best among the two.

Forward-stepped regression allows the evaluation of each effect taken one at a time to determine if it should be included in the final equation based on the entered probability to include or omit values. Therefore, the equation produced by this method is expected to be simpler compared to the full quadratic equation. The forward-stepped equation generated from this method was also checked against effect tests, $\mathrm{R}^{2}$, adjusted $\mathrm{R}^{2}$, residual, and normal distribution tests. 
Runs 7, 11, and 14 in Table 3.2 show significantly higher average pressure drop and average efficiency values than do other runs. These runs had transient behavior in which the system did not reach steady state. The common method to determine if these data are to be included in the statistical analysis is to either eliminate these runs or else transform each response variable. These three runs were initially removed from the entire set for full quadratic and forward-stepped regression to eliminate possible outliers. However, the result of this elimination step generated inappropriate full quadratic models (both APD and AE) because of their high p-values. On the other hand, the elimination of these runs resulted in forward-stepped models having a high $\mathrm{R}^{2}$ of 0.9 for APD, but a very low $\mathrm{R}^{2}$ of 0.3 for AE. Since, in this study we are ultimately interested in finding an optimum region that simultaneously satisfies both high APD and low AE models, the elimination of run 7, 11, and 14 in statistical analysis is not a good idea. Consequently, the transformation of each response variable was utilized to include these runs.

The transformation involved taking the natural logarithm of the values for each response variable. Therefore, the models regressed were in the forms of $\ln (\mathrm{APD})$ and $\ln (\mathrm{AE})$. The full quadratic models (both APD and AE) from the transformation were inadequate because of their high p-values. In addition, the forward-stepped models (both APD and AE) resulted from a transformation with high $\mathrm{R}^{2}$ of 0.9 for $\mathrm{APD}$, but a low $\mathrm{R}^{2}$ of 0.3 for AE. As a result, neither elimination nor transformations of the outlier runs were utilized in statistical analysis.

In the present study, two equations or correlations were regressed, as there were two response variables. Each regressed equation can be used to generate optimum 
operating region for each response variable. However, in actual applications, one is interested in obtaining a single best operating region that simultaneously satisfying all the response variables. This can be achieved by overlaying each contour plot (from each regressed equation), one over the other. This approach helps locate regions that simultaneously satisfy both low average pressure drop and high average efficiency. 


\section{Results and Discussion}

The experimental configuration for all tests was a cold flow, axially symmetric counter-current flow bed designed to simulate filters operating at high temperatures (1088 K) and elevated pressures (10 atmospheres). The granular filter has been evaluated in two separate performance studies: (1) optimization of particle collection efficiency and bed pressure drop in a factorial study at near-atmospheric operating pressures through appropriate use of granular bed materials, particle sizes, and feed rates; and (2) a high temperature and pressure model simulation study utilizing above-atmospheric operating pressures (at room temperature) through appropriate use of dust and granular flow rates, granular size, system pressure, and superficial velocity. In the near-atmospheric pressure factorial study a total of 16 near-atmospheric tests were conducted while 7 tests were carried out for the high-pressure modeling study.

\subsection{Atmospheric tests}

In our near-atmospheric pressure studies, central composite design based on 16 tests was used to develop relationships between independent variables, superficial velocity $(0.16-0.22 \mathrm{~m} / \mathrm{s})$, dust feed rate $(0.08-0.74 \mathrm{~kg} / \mathrm{hr})$, and granular flow rate $(3.32-$ $15.4 \mathrm{~kg} / \mathrm{hr}$ ), and to find the optimum operating conditions in achieving filtration goals. Contour plots generated from developed relationships provide operating conditions that simultaneously satisfy low-pressure drop and high efficiency. A sampling frequency of 1 $\mathrm{Hz}$ via computer was used throughout the entire set of experiments. 


\subsection{1. $\quad$ APD as a function of operating condition variables}

The results from central composite design are shown in Table 4.1. The response variable (APD) was obtained by averaging all the pressure drop data over the duration of the run.

Table 4.1. Average pressure drop obtained from each run

\begin{tabular}{|c|c|c|c|c|}
\hline Run Number & $\frac{\text { Granular Flow }}{\text { Rate (GF), kg/hr }}$ & $\frac{\frac{\text { Superficial }}{\text { Velocity }(\mathrm{VL})}}{\mathrm{m} / \mathrm{s}}$ & $\frac{\text { Dust Feed Rate }}{\text { (DL), kg/hr }}$ & $\begin{array}{l}\begin{array}{c}\text { Average } \\
\text { Pressure Drop }\end{array} \\
\text { (APD), psid }\end{array}$ \\
\hline 1 & 6.85 & 0.175 & 0.2412 & 0.410188 \\
\hline 2 & 13.10 & 0.176 & 0.1712 & 0.400224 \\
\hline 3 & 6.80 & 0.213 & 0.2556 & 0.592271 \\
\hline 4 & 13.00 & 0.216 & 0.2289 & 0.594244 \\
\hline 5 & 6.70 & 0.177 & 0.2680 & 0.431666 \\
\hline 6 & 12.10 & 0.177 & 0.3160 & 0.402229 \\
\hline 7 & 7.27 & 0.190 & 0.5698 & 2.417593 \\
\hline 8 & 15.40 & 0.211 & 0.4257 & 0.583525 \\
\hline 9 & 9.36 & 0.196 & 0.4417 & 0.491264 \\
\hline 10 & 10.16 & 0.197 & 0.5219 & 0.529075 \\
\hline 11 & 3.32 & 0.179 & 0.3973 & 2.081311 \\
\hline 12 & 14.00 & 0.199 & 0.3932 & 0.503971 \\
\hline 13 & 9.12 & 0.161 & 0.3764 & 0.251282 \\
\hline 14 & 8.24 & 0.207 & 0.5734 & 1.517345 \\
\hline 15 & 8.64 & 0.195 & 0.0786 & 0.483909 \\
\hline 16 & 9.68 & 0.200 & 0.7437 & 0.539434 \\
\hline
\end{tabular}

Statistical software called JMP was used to conduct a standard least square regression analysis. A full-quadratic model was first regressed. Details of the statistical analysis for the full-quadratic model are given in Appendix F. Analysis of variance (ANOVA) indicates the p-value of 0.0932 for the full-quadratic model is greater than the significant level of 0.05 , which means that the regressed full-quadratic model is inadequate in explaining the average pressure drop.

In order to obtain a more suitable model, forward stepping regression with probability to enter of 0.25 and probability to leave of 0.1 (default values in JMP for 
stepwise regression) were used to discard effects that are insignificant in predicting APD. Adjusted $\mathrm{R}^{2}$ increases from 0.5531 in full-quadratic model to 0.6721 in forward-stepped model. Root mean square value decreased from 0.4303 to 0.3686 while using stepped model instead of full-quadratic model. By comparing adjusted $\mathrm{R}^{2}$, root mean square and p-values of the variables in full and stepped models, the forward-stepped model was chosen to be the final average pressure drop (APD) model.

Table 4.2. A forward-stepped APD model

\section{Summary of Fit}

$\begin{array}{lr}\text { Rsquare } & 0.781407 \\ \text { RSquare Adj } & 0.672111 \\ \text { Root Mean Square Error } & 0.368611 \\ \text { Mean of Response } & 0.764346 \\ \text { Observations (or Sum Wgts) } & 16\end{array}$

Analysis of Variance

\begin{tabular}{|c|c|c|c|c|}
\hline Source & \multicolumn{2}{|c|}{ Sum of Squares } & \multicolumn{2}{|c|}{ Mean Square } \\
\hline Model & 5 & 571298 & \multicolumn{2}{|c|}{0.971426} \\
\hline Error & 10 & 587443 & \multirow{2}{*}{\multicolumn{2}{|c|}{0.135874}} \\
\hline C. Total & 15 & 158741 & & \\
\hline \multicolumn{5}{|c|}{ Parameter Estimates } \\
\hline Term & Estimate & Std Error & t Ratio & Prob $>|t|$ \\
\hline Intercept & -1.958835 & 1.810777 & -1.08 & 0.3048 \\
\hline GF & -0.158845 & 0.192697 & -0.82 & 0.4290 \\
\hline VL & 8.7451756 & 6.485209 & 1.35 & 0.2073 \\
\hline DL & 10.754496 & 2.896721 & 3.71 & 0.0040 \\
\hline$G F^{*} G F$ & 0.0207601 & 0.008129 & 2.55 & 0.0287 \\
\hline $\mathrm{DL}^{*} \mathrm{GF}$ & -1.001186 & 0.304895 & -3.28 & 0.0082 \\
\hline
\end{tabular}

\section{Effect Tests}

$\begin{array}{lrrrrr}\text { Source } & \text { Nparm } & \text { DF } & \text { Sum of Squares } & \text { F Ratio } & \text { Prob }>\text { F } \\ \text { GF } & 1 & 1 & 0.0923281 & 0.6795 & 0.4290 \\ \text { VL } & 1 & 1 & 0.2470739 & 1.8184 & 0.2073 \\ \text { DL } & 1 & 1 & 1.8728562 & 13.7837 & 0.0040 \\ \text { GF*GF } & 1 & 1 & 0.8861564 & 6.5219 & 0.0287 \\ \text { DL*GF }^{*} & 1 & 1 & 1.4650978 & 10.7827 & 0.0082\end{array}$

The forward-stepped regression gives the following model:

$$
\begin{aligned}
A P D= & -1.958835-0.158845 \cdot G F+8.7451756 \cdot V L+10.754496 \cdot D L \\
& -1.001186 \cdot D L \cdot G F+0.0207601 \cdot G F^{2}
\end{aligned}
$$

The statistical analysis (Table 4.2) in this section indicates that there is lack of evidence to reject the hypotheses that granular flow rate (GF) and superficial velocity (VL) are 
insignificant effects in predicting the average pressure drop (APD) as GF's and VL's pvalues are greater than 0.05 .

It was also found that there is an important interaction between dust loading and granular flow rate from DL•GF's low p-value (0.0082). The square of the granular flow rate $\left(\mathrm{GF}^{2}\right)$ and dust loading (DL) were also determined to significantly affect pressure drop ( $\mathrm{p}$-values are significantly lower than 0.05 respectively). The significance of $\mathrm{GF}^{2}$ in Equation 4.1 designates the parabolic nature of granular flow rate in explaining average pressure drop.

Using Equation 4.1, a series of contour plots were generated for each superficial velocity to determine the optimum APD regions. The details of generating the contour plots are covered in Appendix H. Figures 4.1 - 4.4 show regions where low average pressure drop occurs.

These figures illustrate saddle patterns, which means there are two different slopes (positive and negative) occurring in each plot. In Figure 4.1, for example, to the left of lower-left red $(\mathrm{APD}=0.1)$ contour line is region with APD less than 0.1 psid. Similarly, to the right of upper-right red contour line lies another region with APD less than 0.1 . Moving from APD $=0.2$ to APD $=0.5$ is a "hill-climbing" behavior, which means heading to higher APD.

With GF and DL lay within $3.32-15.4 \mathrm{~kg} / \mathrm{hr}$ and $0.08-0.74 \mathrm{~kg} / \mathrm{hr}$ respectively, all plots (Fig. $4.1-4.4$ ) indicate that there is no single maximum nor single minimum point within the operating ranges studied. However, maximum or minimum points can 
be located if the independent variables' (predictors) values are intentionally bounded to different scales.

The contours in Figures 4.1-4.4 show how the independent variables are closely relate to each other. In a specific region of the plot, the relationship between one of the independent variables and average pressure drop can be positive. However, in another region, the same independent variable can have a negative relationship with average pressure drop because of the existence of two different slopes (positive and negative) in these saddle pattern contour plots. For example, in Figure 4.1 with GF lies from 10.5 $15.4 \mathrm{~kg} / \mathrm{hr}$ and DL lies from $0.08-0.38 \mathrm{~kg} / \mathrm{hr}$, an increase in GF will cause an increase in average pressure drop. However, with GF lies from 3.32 to $10.5 \mathrm{~kg} / \mathrm{hr}$ and DL lies from approximately 0.15 to $0.74 \mathrm{~kg} / \mathrm{hr}$, an increase in GF will cause a decrease in average pressure drop. 


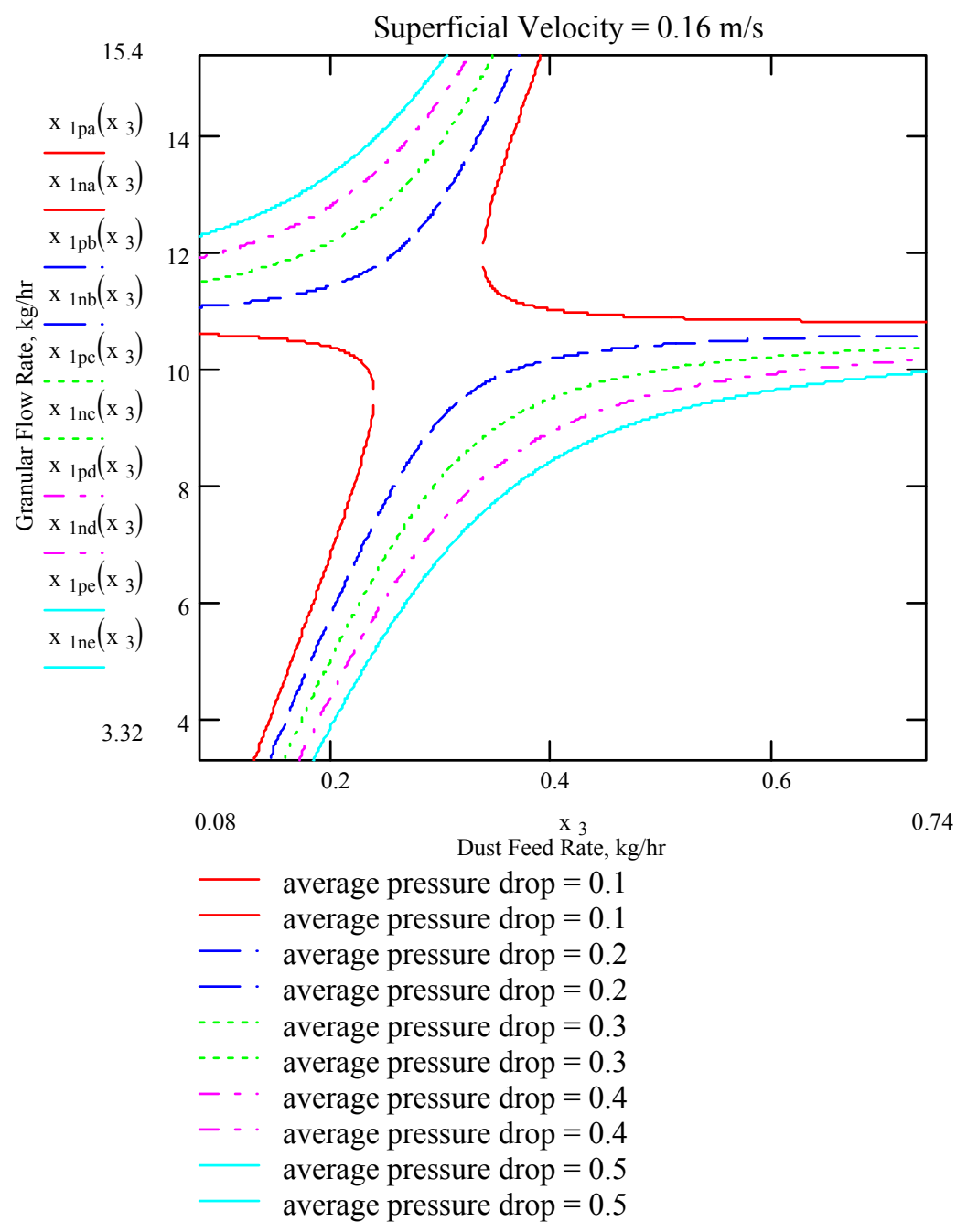

Figure 4.1. Contour plot of APD with respect to GF, DL, and VL at $0.16 \mathrm{~m} / \mathrm{s}$ 


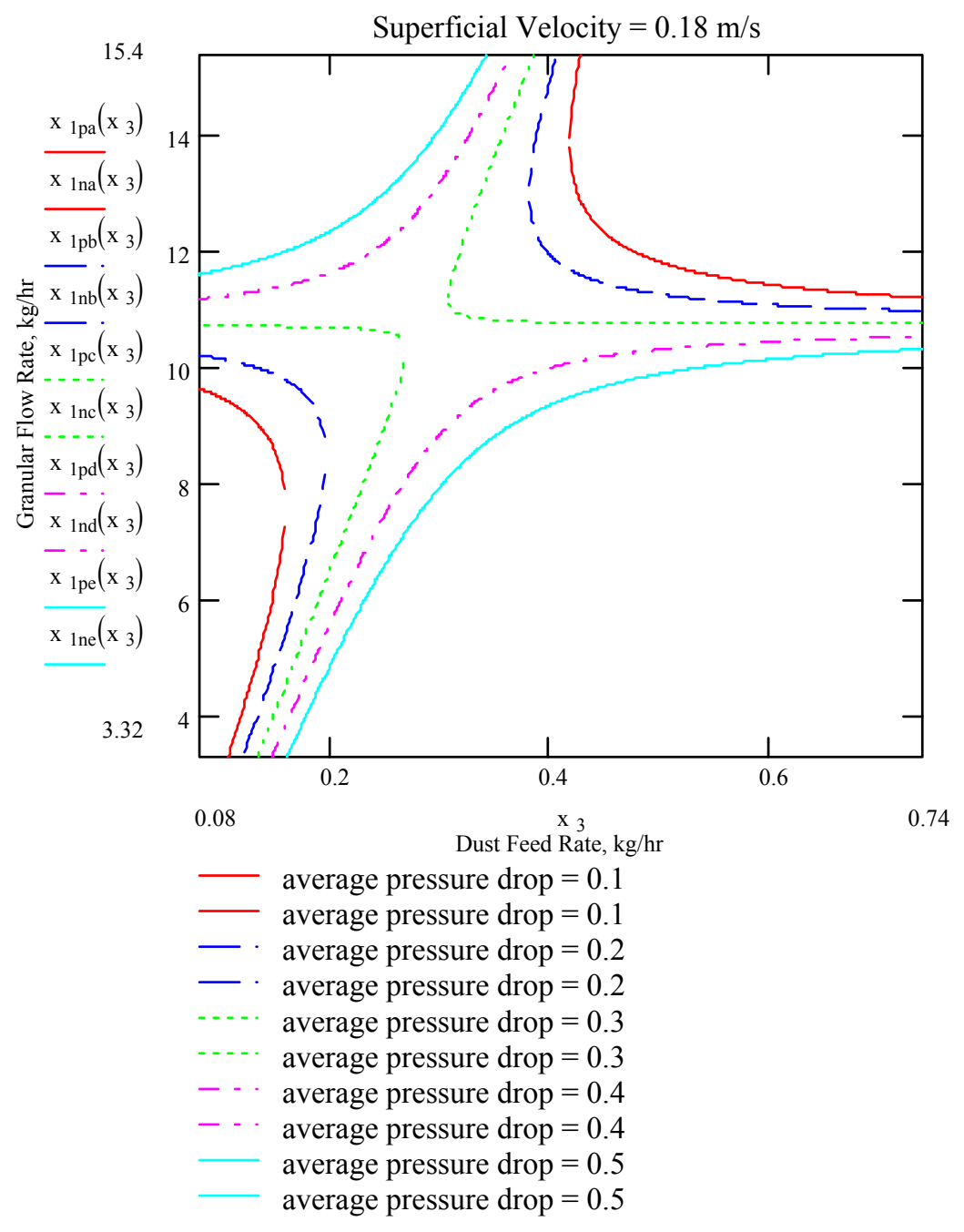

Figure 4.2. Contour plot of APD with respect to GF, DL, and VL at $0.18 \mathrm{~m} / \mathrm{s}$ 


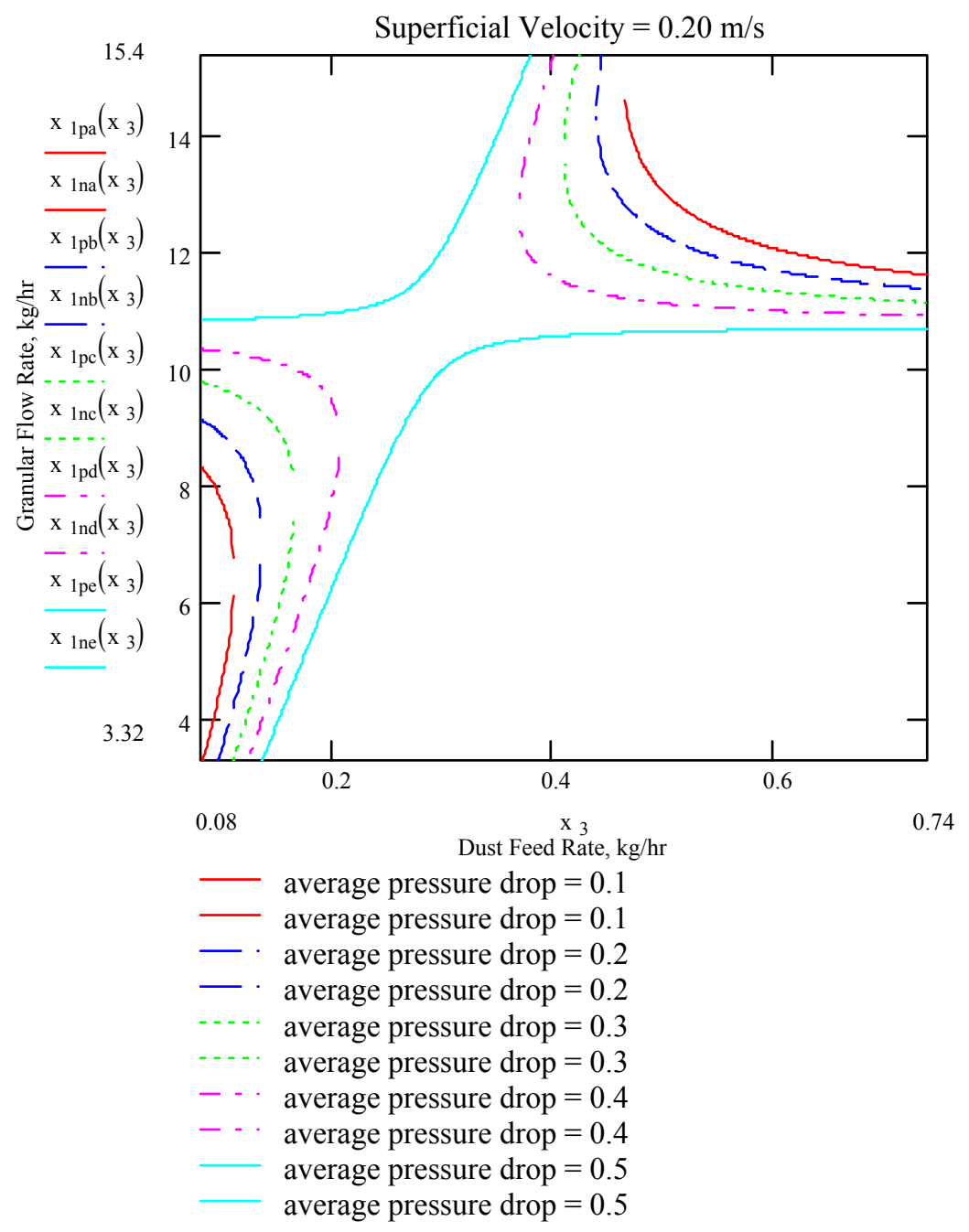

Figure 4.3. Contour plot of APD with respect to GF, DL, and VL at $0.20 \mathrm{~m} / \mathrm{s}$ 


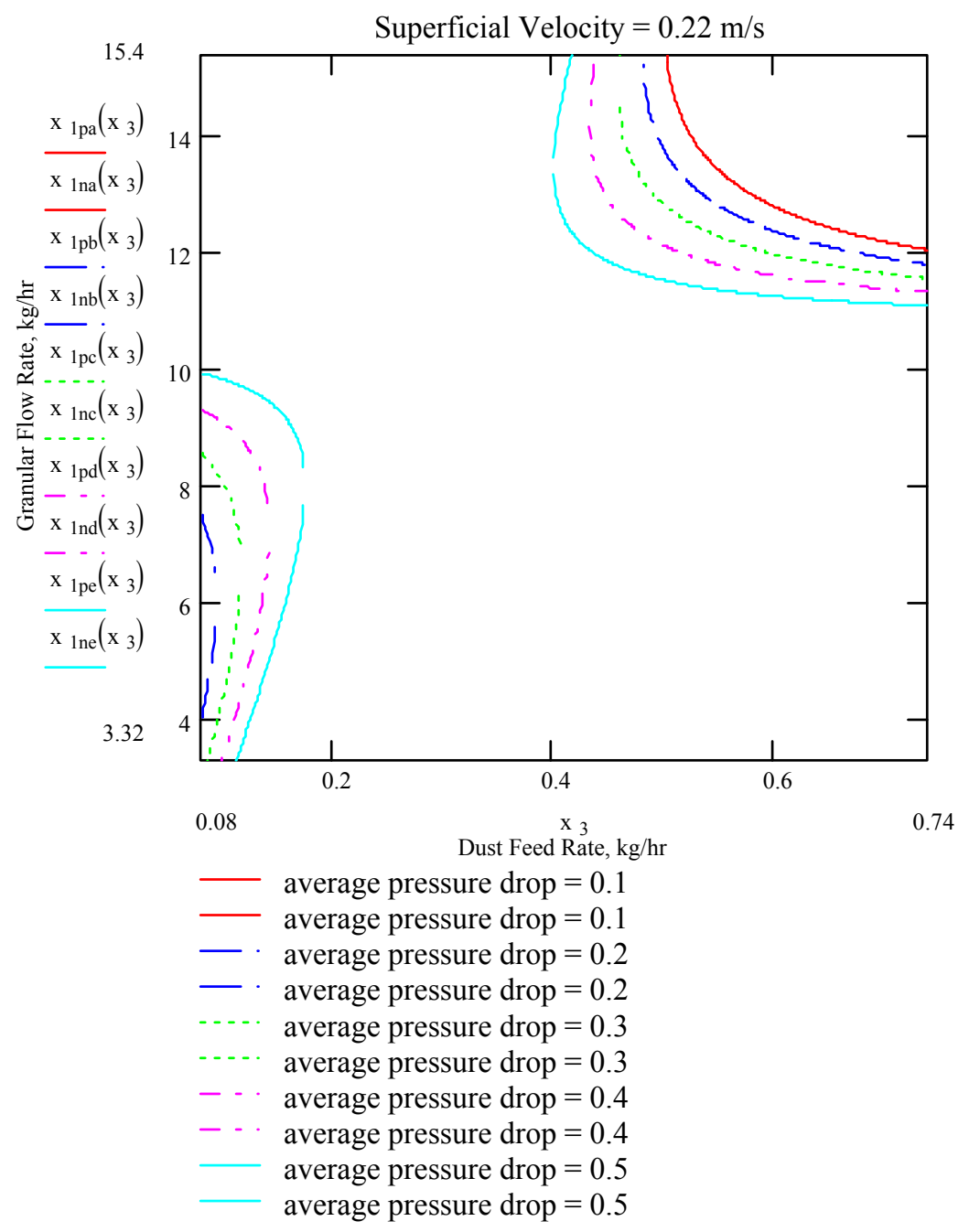

Figure 4.4. Contour plot of APD with respect to GF, DL, and VL at $0.22 \mathrm{~m} / \mathrm{s}$

\subsubsection{Average Efficiency (AE) as a function of GF and DL}

The average particle collection efficiency of the bed, Equation 2.1, collected for each run, given in Table 4.3, was used for model regression. The steps involved are the same as for the regression of the pressure drop. In fact, the main difference is that the values in $5^{\text {th }}$ column in Table 4.3 are replaced with average efficiencies. 
Table 4.3. Average Efficiency obtained from each run

\begin{tabular}{|c|c|c|c|c|}
\hline Run Number & $\frac{\text { Granular Flow }}{\text { Rate (GF), kg/hr }}$ & $\frac{\frac{\text { Superficial }}{\text { Velocity }(V L)},}{\underline{\mathrm{m} / \mathrm{s}}}$ & $\frac{\text { Dust Feed Rate }}{\text { (DL), kg/hr }}$ & $\begin{array}{c}{ }^{2} \text { Average } \\
\text { Efficiency (AE), } \\
\underline{\%}\end{array}$ \\
\hline 1 & 6.85 & $0 . \overline{175}$ & 0.2412 & $9 \overline{8.7}$ \\
\hline 2 & 13.10 & 0.176 & 0.1712 & 99.1 \\
\hline 3 & 6.80 & 0.213 & 0.2556 & 99.2 \\
\hline 4 & 13.00 & 0.216 & 0.2289 & 99.2 \\
\hline 5 & 6.70 & 0.177 & 0.2680 & 96.9 \\
\hline 6 & 12.10 & 0.177 & 0.3160 & 99.2 \\
\hline 7 & 7.27 & 0.190 & 0.5698 & 97.6 \\
\hline 8 & 15.40 & 0.211 & 0.4257 & 100 \\
\hline 9 & 9.36 & 0.196 & 0.4417 & 99.9 \\
\hline 10 & 10.16 & 0.197 & 0.5219 & 99.2 \\
\hline 11 & 3.32 & 0.179 & 0.3973 & 92.7 \\
\hline 12 & 14.00 & 0.199 & 0.3932 & 100 \\
\hline 13 & 9.12 & 0.161 & 0.3764 & 99.4 \\
\hline 14 & 8.24 & 0.207 & 0.5734 & 94.4 \\
\hline 15 & 8.64 & 0.195 & 0.0786 & 99.7 \\
\hline 16 & 9.68 & 0.200 & 0.7437 & 99.5 \\
\hline
\end{tabular}

${ }^{2}$ Refer to Appendix I for details on uncertainty analysis of efficiency.

In Appendix G, the AE full model has p-value (0.0519) greater than 0.05

significant level, which indicates inappropriateness of a full quadratic model. As in

Section 4.1.1, a forward stepping regression with probability to enter of 0.25 and

probability to leave of 0.1 (default values in JMP for stepwise regression) were used to

trim out the insignificant effects. The forward-stepped model and its analysis are given

in Table 4.4 .

Adjusted $\mathrm{R}^{2}$ increases from 0.6451 in full-quadratic model to 0.6750 in a forwardstepped model. Root mean square value decreases from 1.2476 to 1.1940 using the stepped model instead of full-quadratic model. By comparing adjusted $\mathrm{R}^{2}$, root mean square and p-values of the variables in both full and stepped models, a forward-stepped model was chosen to be the final average efficiency (AE) model.

The forward-stepped average efficiency model is given as follow: 


$$
\begin{aligned}
A E= & 96.321416+1.1247304 \cdot G F-23.97655 \cdot D L-0.077787 \cdot G F^{2} \\
& +2.2987478 \cdot D L \cdot G F
\end{aligned}
$$

Table 4.4. A forward-stepped AE model

\section{Summary of Fit}

$\begin{array}{lr}\text { Rsquare } & 0.761632 \\ \text { RSquare Adj } & 0.674953 \\ \text { Root Mean Square Error } & 1.193957 \\ \text { Mean of Response } & 98.41875 \\ \text { Observations (or Sum Wgts) } & 16\end{array}$

Analysis of Variance

$\begin{array}{lrrrr}\text { Source } & \text { DF } & \text { Sum of Squares } & \text { Mean Square } & \text { F Ratio } \\ \text { Model } & 4 & 50.103499 & 12.5259 & 8.7868 \\ \text { Error } & 11 & 15.680876 & 1.4255 & \text { Prob }>\text { F } \\ \text { C. Total } & 15 & 65.784375 & & 0.0019\end{array}$

\section{Parameter Estimates}

$\begin{array}{lrrrr}\text { Term } & \text { Estimate } & \text { Std Error } & \text { t Ratio } & \text { Prob>|t| } \\ \text { Intercept } & 96.321416 & 4.076114 & 23.63 & <.0001 \\ \text { GF } & 1.1247304 & 0.621371 & 1.81 & 0.0977 \\ \text { DL } & -23.97655 & 9.329298 & -2.57 & 0.0260 \\ \text { GF*GF } & -0.077787 & 0.026258 & -2.96 & 0.0129 \\ \text { DL*GF } & 2.2987478 & 0.975405 & 2.36 & 0.0380\end{array}$

\section{Effect Tests}

Source

GF

$\mathrm{DL}$

$\mathrm{GF}^{\star} \mathrm{GF}$

$D^{*} \mathrm{GF}$

$\begin{array}{rr}\text { Nparm } & \text { DF } \\ 1 & 1 \\ 1 & 1 \\ 1 & 1 \\ 1 & 1\end{array}$

$$
\begin{array}{r}
\text { Sum of Squares } \\
4.670595 \\
9.415714 \\
12.510789 \\
7.917548
\end{array}
$$

$\begin{array}{lr}\text { F Ratio } & \text { Prob > F } \\ 3.2764 & 0.0977 \\ 6.6050 & 0.0260 \\ 8.7762 & 0.0129 \\ 5.5541 & 0.0380\end{array}$

Likewise, Equation 4.2 was used to generate the contour plot shown in Figure 4.5.

This plot also indicates the saddle pattern. It has both positive and negative slopes in the same plot. Again, with the independent variables' scales of this research (GF and DL lay within $3.32-15.4 \mathrm{~kg} / \mathrm{hr}$ and $0.08-0.74 \mathrm{~kg} / \mathrm{hr}$ respectively), this plot cannot capture a single maximum average efficiency point.

The finding from this study on AE: superficial velocity does not have a significant effect on efficiency, which differs from the observations examined by Moresco et al. (1981) at Combustion Power Company (CPC) and Tsubaki and Tien. (1988). They determined high efficiency with respect to high superficial velocity. On the other hand, Kalinowski and Leith (1982), Peukert and Loffler (1990), and Yang et al. (1992) found that higher superficial gas velocity caused lower dust collection efficiency. 
Note that our research has looked only at a narrow range of superficial velocity $(0.16-0.22 \mathrm{~m} / \mathrm{s})$; thus it might be the reason little or no significant superficial velocity effect was observed. One would expect higher superficial gas velocity to lower efficiency because of re-entrainment of dust particles was settled on the granules' surface.

The saddle pattern in Figure 4.5 shows two different (both positive and negative) relationships between each independent variable and the average efficiency. In addition, this figure also indicates how independent variables are closely related for explaining average efficiency. For example, with dust feed rate (DL) from 0.08 to $0.38 \mathrm{~kg} / \mathrm{hr}$ and granular flow rate (GF) lies from 3.32 to $10 \mathrm{~kg} / \mathrm{hr}$, an increase in granular flow rate (GF) will cause an increase in average efficiency. On the other hand, with DL lies between 0.08 to $0.38 \mathrm{~kg} / \mathrm{hr}$ and GF lies from 10 to $15.4 \mathrm{~kg} / \mathrm{hr}$, an increase in GF will cause a decrease in average efficiency.

Statistical analysis (Table 4.4) in this section for average efficiency (AE) also indicates significant effects of dust loading or dust feed rate (DL), square of granular flow $\left(\mathrm{GF}^{2}\right)$, and interaction between dust loading and granular flow rate $(\mathrm{DL} \bullet \mathrm{GF})$ in explaining average efficiency. The significance of $\mathrm{GF}^{2}$ in Equation 4.2 also designates the parabolic nature of granular flow rate in explaining average efficiency. 


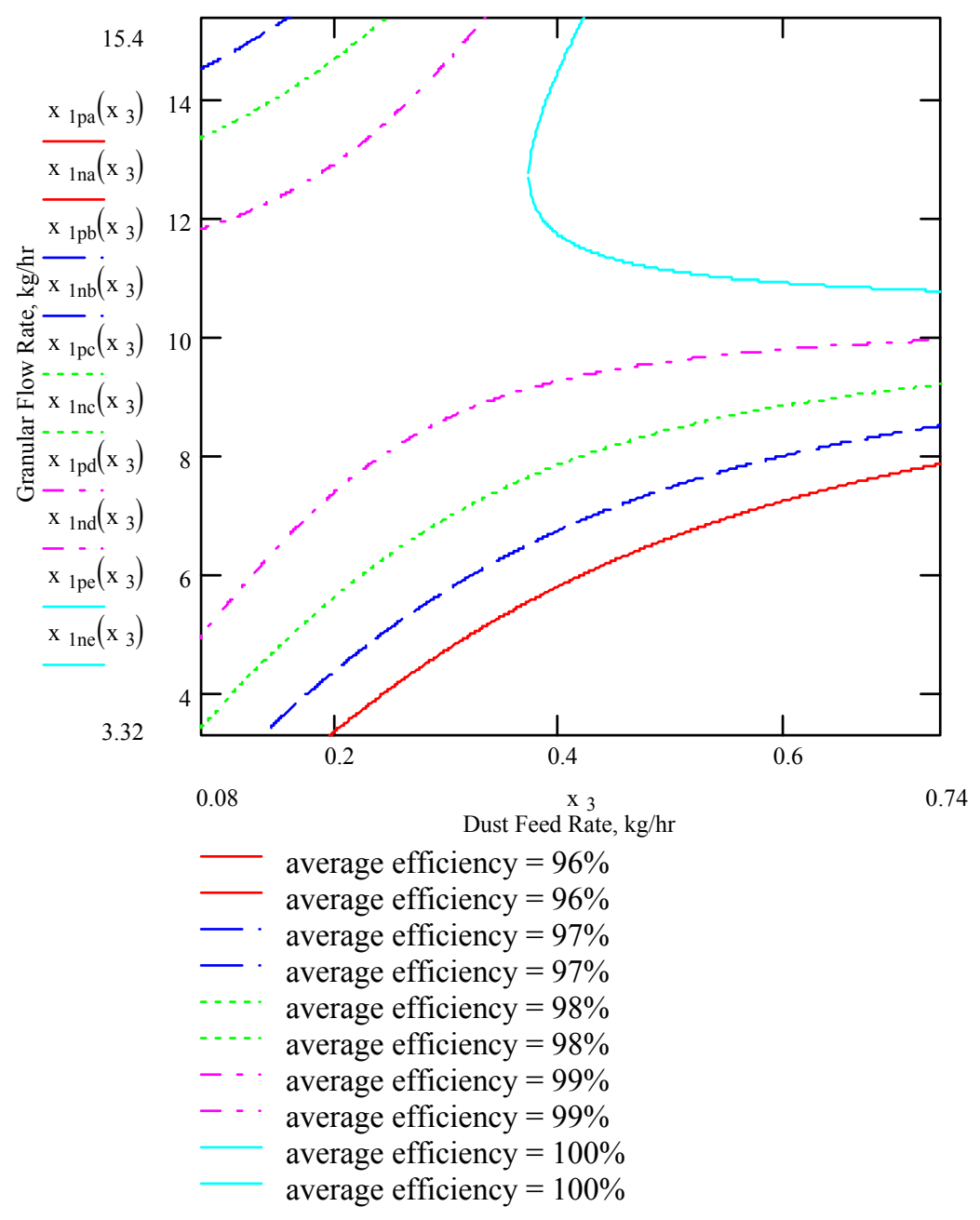

Figure 4.5 Contour plot of AE versus GF and DL

\subsubsection{Residual analysis for APD Model}

In this section, Equation 4.1 is checked using residual analysis to test its usability. Since

Figure 4.6 does not show trend of increasing or decreasing with respect to increasing

APD, it indicates Equation 4.1 is an adequate model to predict average pressure drop.

Similarly, the scattered data points (no trend) in Figures $4.7-4.9$ also indicate the appropriateness of Equation 4.1 in prediction of the average pressure drop. In Figure 4.10, the validity of the assumption that random error is normally distributed indicates once again that Equation 4.1 is an appropriate model. 


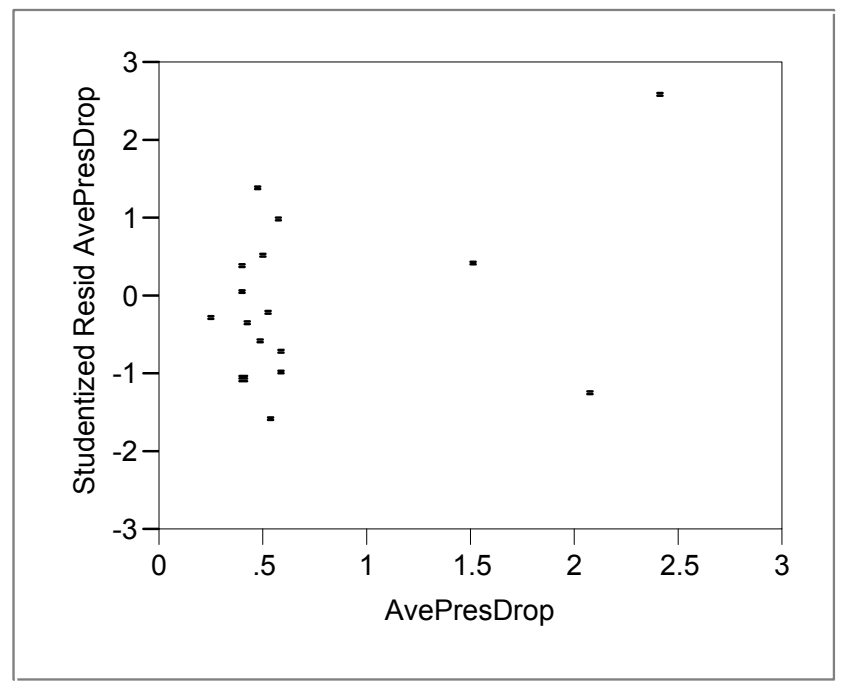

Figure 4.6. Residual APD versus APD

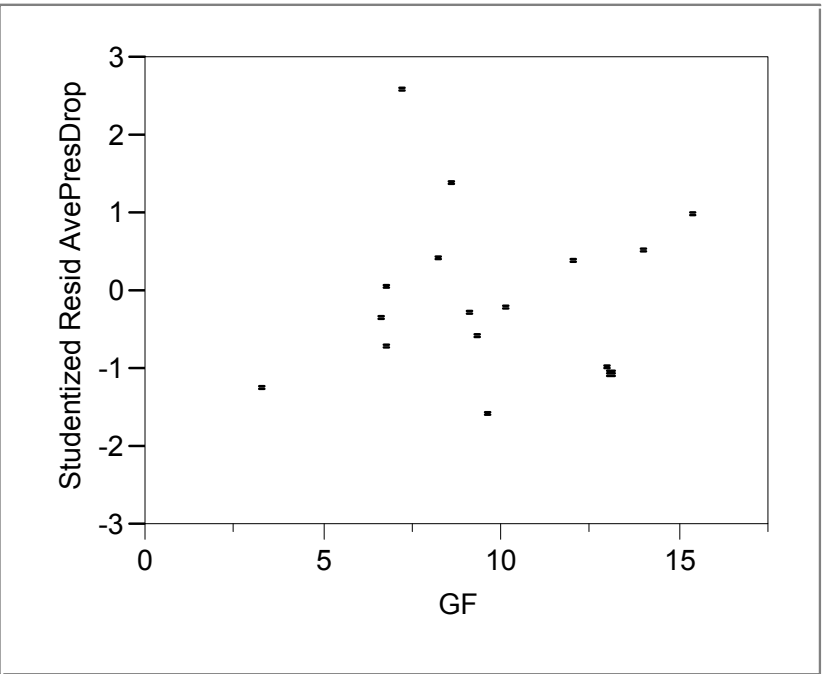

Figure 4.7. Residual APD versus GF 


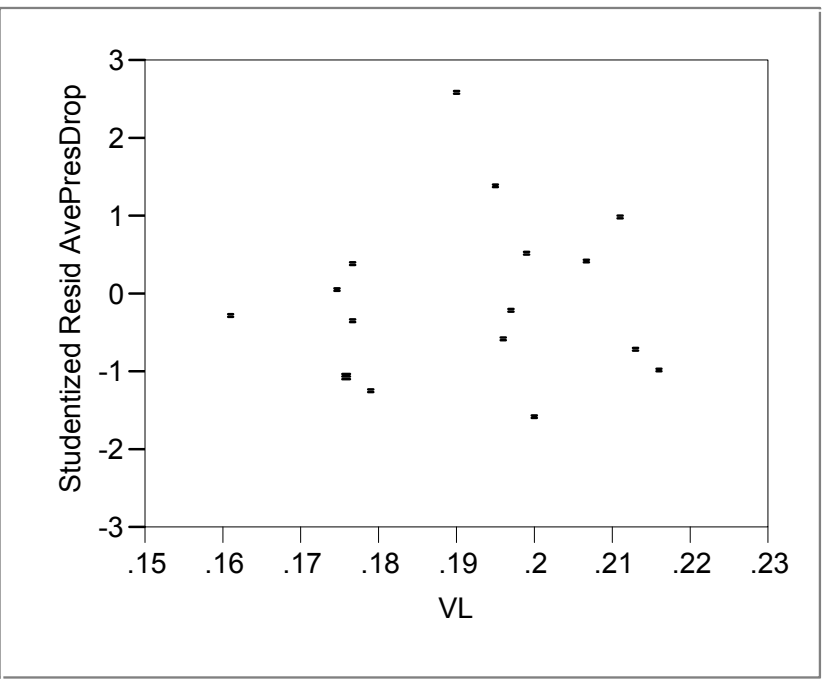

Figure 4.8. Residual APD versus VL

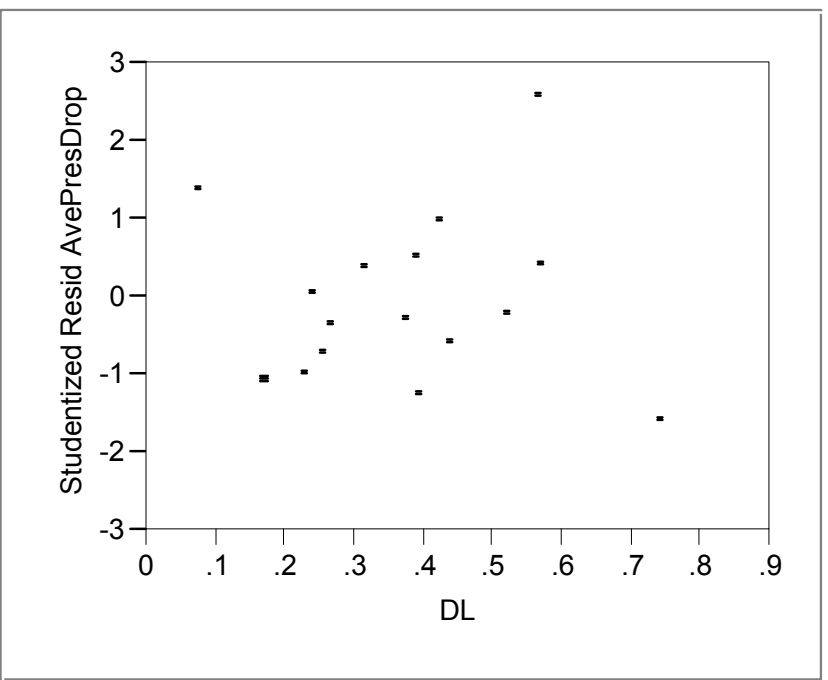

Figure 4.9. Residual APD versus DL 


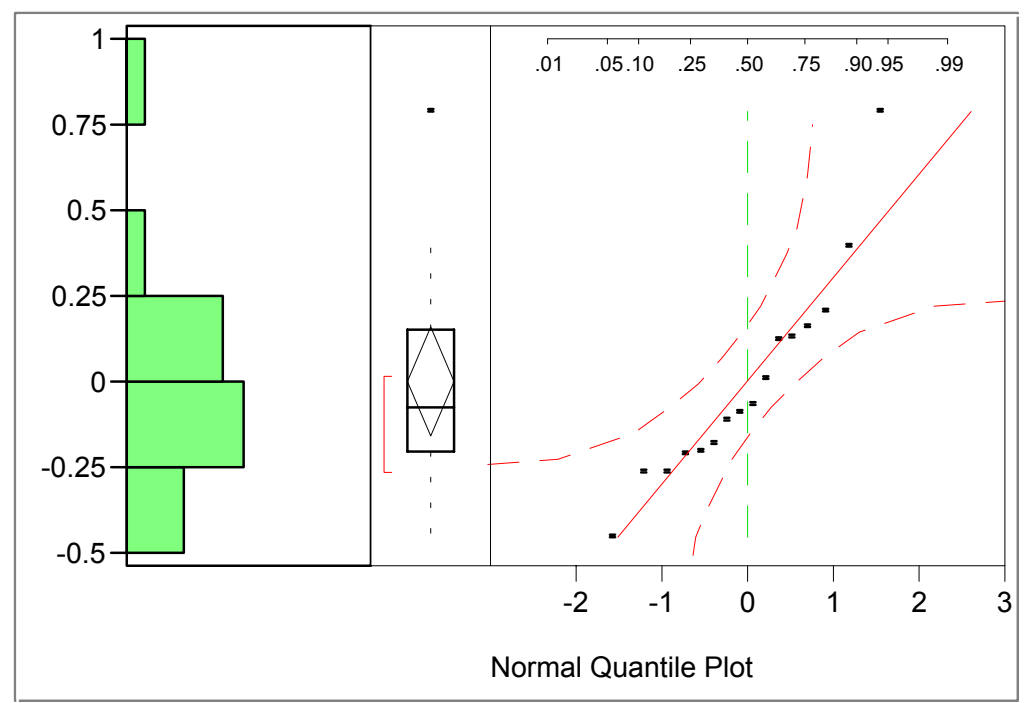

Figure 4.10. Normal Quantile Plot for APD model

\subsubsection{Residual analysis for AE Model}

As in previous section, Figures $4.11-4.14$ show that Equation 4.2 is an effective summarization of the data in predicting average efficiency because of their random pattern in residual plots and normal distribution of random error.

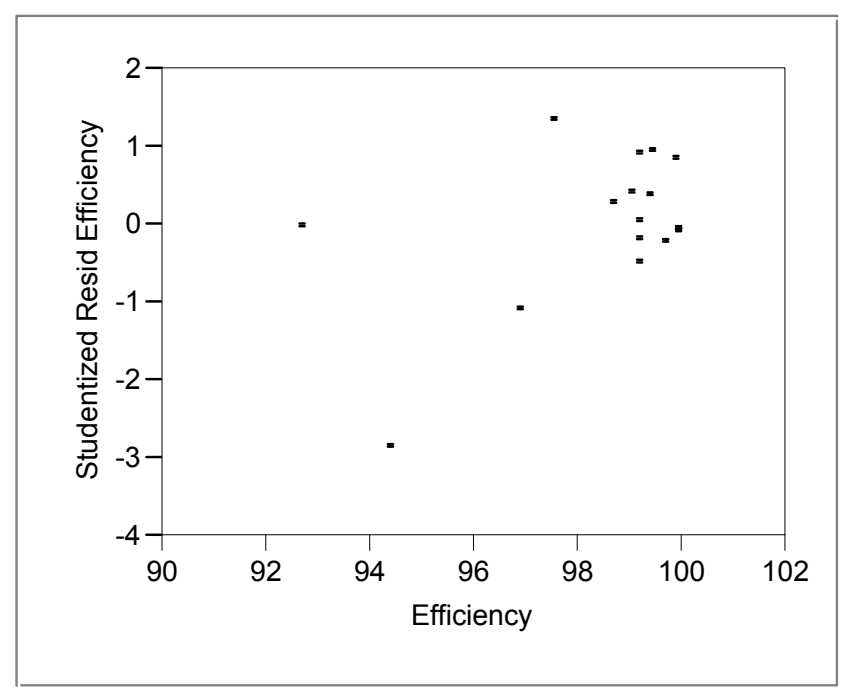

Figure 4.11 Residual AE versus AE 


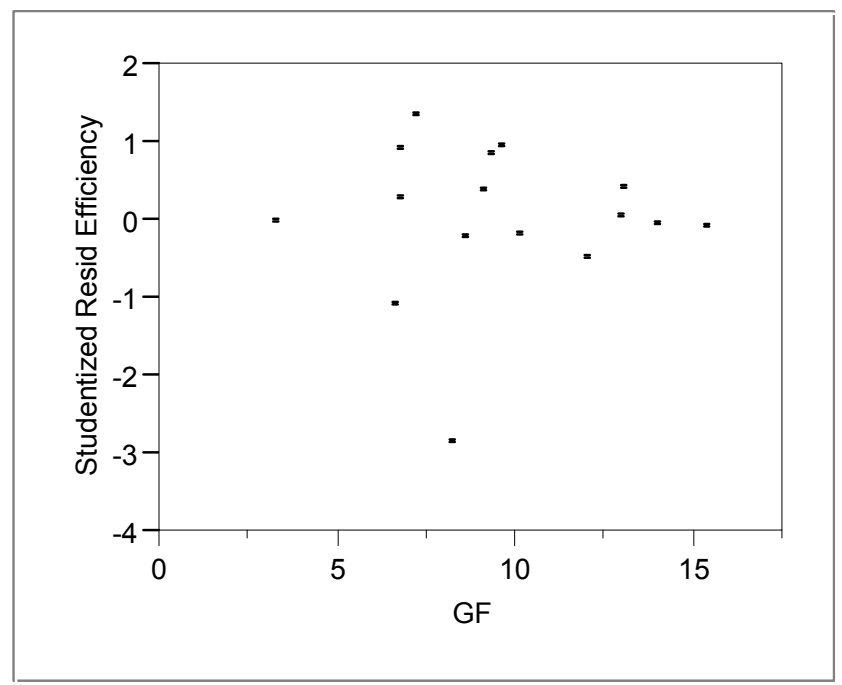

Figure 4.12. Residual AE versus GF

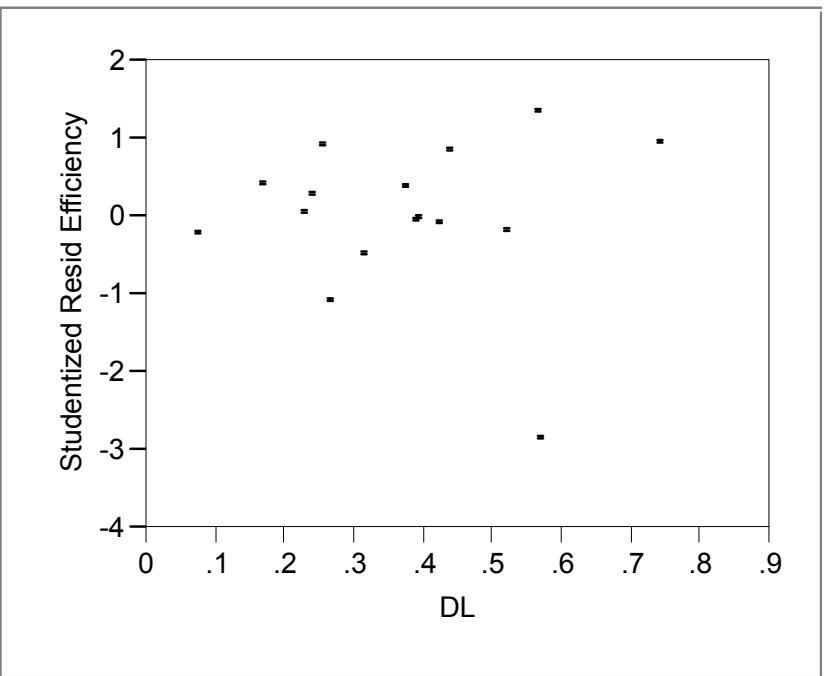

Figure 4.13. Residual AE versus DL 


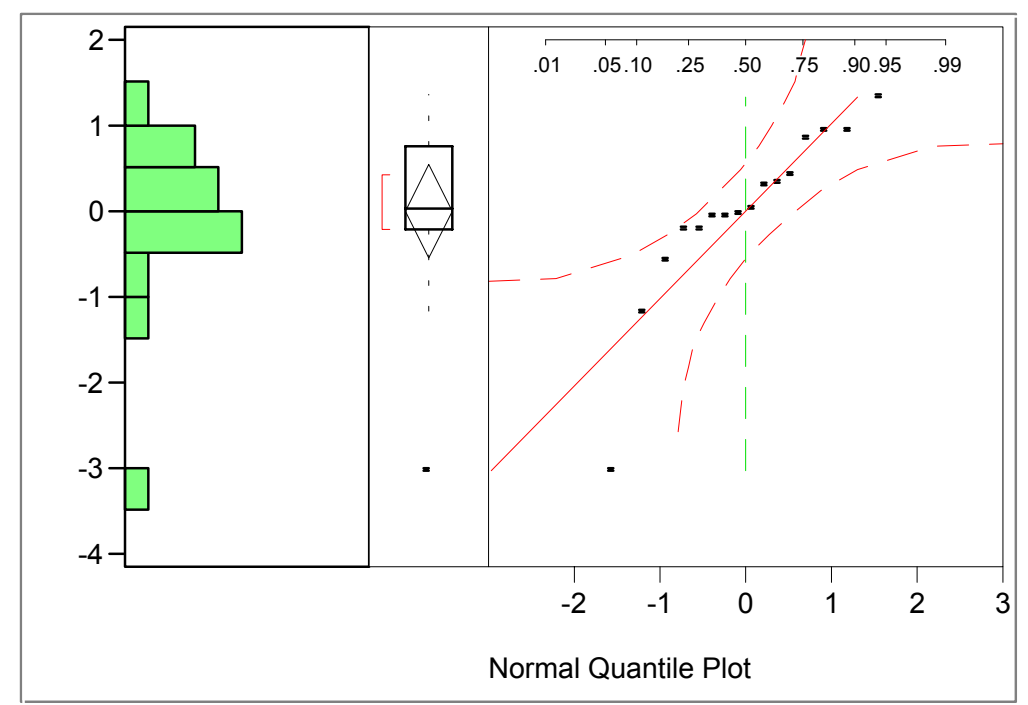

Figure 4.14. Normal Quantile Plot for AE model

\subsubsection{F-test for APD and AE models}

Although it was determined in previous sections in this chapter that forwardstepped models for APD and AE are more suitable compared to full quadratic models, there is another formal way of verifying that claim. The model utility F test equation as given in Equation 4.3 (Devore, 1995) was used for that approach:

$$
f=\frac{\left(S S E_{l}-S S E_{k}\right) /(k-l)}{S S E_{k} /[n-(k+1)]}
$$

where $f$ is the test statistic value, $k$ is the number of effects in the full model, $l$ is the number of effects in reduced or stepped model, $S S E_{l}$ is the sum of squares of the reduced model residuals, and $S S E_{k}$ is the sum of squares of the full model residuals. When $f \geq F_{\alpha, k-l, n-(k+l)}$, where the $\mathrm{F}$ values can be read from any $\mathrm{F}$ distribution table in most statistic books, it conveys the fact that the full model is statistically more suitable. 
The test statistic values, $f$, for APD and AE models are less than the F values in this study. Thus, forward-stepped models are once shown the better models in comparison to full models for both APD and AE.

\subsection{Similitude tests}

Four experiments were conducted under similitude conditions at about $160 \mathrm{kPa}$ gage (23.16 psig) on $4 \mathrm{~mm}$ granules to investigate the effect of mass dust ratio on filter collection efficiency. An additional similitude test was performed with $2 \mathrm{~mm}$ granules to evaluate the effect of granule size under simulated conditions of high pressure and high temperature. All similitude experiments were carried out at a bed pressure of $160 \mathrm{kPa}$ gage $(23.2 \mathrm{psig})$, air temperature of $20 \mathrm{C}$ and superficial velocity around $0.2 \mathrm{~m} / \mathrm{s}$. The frequency of sampling was taken as $30 \mathrm{~min}$ for all tests to give trends for filter collection efficiency versus time. The operating conditions for the prototype and model filters are given in Table 3.1.

\subsubsection{Similitude tests on $4 \mathrm{~mm}$ granules}

The purpose of these tests was to investigate the effect of mass dust ratio on the filtration collection efficiency. The model was achieved by controlling the ash flow rate and granule flow rate. Each of them has two levels, high and low, resulting in a total of four experiments. Each experiment had the same hydrodynamic properties satisfying similitude conditions described in Table 5.1. A feed button setting controls the ash flow rate. The inlet concentration is determined by sampling probes during experiments. The 
assumption was made that the inlet concentration is uniform in the vertical profile. The granule flow rate is controlled by the motor and auger system. In the experiments, the desired high level for granule flow rate was $200 \mathrm{~g} / \mathrm{min}$ and the low level was $100 \mathrm{~g} / \mathrm{min}$. The actual rates varied slightly from these values. Important experimental conditions and dimensionless numbers for the four similitude experiments are summarized in Table 5.2.

From Table 4.6, all four experiments satisfy similitude conditions. Average bed pressures were taken from the pressure values recorded by the pressure transducer. Bed pressure fluctuations were less than $2.5 \%$ in all runs. The four experiments and prototype had nearly the same dimensionless numbers. The combination of different levels of ash flow rate and granule flow rate produces four different numbers of mass dust ratio, $11.04 \%, 6.89 \%, 5.08 \%$ and $3.33 \%$. The experiment model is satisfied and results should be meaningful for evaluating granular filter under similitude conditions.

Three important figures for evaluating inlet concentration versus time, outlet concentration versus time and filter collection efficiency versus time are shown in Figures $4.15-4.17$

Table 4.5 Test matrix used to investigate the effect of dustto-granule ratio on filter efficiency

\begin{tabular}{ccc}
\hline Ash flow rate level & Granule flow rate & Mass dust ratio \\
\hline High & Low & High \\
Low & Low & Medium1 \\
High & High & Medium2 \\
Low & High & Low \\
\hline
\end{tabular}


Table 4.6 Experimental conditions and dimensionless numbers for four similitude experiments

\begin{tabular}{|c|c|c|c|c|c|c|c|c|c|c|}
\hline $\begin{array}{l}\text { Avg. ash } \\
\text { flow rate } \\
(\mathrm{g} / \mathrm{min})\end{array}$ & $\begin{array}{c}\text { Granule } \\
\text { flow rate } \\
\text { (g/min) }\end{array}$ & $\begin{array}{c}\text { Mass } \\
\text { dust } \\
\text { ratio \% }\end{array}$ & $\begin{array}{c}\text { Bed } \\
\text { pressure } \\
\text { kPa gage } \\
\text { (psig) }\end{array}$ & $\begin{array}{c}\text { Actual } \\
\text { air } \\
\text { density } \\
\left(\mathrm{kg} / \mathrm{m}^{\wedge}\right. \\
3)\end{array}$ & $\begin{array}{c}\text { Superf } \\
\text { icial V } \\
(\mathrm{m} / \mathrm{s})\end{array}$ & $\mathrm{St}$ & $\mathrm{Re}$ & $\mathrm{R}$ & $\mathrm{R}_{\text {rho }}$ & $\mathrm{Fr}$ \\
\hline $\mathrm{N} / \mathrm{A}$ & N/A & $\mathrm{N} / \mathrm{A}$ & $\begin{array}{c}898.67 \\
(130.34)\end{array}$ & 3.10 & 0.27 & 0.10 & 136 & 0.0029 & 790 & 1.02 \\
\hline 11.1 & 101 & 11.04 & $\begin{array}{l}157.65 \\
(22.87)\end{array}$ & 3.08 & 0.20 & 0.10 & 135 & 0.0029 & 795 & 1.02 \\
\hline 6.8 & 99 & 6.89 & $\begin{array}{l}157.13 \\
(22.79)\end{array}$ & 3.07 & 0.20 & 0.10 & 135 & 0.0029 & 798 & 1.02 \\
\hline 10.5 & 206 & 5.08 & $\begin{array}{l}159.66 \\
(23.16)\end{array}$ & 3.10 & 0.20 & 0.10 & 136 & 0.0029 & 790 & 1.02 \\
\hline 7.1 & 214 & 3.33 & $\begin{array}{l}158.42 \\
(22.98) \\
\end{array}$ & 3.09 & 0.20 & 0.10 & 135 & 0.0029 & 793 & 1.02 \\
\hline
\end{tabular}

The ash concentrations $\left(\mathrm{g} / \mathrm{m}^{3}\right)$ for inlet and outlet and efficiency were calculated based on the ash mass collected in the sampling probes. The mass of ash collected in the sampling probes was measured by a precise balance (to $10^{-5} \mathrm{~g}$ ). The error bar in the plot for each point is based on the scale's measuring error, which is $\pm 18.4 \times 10^{-5} \mathrm{~g}$. In Figure 4.15, the error bars are too small to be evident. In the outlet ash concentration versus time figure, the bars are added only to the test with $11.04 \%$ mass dust ratio to avoid cluttering the chart, although magnitudes of variations are comparable for all points, which is about $\pm 0.2 \mathrm{~g} / \mathrm{m}^{3}$. The error bars for efficiency points are less than $\pm 0.2 \%$.

Figure 4.17 and Table 4.7 indicate that for all four experiments with different mass dust ratios the average filter collection efficiencies are similarly high and with very small deviations with time. It indicates that the filter can reach steady state very quickly and is robust to changes in the mass dust ratio. Statistical analysis on the data of Table 4.7 in Appendix $\mathrm{J}$ also supports that filter works in a robust way to time and the change of 
mass dust ratio. Pressure drop across the bed is very important information for analyzing the performance of a moving bed filter. For a moving bed, a steady or quasi-steady state is expected to be reached when the amount of ash entering the filter equals the amount of ash pushed out of the bed with the granules at the bottom of the filter. The pressure drop measured against time is a criterion for steady state.

In all four tests, Figure 4.18 indicates that the pressure drop increased quickly in 5-20 minutes after starting the experiment. For the remaining time, the pressure drop was stable and increased slowly. A possible explanation is that the ash mixed with granules in the bed reaching a quasi-steady state pressure drop in a short time when the amount of ash entering equaled that leaving. It is speculated that the fly ash penetrated a region or zone of the bed as shown in Figure 4.19. This penetration zone is also thought to be the region where essentially all filtration occurs.

From Figure 4.18, we also find that for the test with a dust ratio of 5.08\% and the test with a dust ratio of $3.33 \%$, the pressure drop reached steady state more quickly than for the other two tests. This can be explained by the different granule flow rates. For tests with dust ratios of $5.08 \%$ and $3.33 \%$, the average granule flow is around $210 \mathrm{~g} / \mathrm{min}$ while for test with dust ratios of $11.04 \%$ and $6.89 \%$ the granule flow rate was about $100 \mathrm{~g} / \mathrm{min}$. A reduced granule flow rate will make granules in the penetration zone move more slowly, which increases the length of time for reaching steady state. 
Table 4.7 Filter collection efficiency against time for different dust-to-granule ratios

\begin{tabular}{|c|c|c|c|c|}
\hline Time (min) $\quad$ Mass dust ratio $\%$ & 11.04 & 6.89 & 5.08 & 3.33 \\
\hline${ }^{2}$ & 99.40 & 99.23 & 99.43 & 99.68 \\
\hline 60 & 99.78 & 99.07 & 99.74 & 98.93 \\
\hline 90 & 99.72 & 99.33 & 99.63 & 99.68 \\
\hline 120 & 99.56 & 99.69 & 99.80 & 99.64 \\
\hline 150 & 99.51 & 99.85 & & \\
\hline 180 & 99.85 & 99.41 & & \\
\hline 210 & 99.81 & 98.66 & & \\
\hline 240 & 99.58 & 99.60 & & \\
\hline Avg. collection efficiency $\%$ & 99.65 & 99.36 & 99.65 & 99.48 \\
\hline $\begin{array}{c}\text { Standard deviation of collection efficiency } \\
\%\end{array}$ & 0.16 & 0.38 & 0.16 & 0.37 \\
\hline
\end{tabular}




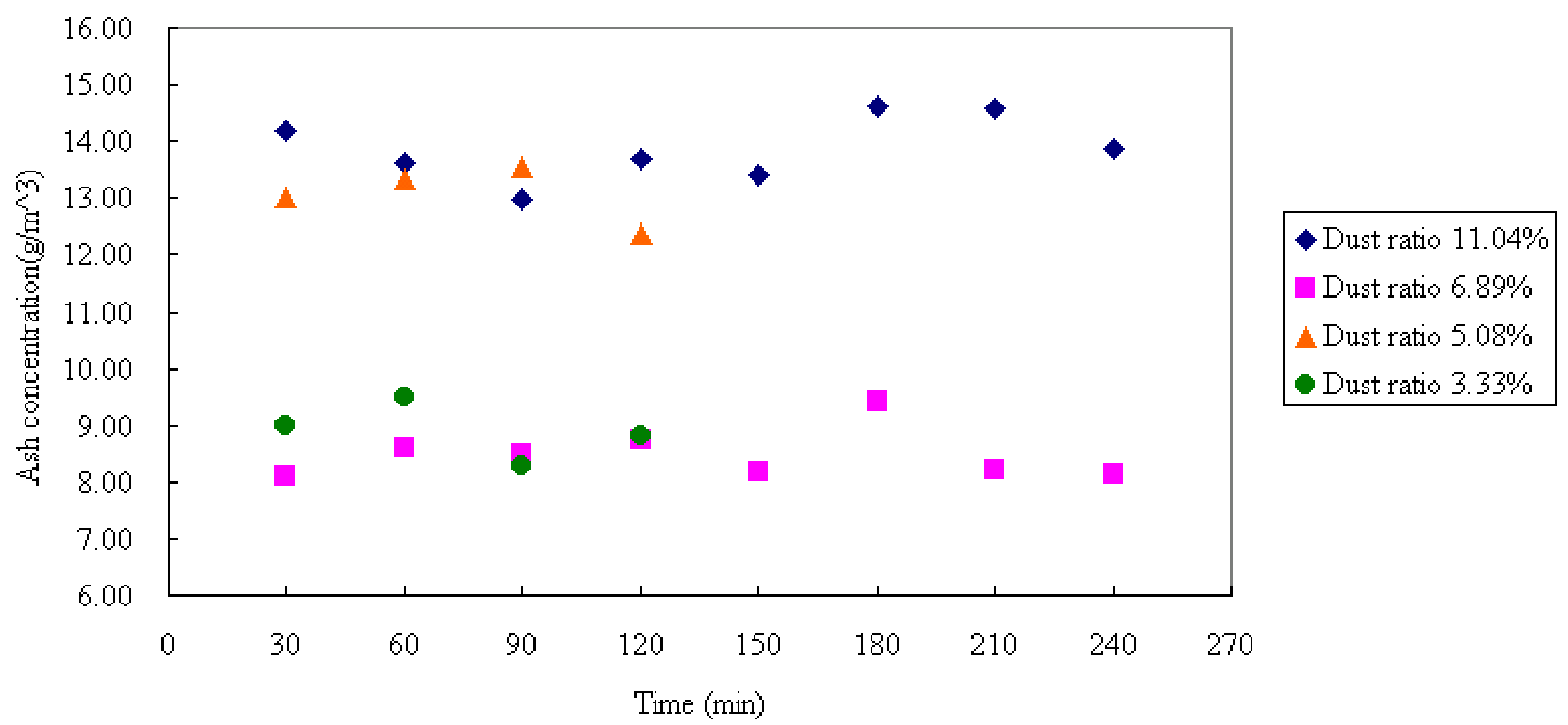

Figure 4.15. Inlet ash concentration vs. time for several dust-to granule ratios 


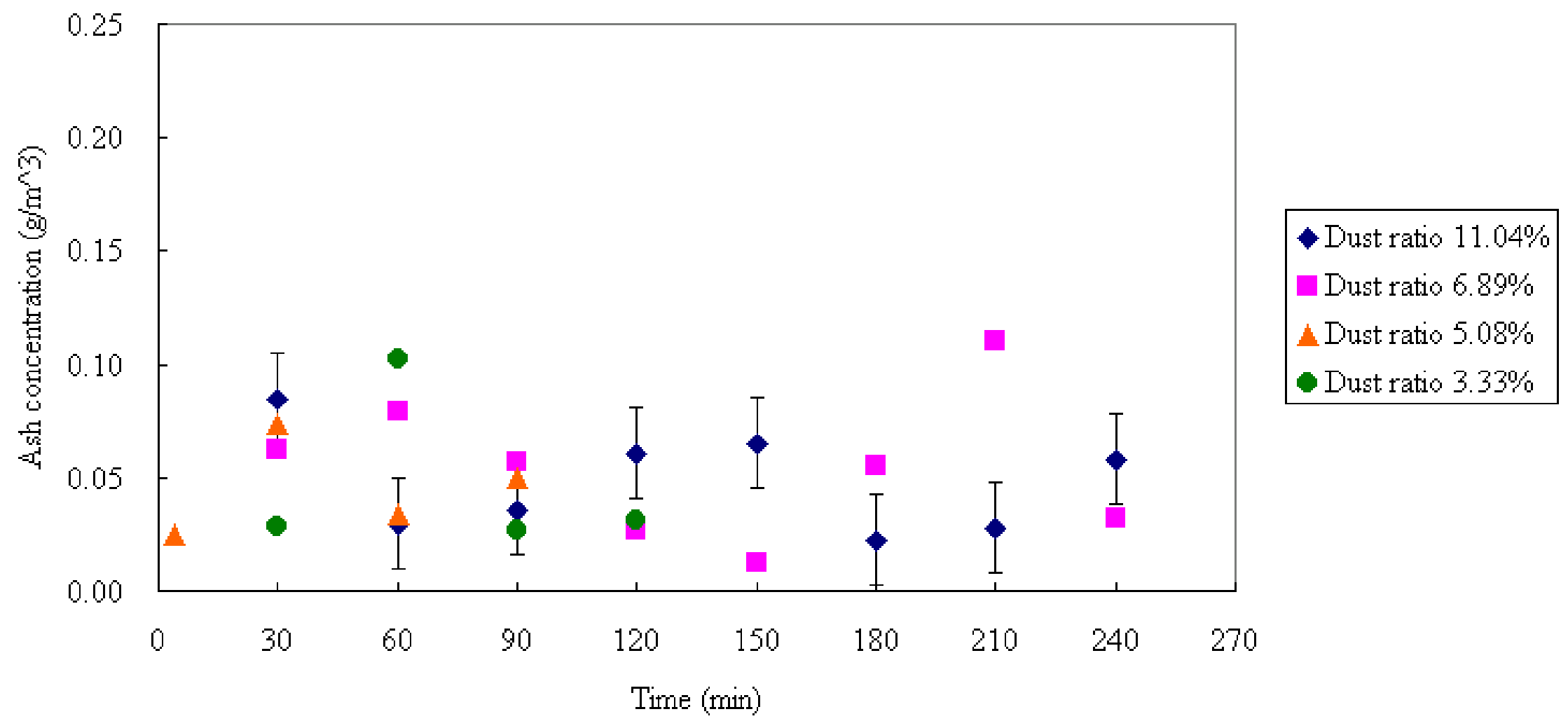

Figure 4.16. Outlet ash concentration vs. time for several dust-to-granule ratios 


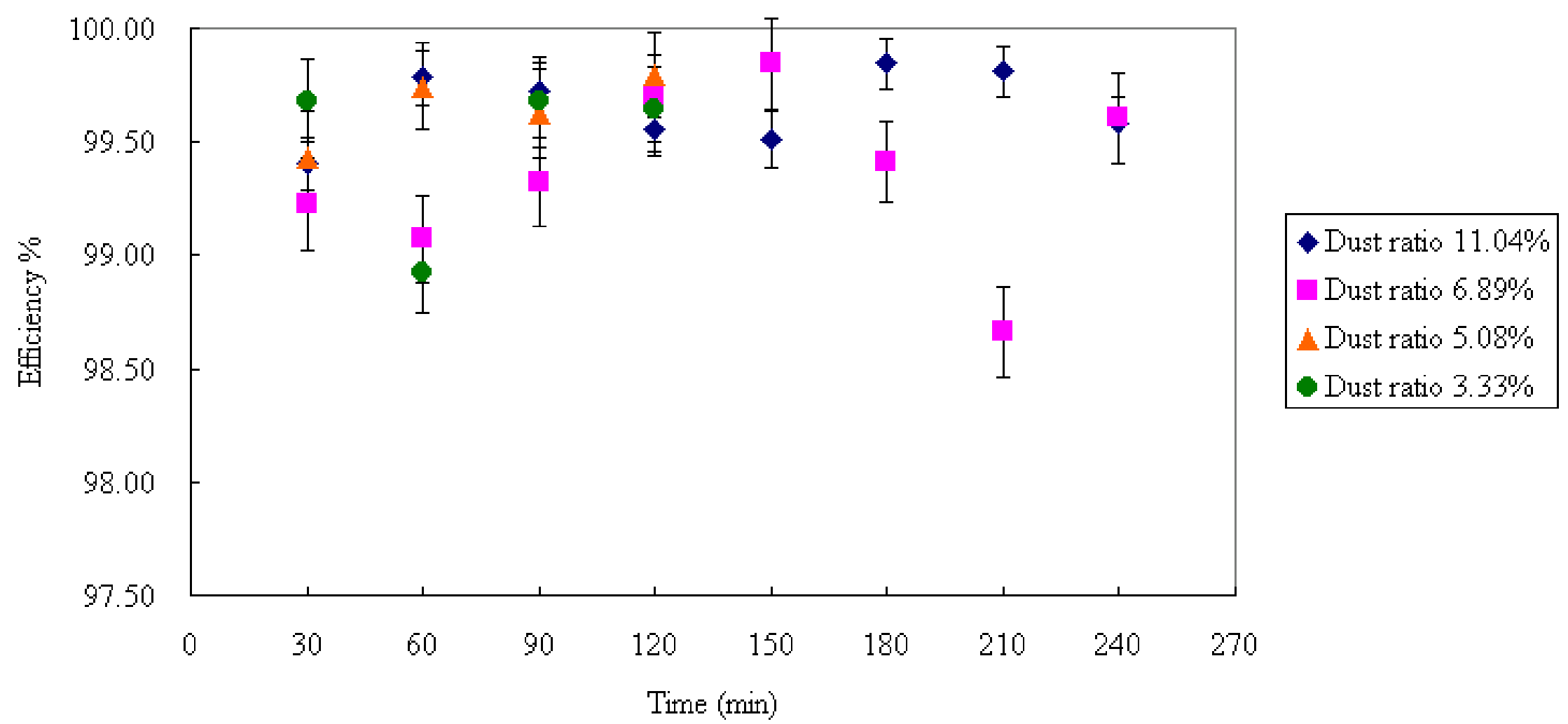

Figure 4.17. Filter efficiency vs. time for several dust-to-granule rate 


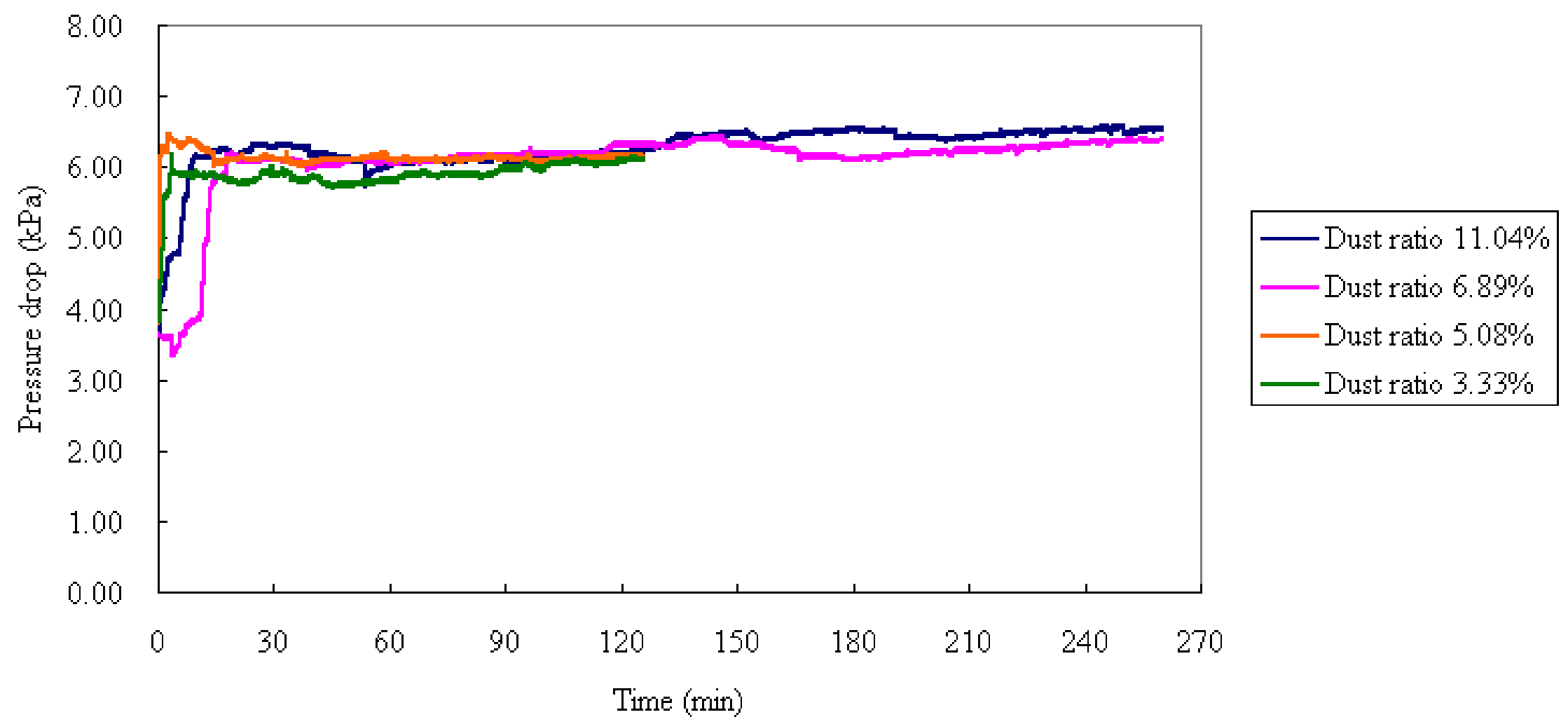

Figure 4.18. Pressure drop vs. time for several dust-to-granule ratio 


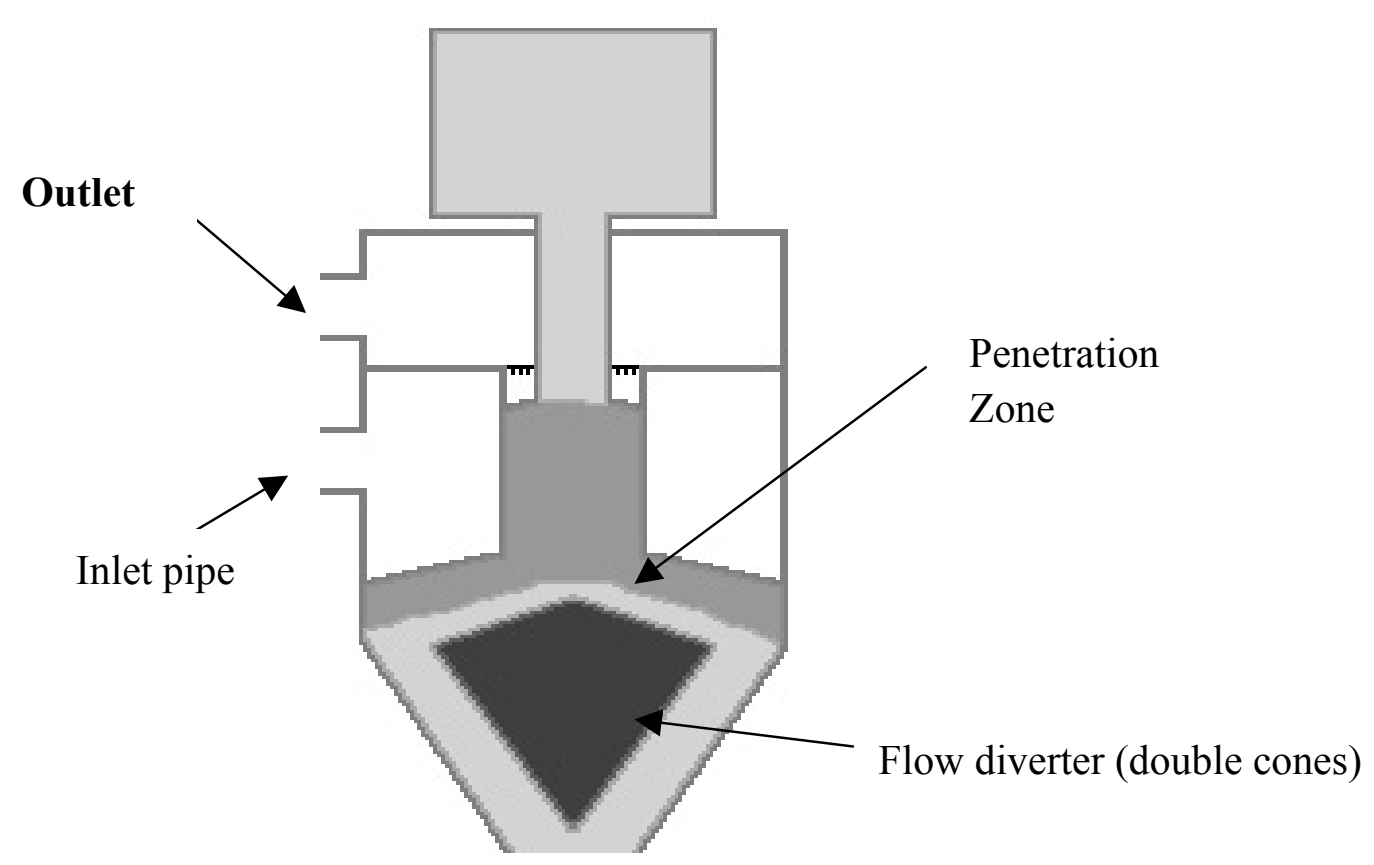

Figure 4.19 Zone resulting the pressure drop across the bed

\subsubsection{Comparison between $2 \mathrm{~mm}$ and $4 \mathrm{~mm}$ granules}

An experiment was conducted to compare $2 \mathrm{~mm}$ granules to $4 \mathrm{~mm}$ granules under similitude conditions. Both tests were conducted under similitude conditions with a bed pressure of around $160 \mathrm{kPa}$ gage (23.16psig), air temperature of $20 \mathrm{C}$ and superficial velocity around $0.2 \mathrm{~m} / \mathrm{s}$. Granule size is the only different independent variable between them. Figures 4.20 and 4.21 indicate that operation with small beads produced a decreasing efficiency and a larger pressure drop that increased monotonically.

Table 4.8 Experimental conditions and dimensionless numbers for comparisons between $4 \mathrm{~mm}$ and $2 \mathrm{~mm}$ granules

\begin{tabular}{|c|c|c|c|c|c|c|c|c|c|c|}
\hline & $\begin{array}{l}\text { Ash } \\
\text { flow } \\
\text { rate } \\
(\mathrm{g} / \mathrm{min})\end{array}$ & $\begin{array}{l}\text { Granule } \\
\text { flow } \\
\text { rate } \\
\text { (g/min) }\end{array}$ & $\begin{array}{c}\text { Pressure } \\
\text { kPa gage } \\
\text { (psig) }\end{array}$ & $\begin{array}{c}\text { Air } \\
\text { density } \\
\left(\mathrm{kg} / \mathrm{m}^{\wedge} 3\right)\end{array}$ & $\begin{array}{c}\text { Velocity } \\
(\mathrm{m} / \mathrm{s})\end{array}$ & $\mathrm{St}$ & $\mathrm{Re}$ & $\mathrm{R}$ & $\mathrm{R}_{\text {rho }}$ & Fr \\
\hline $\begin{array}{c}4 \mathrm{~mm} \\
\text { test }\end{array}$ & 10.94 & 203.20 & $\begin{array}{l}158.88 \\
(23.04)\end{array}$ & 3.09 & 0.20 & 0.10 & 136 & 0.0029 & 792 & 1.02 \\
\hline $\begin{array}{c}2 \mathrm{~mm} \\
\text { test }\end{array}$ & 11.18 & 214.29 & $\begin{array}{l}157.62 \\
(22.86)\end{array}$ & 3.08 & 0.20 & 0.19 & 67 & 0.0057 & 796 & 2.04 \\
\hline
\end{tabular}




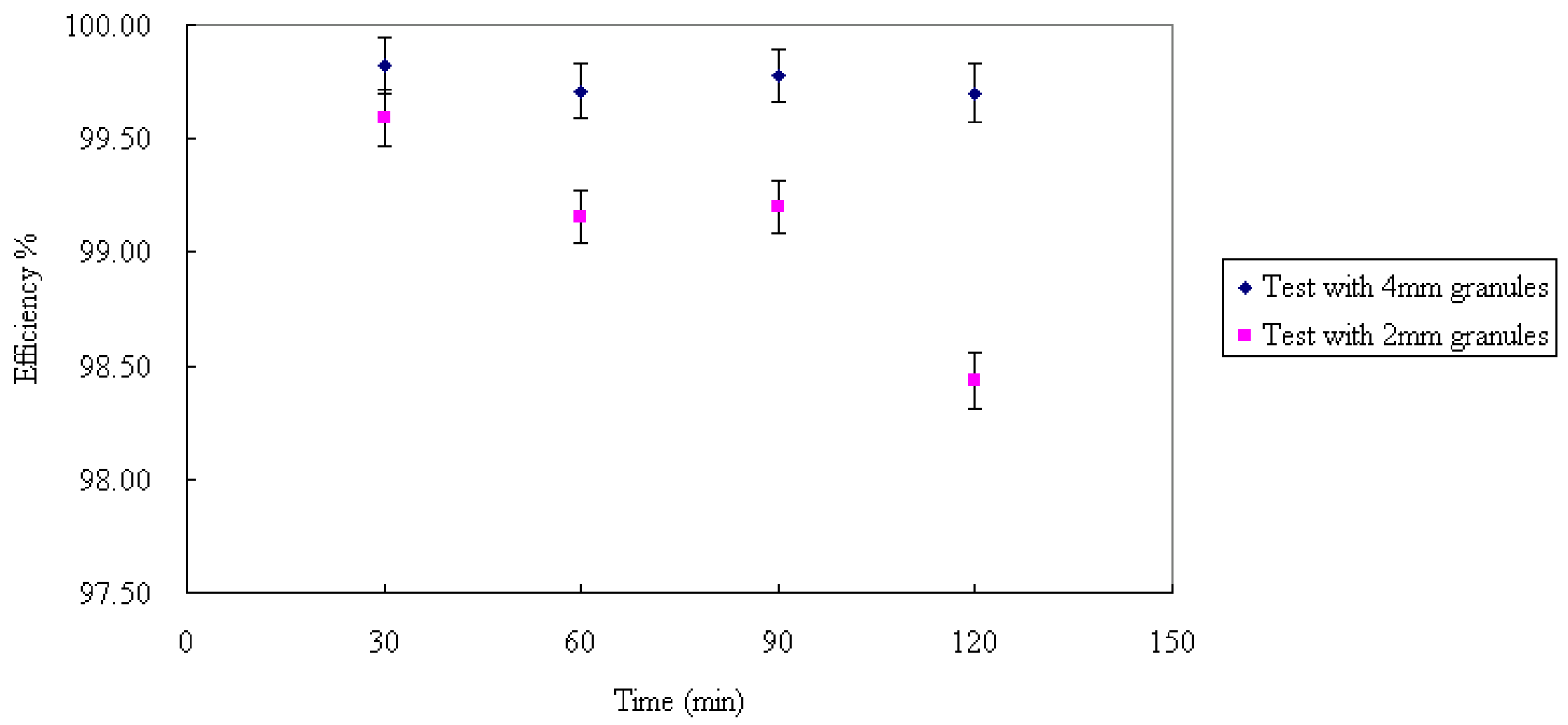

Figure 4.20. Filter efficiency vs. time for experiment with $4 \mathrm{~mm}$ and $2 \mathrm{~mm}$ granules 


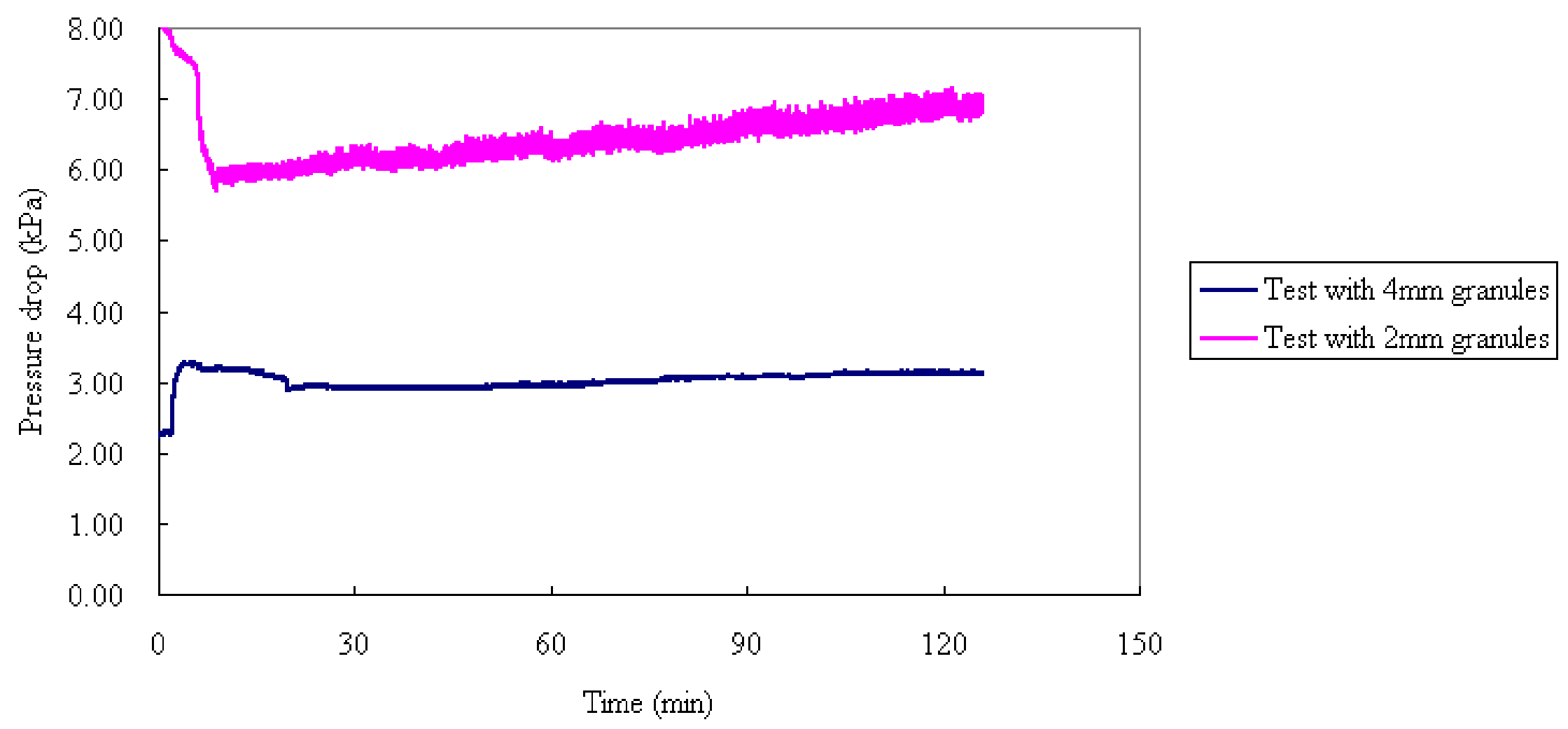

Figure 4.21 Pressure drop vs. time for $4 \mathrm{~mm}$ and $2 \mathrm{~mm}$ granules 
Table 4.9 Filter efficiency vs. time for $4 \mathrm{~mm}$ and $2 \mathrm{~mm}$ granules

\begin{tabular}{ccc}
\hline & \multicolumn{2}{c}{ Granule size } \\
\hline Time (min) & $4 \mathrm{~mm}$ & $2 \mathrm{~mm}$ \\
\hline 30 & 99.82 & 99.59 \\
60 & 99.71 & 99.15 \\
90 & 99.78 & 99.20 \\
120 & 99.70 & 98.44 \\
Avg. collection efficiency\% & 99.75 & 99.10 \\
Standard deviation of collection efficiency \% & 0.06 & 0.48 \\
\hline
\end{tabular}

According to the statistical analysis in Appendix $\mathrm{J}$ of the data in Table 4.9, it was found that time has a statistically significant negative linear relationship with filter collection efficiency ( $\mathrm{P}$-value $=0.08)$ in the experiment for $2 \mathrm{~mm}$ granules, opposite to the situation in experiment with $4 \mathrm{~mm}$ granule with a P-value of 0.35 . It was also found that granule size has a statistically significant negative linear relationship with filter collection efficiency (P-value $=0.034$, less than 0.1 ). The filter with $2 \mathrm{~mm}$ granules will have statistically poorer collection efficiency at significance level of 0.1 than with $4 \mathrm{~mm}$ granules.

For each experiment, the upper granule storage tank was removed following the test in order to see whether dust had penetrated the granular bed (see Figure 4.22). For the test with $4 \mathrm{~mm}$ granules, zone B was found to be clean, which supports the observation of high collection efficiency. For the test with $2 \mathrm{~mm}$ granules, the B zone was dirty, and a thin layer of ash was attached to the surface of region B. More importantly, considerable ash was observed on the internal surface of the downcomer and to the 


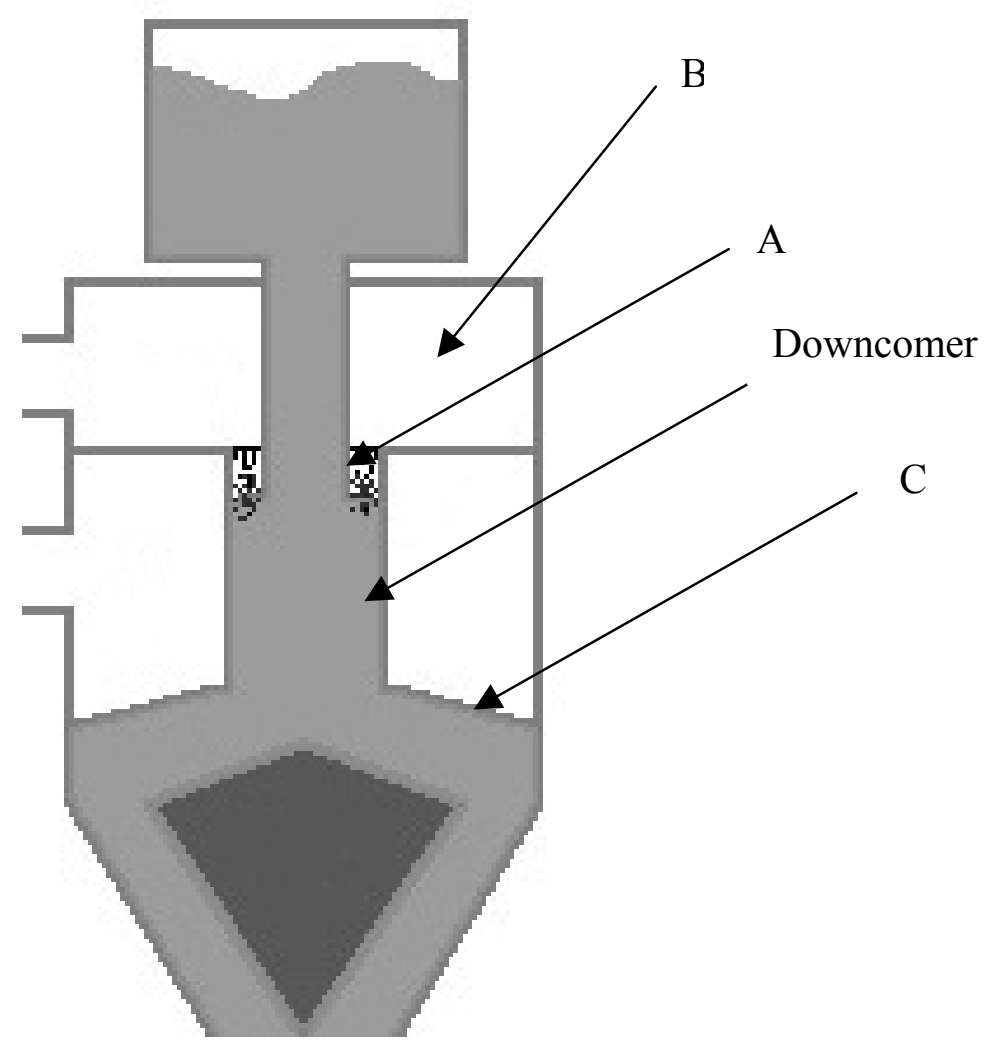

Figure 4.22. Designations of regions A, B and C in filter body described in text

screen at the zone A. As more and more ash accumulated, more and more ash would move to outlet, resulting in an increased pressure drop and a decreased efficiency trend.

The efficiency contrast between $4 \mathrm{~mm}$ and $2 \mathrm{~mm}$ tests may be explained by the granule fluidization in downcomer. For two experiments, they have the same hydrodynamic conditions of approximately $0.2 \mathrm{~m} / \mathrm{s}$ superficial velocity, $0.76 \mathrm{~m} / \mathrm{s}$ where air enters the downcomer and $1.04 \mathrm{~m} / \mathrm{s}$ where air leaves. The air velocity in the downcomer is within a range of $0.76 \mathrm{~m} / \mathrm{s}$ to $1.04 \mathrm{~m} / \mathrm{s}$. Appendix K gives the minimum fluidization velocities for both $4 \mathrm{~mm}$ and $2 \mathrm{~mm}$ granules. At an airflow rate corresponding to $23 \mathrm{psig}$, the minimum fluidization velocity for $4 \mathrm{~mm}$ granules is $1.1 \mathrm{~m} / \mathrm{s}$ and about $0.7 \mathrm{~m} / \mathrm{s}$ for $2 \mathrm{~mm}$ granules. It follows that for the $4 \mathrm{~mm}$ granule experiment, 
the granules in downcomer were not fluidized, whereas with the $2 \mathrm{~mm}$ granule experiments, granules were fluidized. Granule fluidization in the downcomer makes ash particles easier to move through the total granule bed. A condition of fluidization in downcomer should be avoided.

\subsection{Miscellaneous Trials}

\subsubsection{Effect of operating pressure}

The previous experiments showed that the moving bed filter works very well under similitude conditions. The similitude experiments were conducted at about $160 \mathrm{kPa}$ gage (23.16 psig) pressure. An experiment with a reduced pressure of $34.5 \mathrm{kPa}$ gage (5 psig) holding the superficial velocity constant at previous values $(0.2 \mathrm{~m} / \mathrm{s})$ was carried out to help understand the effect of pressure on filter collection performance.

The apparent reason for the different ash flow rates in Table 4.10 is that for high pressure tests the jet hydrodynamics at the inlet pipe entrained ash from the feeder compared to the low pressure test, which will to lead different mass dust ratios in the bed. However, since it has been demonstrated that mass dust ratio has little effect on filter performance, the comparison between high pressure and low-pressure tests is still meaningful.

Figure 4.23 shows a comparison in the collection efficiency for a high-pressure test at about $160 \mathrm{kPa}$ gage (23.16psig) and a low pressure test at about $34.5 \mathrm{kPa}$ gage (5 psig). The operating pressure in the bed is the only independent variable between two tests. Both tests were conducted with $4 \mathrm{~mm}$ granules. 
Table 4.10. Comparison of experimental conditions and dimensionless numbers for high and low pressure tests

\begin{tabular}{ccccccccccccc}
\hline Pressure & $\begin{array}{c}\text { Ash flow } \\
\text { rate } \\
(\mathrm{g} / \mathrm{min})\end{array}$ & $\begin{array}{c}\text { Granule } \\
\text { flow rate } \\
(\mathrm{g} / \mathrm{min})\end{array}$ & $\begin{array}{c}\text { Mass } \\
\text { dust } \%\end{array}$ & $\begin{array}{c}\text { Bed pressure } \\
\mathrm{kPa} \text { gage } \\
(\mathrm{psig})\end{array}$ & $\begin{array}{c}\text { Actual air } \\
\text { density } \\
\left(\mathrm{kg} / \mathrm{m}^{\wedge} 3\right)\end{array}$ & $\begin{array}{c}\mathrm{V} \\
(\mathrm{m} / \mathrm{s})\end{array}$ & $\mathrm{St}$ & $\mathrm{Re}$ & $\mathrm{R}$ & $\mathrm{R}_{\text {rho }}$ & Fr \\
\hline High & 10.9 & 203 & 5.38 & $\begin{array}{c}159 \\
(23.04)\end{array}$ & 3.09 & 0.20 & 0.10 & 136 & 0.0029 & 792 & 1.02 \\
Low & 6.99 & 211 & 3.31 & $\begin{array}{c}34.9 \\
(5.06)\end{array}$ & 1.62 & 0.20 & 0.10 & 71 & 0.0029 & 1513 & 1.02 \\
\hline
\end{tabular}

Statistical analysis in Appendix $\mathrm{J}$ based on the data of Table 4.11 indicates that time is not statistically significant confirming a linear relationship with filter collection efficiency for both low $(\mathrm{P}$-value $=0.26)$ and high pressure $(\mathrm{P}$-value $=0.35)$ experiments. It was also found that pressure did not show a statistically significant (negative) linear relationship with filter collection efficiency $(\mathrm{P}$-value $=0.0002)$. The filter operated under lower pressure will have reduced collection efficiency statistically.

Table 4.11. Filter efficiency vs. time for high and low pressure tests

\begin{tabular}{ccc}
\hline & \multicolumn{2}{c}{ Bed pressure } \\
\hline Time (min) & High & Low \\
\hline 30 & 99.82 & 98.24 \\
60 & 99.71 & 98.06 \\
90 & 99.78 & 98.22 \\
120 & 99.70 & 98.82 \\
Avg. collection efficiency\% & 99.75 & 98.33 \\
Standard deviation of collection efficiency \% & 0.06 & 0.33 \\
\hline
\end{tabular}

From the point of view of dimensionless numbers, only the Reynolds number Re was varied. High pressure implies higher air density and larger Re. This result is consistent with the experiments of Gal et al. [4]. One possible explanation is that a higher 
Re number implies more severe wake turbulence behind the granules, which can help retain the capture.

Both experiments reached quasi-steady state very quickly based on the pressure drop curves shown in Figure 4.24. However, the pressure drop for the high-pressure test was about $1.6 \mathrm{kPa}$ higher than the low-pressure test for the same superficial velocity. A larger Re number will produce more severe wake turbulence behind granules, which will increase the energy loss of flow and increase the total pressure drop.

\subsection{2. $\quad$ Effect of superficial velocity}

Superficial velocity is one of the important factors that influences filter performance. However, superficial velocity was not included in the similitude model in the section of 5.2 because of the limited range of the system tested. At $159.67 \mathrm{kPa}$ gage pressure $(23.16 \mathrm{psig})$, the maximum superficial velocity is only $0.2 \mathrm{~m} / \mathrm{s}$, so in the present study there was insufficient range to investigate superficial velocity as a variable under similitude conditions. Another experiment was conducted at a low pressure of about 5 psig and high superficial velocity of about $0.42 \mathrm{~m} / \mathrm{s}$ for comparison with a low pressure test of $5 \mathrm{psig}$ and low superficial velocity of $0.2 \mathrm{~m} / \mathrm{s}$ (the low pressure test in section 5.4 ).

Table 4.12 Experimental conditions and dimensionless numbers for experiments with high and low superficial velocities

\begin{tabular}{|c|c|c|c|c|c|c|c|c|c|c|}
\hline $\begin{array}{l}\text { Superficial } \\
V(\mathrm{~m} / \mathrm{s})\end{array}$ & $\begin{array}{c}\text { Ash } \\
\text { flow } \\
\text { rate } \\
\text { (g/min) }\end{array}$ & $\begin{array}{c}\text { Granule } \\
\text { flow } \\
\text { rate } \\
\text { (g/min) }\end{array}$ & $\begin{array}{l}\text { Mass } \\
\text { dust } \\
\text { ratio \% }\end{array}$ & $\begin{array}{c}\text { Bed } \\
\text { pressure } \\
\text { kPa gage } \\
\text { (psig) }\end{array}$ & $\begin{array}{c}\text { Actual } \\
\text { air } \\
\text { density } \\
\left(\mathrm{kg} / \mathrm{m}^{\wedge} 3\right)\end{array}$ & St & $\mathrm{Re}$ & $\mathrm{R}$ & $\mathrm{R}_{\text {rho }}$ & $\mathrm{Fr}$ \\
\hline 0.42 & 20.1 & 214 & 9.39 & $\begin{array}{l}34.75 \\
(5.04)\end{array}$ & 1.62 & 0.20 & 149 & 0.0029 & 1515 & 4.50 \\
\hline 0.20 & 7.0 & 211 & 3.31 & $\begin{array}{l}34.91 \\
(5.06)\end{array}$ & 1.62 & 0.10 & 71 & 0.0029 & 1513 & 1.02 \\
\hline
\end{tabular}


In this way the effect of superficial velocity on filter performance could be investigated. The reason for different ash flow rates in Table 4.12, as previously explained, was the result of the higher inlet velocity entraining additional ash from the feeder.

Figures 4.25 and 4.26 show a comparison of a test with low pressure $(34.9 \mathrm{kPa}$, gage, $5.06 \mathrm{psig})$, low superficial velocity $(0.20 \mathrm{~m} / \mathrm{s})$ to a test with low pressure $(34.75$ $\mathrm{kPa}$, gage, $5.04 \mathrm{psig})$ and high superficial velocity $(0.42 \mathrm{~m} / \mathrm{s})$ in the aspect of filter collection efficiency and pressure drop.

The experiment with low superficial velocity has nearly constant collection efficiency over time, while the experiment at high superficial velocity has rapidly dropping collection efficiency with time. 


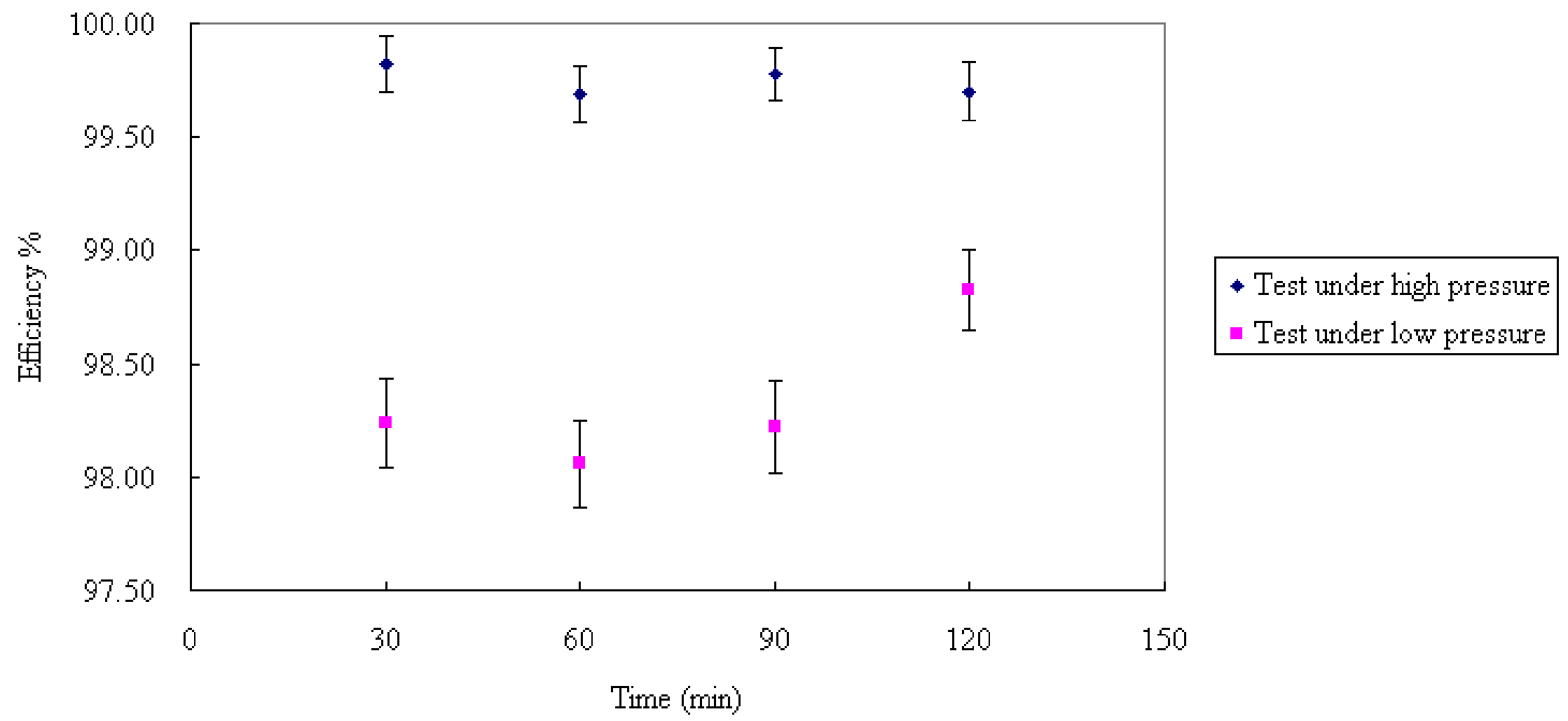

Figure 4.23. Filter efficiency vs. time for high and low pressure tests 


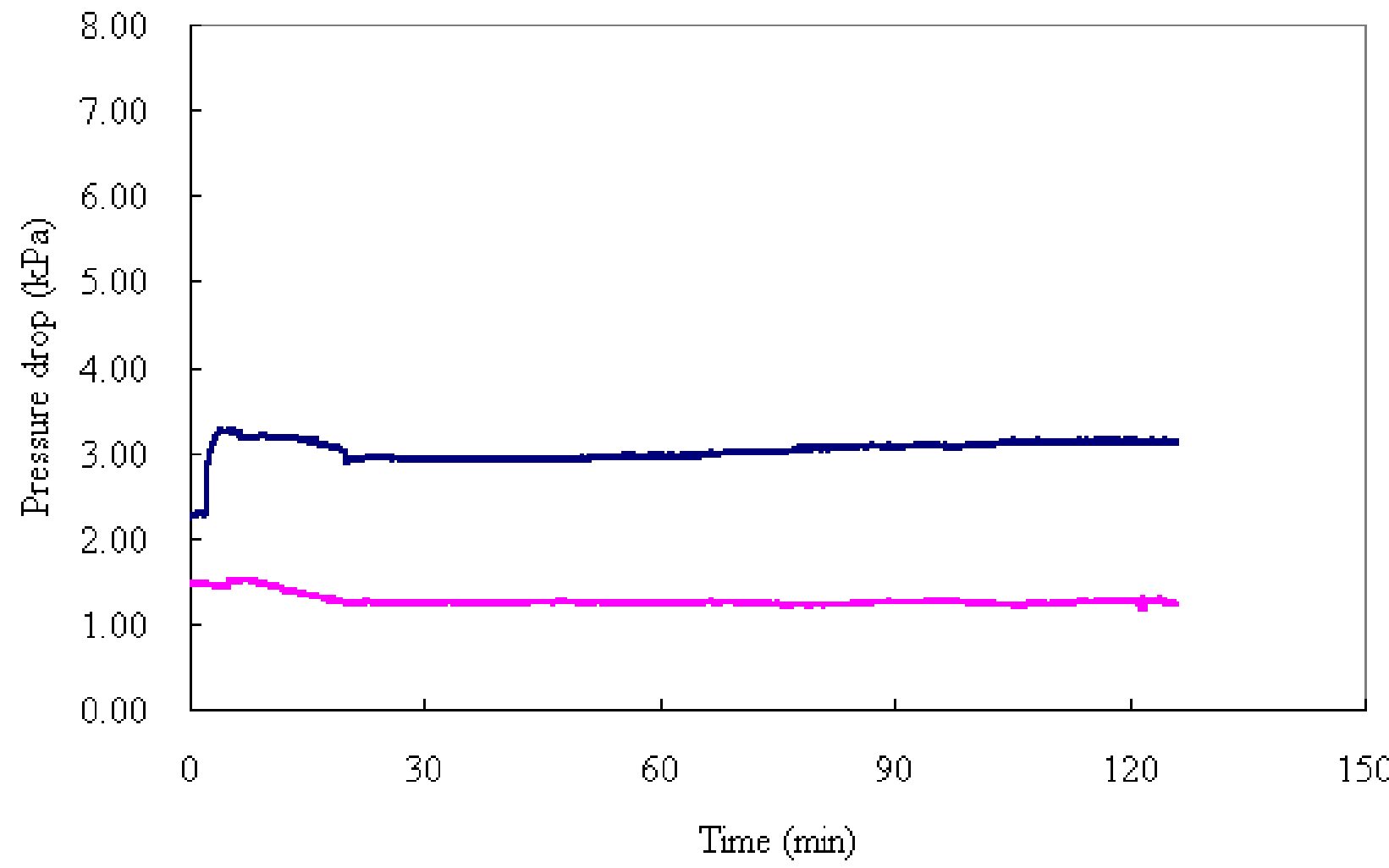

- Test under high pressure Test under low pressure

Figure 4.24. Pressure drop vs. time for high and low pressure tests 


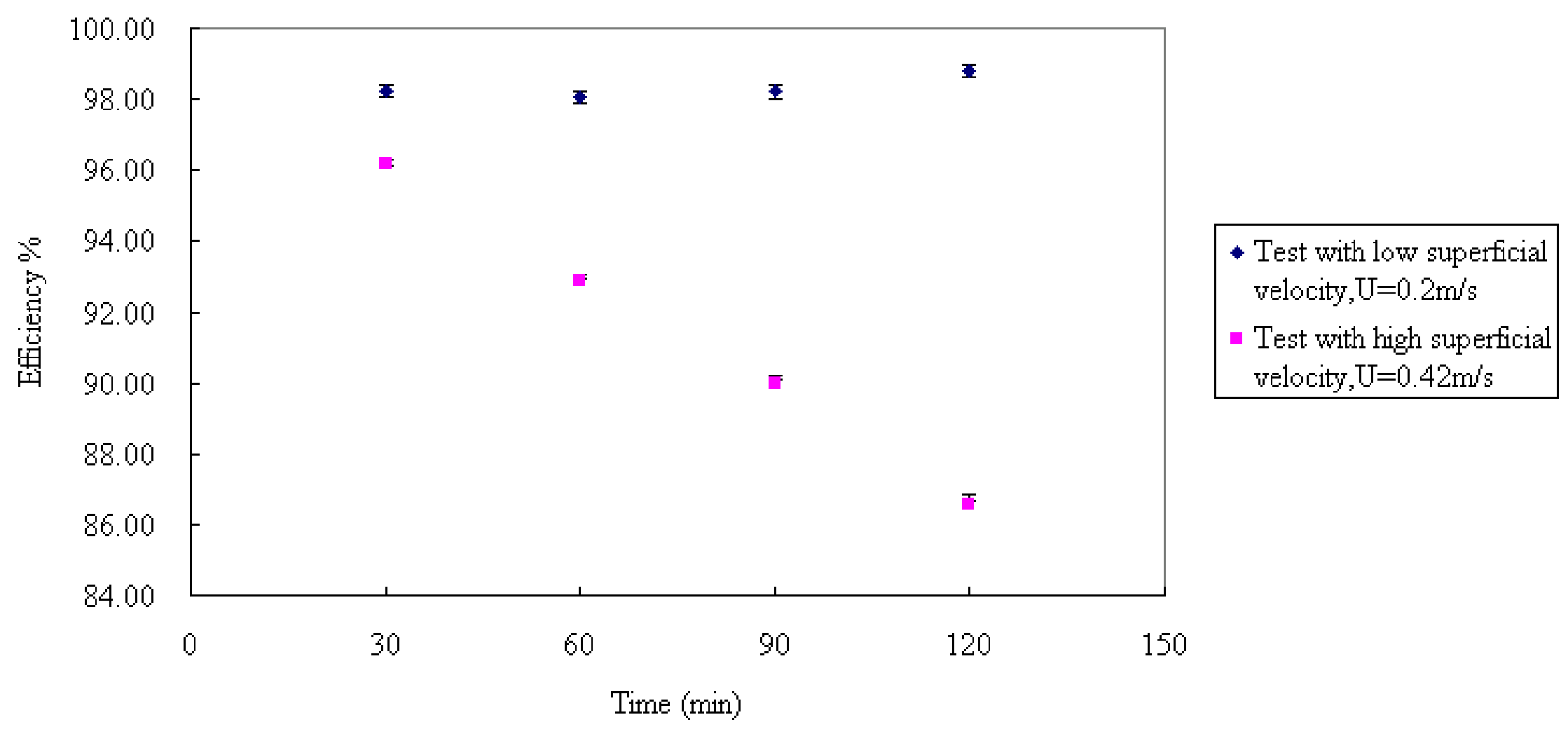

Figure 4.25. Filter collection efficiency vs. time for high and low superficial velocities 


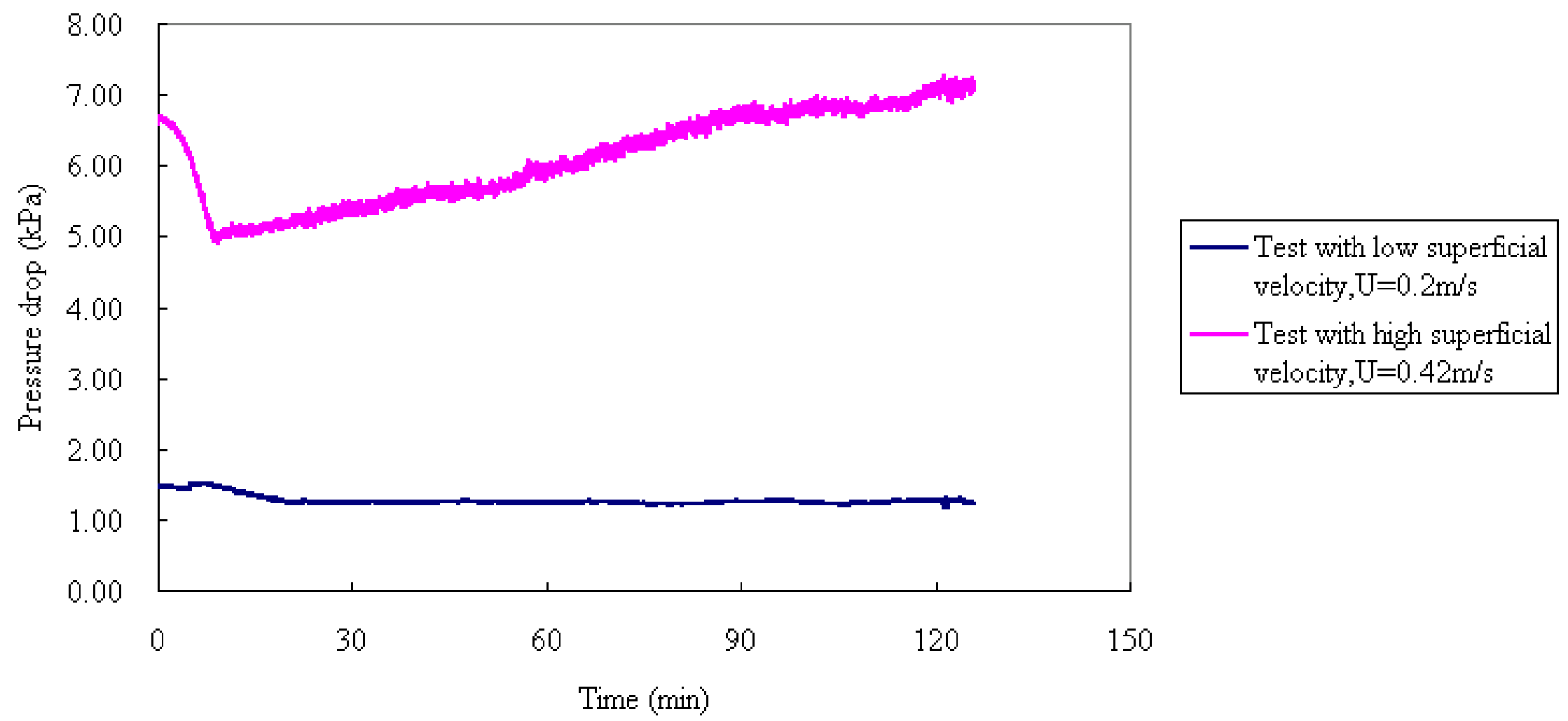

Figure 4.26. Pressure drop vs. time for high low superficial velocities 
Table 4.13. Filter collection efficiency vs. time for high and low superficial velocities

\begin{tabular}{lcc}
\hline & \multicolumn{2}{c}{$\begin{array}{c}\text { Superficial } \\
\text { velocity }\end{array}$} \\
\hline Time (min) & High & Low \\
\hline 30 & 96.16 & 98.24 \\
60 & 92.87 & 98.06 \\
90 & 90.00 & 98.22 \\
120 & 86.55 & 98.82 \\
Avg. collection efficiency\% & 99.75 & 91.39 \\
Standard deviation of collection efficiency \% & 0.06 & 0.4 \\
\hline
\end{tabular}

The statistical analysis in Appendix $\mathrm{J}$ based on the data of Table 4.13 also supports the idea that time has a statistically significant effect on the negative linear relationship with filter collection efficiency for the experiment at high superficial velocity. This is opposite to the situation in the low superficial velocity experiment. It was also found that superficial velocity has a statistically significant negative linear relationship with filter collection efficiency. The filter with higher superficial velocity will have the lowest collection efficiency statistically.

The reason for the poor collection efficiency at high superficial velocity can also be explained by granule fluidization in the downcomer. The high value superficial velocity experiment $0.42 \mathrm{~m} / \mathrm{s}$ produces $1.58 \mathrm{~m} / \mathrm{s}$ at the inlet to the downcomer and $2.18 \mathrm{~m} / \mathrm{s}$ at its exit retainer screen. The reduced superficial velocity experiment has corresponding values of 0.2 $\mathrm{m} / \mathrm{s}, 0.75 \mathrm{~m} / \mathrm{s}$ and $1.04 \mathrm{~m} / \mathrm{s}$ respectively. Calculations at 5 psig of air give the minimum fluidization velocities for $4 \mathrm{~mm}$ granules at about $1.46 \mathrm{~m} / \mathrm{s}$. Therefore for the low superficial velocity experiment, granules in the downcomer were not fluidized, while in high superficial 
velocity experiment, granules in downcomer were fluidized. Granule fluidization in downcomer assists in releasing the trapped fly ash.

The two dimensionless numbers for controlling the collection mechanism are St and Re changed (Table 4.12). Values of St and Re for the high superficial velocity test were twice the values of the low superficial velocity test. Gal el al.'s research [4] found that both of the large St and large Re numbers could improve filter collection efficiency, which is not consistent with the experimental phenomenon observed in this research. Previous investigators $[8,9]$ also found that higher superficial velocity would reduce the effectiveness of a granular filter. For the type of moving bed granular filter used in this research, evidence supports suggests that larger St number and/or a high superficial velocity diminishes filter collection efficiency.

\subsubsection{Occurrence of dust cake}

Previous researchers have suggested that build-up of dust cake around granules is important to high efficiency performance of granular filters. Although pressure drop through a filter increased with time before reaching a steady state level (Figure 4.18), the time to reach steady state was too short to determine whether filter efficiency displayed similar behavior (it took 30 minutes or longer to catch enough dust in sampling filters to measure dust concentrations in the gas stream after the granular filter and less than 30 minutes for the granular filter to reach steady state). Figure 4.18 does not provide strong evidence that efficiency of dust removal was a function of dust-to-granule ratio, at least in the range evaluated (dust ratios of $3.33-11.04 \%$ ).

A boroscope was used to examine the granular filter after completion of a test to see whether dust cake formed in the filter in the manner hypothesized at the outset of this project. 
For the vary lowest dust-to-granule ratios, no dust cake was evident at the interfacial region between the entering gas flow and the granule bed. Insertion of the boroscope into the granular bed showed no perceptible gradient of dust through the bed. On the other hand, at dust ratios on the order of $10 \%$ or higher, a very prominent dust cake formed at the interface of entering dust and granular bed, as shown in Figure 4.27 a. Insertion of the boroscope through this dust cake and into the bed revealed very little dust below the surface of the bed, as illustrated in Figure 4.27 b. This behavior is very similar to that of ceramic candle filter, in which a dust cake is considered critical to high efficiency of dust filtration. It may be that even higher dust-to-granule ratios would have demonstrated improvements in filter performance; however, the system as currently configured could not achieve higher ratios and much longer sampling time would be required to improve measurement sensitivity for resolving higher filtration efficiency.
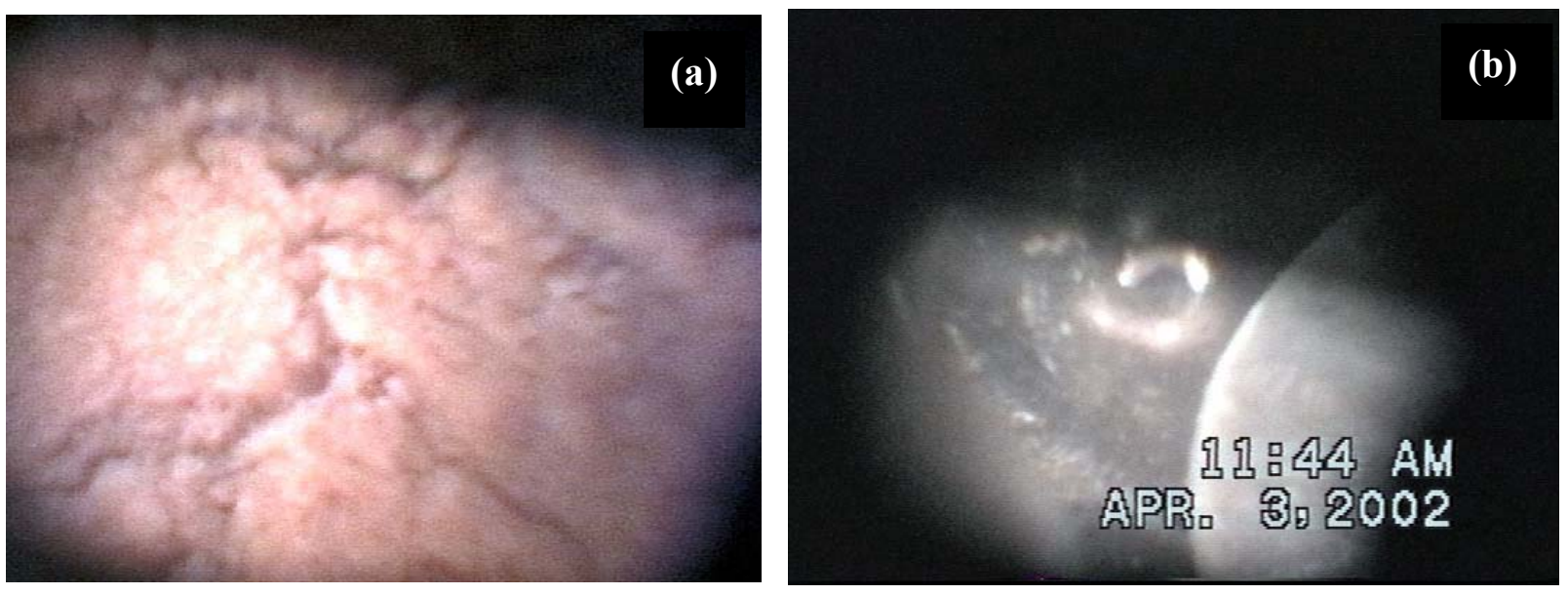

Fig. 4.27. Boroscopic examination of granules for dust cake (dust-to-granule ratio $=9.8 \%$ ) (a) Dust cake evident at interfacial region (b) Little evidence of dust just below the interfacial region. 


\section{CONCLUSIONS}

The goal of this research was to develop a moving bed granular filter for the removal of particles in particle-laden gas at high efficiency and low pressure drop. A second objective was to study cake formation and the effects of variables superficial velocity, dust feed rate, and granular flow rate on filtration performance. Using regressed correlations, an optimum operating region has been found giving filter performance that simultaneously has a high collection efficiency and low pressure drop across the bed.

The design features incorporated in our granular filter different from traditional designs are cyclonic motion, counter-current flow, and flow straightening fins and the natural conical shape of the bed. The performance of this bed has been found to give promising low pressure drop and high particle collection efficiency. The filter system is able to achieve collections efficiencies approaching $100 \%$ with a standard deviation of $0.113 \%$ and pressure drop as low as $0.689 \mathrm{kPa}(0.1 \mathrm{psid})$.

Within the operating range of each independent variable, the results from Central Composite Design show that superficial velocity is significant in predicting pressure drop. However, superficial velocity was found to be insignificant in predicting collection efficiency. The granular flow (its squared value) rate was found to have a significant effect on both pressure drop and efficiency, while dust feed rate is important in the predicting both pressure drop and collection efficiency. The significance of $\mathrm{GF}^{2}$ designates the parabolic nature of granular flow rate in explaining pressure drop as well as efficiency in moving bed granular filters.

Contour plots generated from regressed equations indicate a saddle behavior, which means there are two different slopes or relationships (both positive and negative) between 
each independent variable and each response variable. The contour plots indicate that the independent variables are closely related to each other in predicting pressure drop and efficiency.

Another purpose of this research was to study the performance of the moving bed granular filter under similitude conditions and to gain a better understanding of the filtration mechanism in moving bed filters. Based on experimental results, several conclusions can be made.

1. This type of moving bed filter is robust having a high efficiency when $4 \mathrm{~mm}$ granules are used as the filtration media and the superficial velocity is $0.2 \mathrm{~m} / \mathrm{s}$ under similar conditions. Based on similitude theory, the filter should still achieve similar collection efficiency as the corresponding prototype.

2. Under the same hydrodynamic conditions, tests with $4 \mathrm{~mm}$ granules showed higher collection efficiency than tests with $2 \mathrm{~mm}$ granules. The possible explanation is that for 2 $\mathrm{mm}$ granules, the granules in downcomer were fluidized allowing trapped flyash ash to move through the filter bed more easily and reducing the collection efficiency.

3. Flows at high pressure may help to improve the collection efficiency of the filter. A higher-pressure gas stream has a greater Re number possibly resulting in turbulent wakes behind the filtration granules helping to capture the ash particles.

4. Superficial velocity has a significant (negative) influence on the performance of the filter. There is good evidence that a high velocity results in ash breaking through the filter bed and exiting at the outlet. However, the result is not consistent with the research of Gal el al.[4]. They found that either a larger St number or a higher superficial velocity could improve the collection efficiency of the filter. The difference in geometry between the filters 
may explain this difference. The filtration mechanism in moving bed granular filter is complex and depends on filter dimensions and configuration, fluid properties, the filtration media properties, as well as other properties. 


\section{REFERENCES}

Basetty, P. (1997) Improvements on low-cost high resolution CT system, MS Thesis, ISU.

Blasewitz, A. G. and B. F. Judson, (1955) Chem. Eng. Progress, 51(1), 6J-11J

Brown, R. C. (1997) Filtration \& Separation, March, pp. 165-171.

Cooper, D. W. and Reist, P. C. (1973) J. Colloid Interface Sci., 45, pp. 18-26.

Engelbrecht, H. L. (1965) J. Air Pollut. Control Assoc.15, 43-45.

Freidlander, S. K. (1977). Smoke, Dust, and Haze, John Wiley \& Sons, NY.

Fuchs, , N. A. (1989). The Mechanics of Aerosols, Revised Edition, C. N. Davies, Translator \& Editor, Dover Publications, Inc., Mineola, N.Y.

Gal, E., Tardos, G., and Pfeffer, R. (1985). AIChE J. 31, 1093-1104.

Geffken, J., et al. (1979) Symp. on Transfer and Utilization of Particulate Control Technology, Vol. 3, EPA 600/7-70-044c, pp. 471-488.

Glicksman, L.R., M. Hyre, and K. Woloshun. (1993). Powder Technology 77, 177-199.

Goren, S. L. (1979) Symp. on Transfer and Utilization of Particulate Control Technology, Vol. 3, EPA-600/7-79-044c, pp. 459-469.

Guillory, J. L. (1978) Proc. $5^{\text {th }}$ Int. Conf. On FBC, Vol. 3, pp. 567-582.

Gutfinger, C. and Tardos, G. E. (1979) Atmosph. Envir. 13, 853-867.

Gutfinger, C., Fichman, M., and Pnueli, D. (1991) Aerosol Science \& Technology 15, 217227.

Hodkinson, J. R. Aerosol Sci., C.N. Davies ED., (1966), Academic Press, N.Y., , pp. 287357.

Hall, H. J. and J. C. Munday (1946) Purification of gases. U.S. Patent 2,411,208.

Juvinall, R. A., (1970) Sand-bed filtration of Aerosols. U.S. AEC Rep. ANL-7683, NTIS..

Jung, Y. and Tien, C. (1991) J. Aerosol Science 22, 187-200.

Kalinowski, W. and Leith, D. (1981) Environment International, Vol. 6, 379-386 
Kunii, D and Levenspiel, O, (1991), Fluidization Engineering, $2^{\text {nd }}$ Ed., 68-70, ButterworthHeinemann, Boston.

Kuo, J. T., et al. (1998a) Proc. Nat. Sci. Council ROC (A) 22, 17-34.

Kuo, J. T., et al. (1998b) J. Petroleum Science \& Engineering, 20, 529-534.

Lipert, T. E. et al. (1981) Proc. High Temperature, High Pressure Particulate and Alkali Control U.S. DOE Contractors' Meeting, CONF-810249, pp. 471-489.

Molian, P., private communication, Iowa State University, 1998.

Miyanoto, S. and H. L. Bohn (1974) J. Air Pollut. Control Assoc. 24, 1051-1054.

Moresco, L. L and Cooper, J. L. (1981) Symp. on Industrial Aerosol Technology, AIChE $91^{\text {st }}$ National Mtg., Detroit, MI.

National Resource Council (1995) Coal: Energy for the Future, National Academy Press, Washington, D. C., pp. 6-10.

Nutkis, M.S., et al. (1978) Proc. $5^{\text {th }}$ Int. Conf. FBC, Vol. 3, pp. 504-515.

Otani, Y., K. Miyajima, and H. Emi (1990) Proc. International Aerosol Conference, pp. 733-735, New York, Elmsford: Pergamon Press Ins.

Peukert, W. and Loffler, F. (1991) Powder Technology 68, 263-270.

Saxena, S. C. (1981) Recent developments in granular bed filters. Morgantown Energy Technology Center Report, DOE/METC-82-7.

Saxena, S. C. et al. (1985) Prog. Energy Combust. Sci. 11, 193-251.

Sittig, M. (1977) Pollution Technology Rev. No. 34, Noyes Data Corp., Park Ridge, NJ.

Squires, A.M. and R. Pfeffer (1970) J. Air Pollut. Control Assoc. 20, 534-538.

Staubly, R. K. et al. (1994) Overview of METC's gas stream cleanup program. Int. Pittsburgh Coal Conf., Pittsburgh, PA.

Swift, W. M., et al. (1978) Proc. $5^{\text {th }}$ Int. Conf. FBC, Vol. 2, pp. 493-521.

Thring, M. W. and W. Strauss (1963) Trans.Inst. Chem. Engrs. 41, 248-254.

Tien, C. (1989) Granular filtration of aerosols and hydrosols, Butterworth, NY. 
Tsubaki, J. and Tien, C. 1988. the Canadian Journal of Chemical Engineering, Vol 66, 271275

Vardeman, S. B. and J. M. Jobe (1999) Statistical quality assurance methods for engineers. New York: John Wiley \& Sons, Inc.

Wigton, H. F. (1978) Proc. $5^{\text {th }}$ Int. Conf. On FBC, Vol. 3, pp. 583-605.

Wilder, E. A. (1896) Filter. U.S. Patent 557,177.

Wilson, K. B. and Haas, J. C. (1994) Proc. Eleventh International Pittsburgh Coal Conference, Vol. 1, pp. 131-136, Pittsburgh, PA.

Wu, J. et al. 1998. Coal Conversion Vol. 21, 63-67, in Chinese.

Yang, W. C et al. (1992) Proc. $7^{\text {th }}$ Eng. Found. Conf. on Fluidization, pp. 703-712, Australia.

Zevenhoven, C. A. P., B. Scarlett, and J. Andries (1992) The filtration of PFBC combustion gas in a granular bed filter. Filtration and Separation, 29(3), 239-244. 


\section{APPENDIX A. ISOKINETIC SAMPLING VELOCITY CALCULATION}

A run will be assumed having the following parameters:

Rotameter setting, Qrot $=31.5 \cdot S C F M$

Pressure at the inlet of rotameter, $P a b s_{\text {rot }}=56.7 \cdot \mathrm{psia}$

Temperature of the air, Temp $=72.5 \cdot F$

S type pitot pressure difference, $\Delta P_{\text {volt }}=2.325 \cdot$ volt

Inlet duct pressure, $\mathrm{Pabs}_{\text {in }}=21.3 \cdot \mathrm{psia}$

Standard atmospheric pressure, $P$ std $=14.7 \cdot$ psia

Inlet duct inside diameter, $D=4 \cdot$ in

Sampling probe inside diameter, $d=0.08625 \cdot$ in

Air gas constant, $R=53.5713 \cdot \frac{f t \cdot l b f}{l b \cdot R}$

Density of water, $\rho_{\text {water }}=62.4 \cdot \frac{\mathrm{lb}}{\mathrm{ft}^{3}}$

Analysis:

Real volumetric flow rate passing through rotameter at 1atm:

$$
\begin{aligned}
& Q=Q r o t * \sqrt{\frac{\operatorname{Pr} o t}{P s t d}} \\
& Q=31.5 * \sqrt{\frac{56.7}{14.7}}=1.031 \cdot \frac{f t^{3}}{\mathrm{sec}}
\end{aligned}
$$

Real volumetric flow rate passing through inlet duct at inlet duct pressure:

$$
Q_{\text {in }}=Q * \frac{P s t d}{P a b s_{i n}}
$$


$Q_{\text {in }}=(1.031) \frac{f t^{3}}{\sec } * \frac{(14.7) p s i a}{(21.3) p s i a}=0.712 \cdot \frac{f t^{3}}{\mathrm{sec}}$

Real air velocity through inlet duct at inlet duct pressure:

$$
\begin{aligned}
V_{\text {in }} & =\frac{Q_{\text {in }}}{\frac{\pi}{4} * D^{2}} \\
V_{\text {in }} & =\frac{(0.712) \frac{f t^{3}}{\mathrm{sec}}}{\frac{\pi}{4} *(4)^{2} i^{2}}=8.154 \cdot \frac{f t}{\mathrm{sec}}
\end{aligned}
$$

Using S-type pitot tube with transducer ( 0 - 5 volt gives $0-0.1$ in $\mathrm{H}_{2} \mathrm{O}$ ), the pressure difference read by S-type pitot tube in inch of water:

$$
\Delta h=\frac{\Delta P_{\text {volt }}}{5} * 0.1=\frac{(2.325) \text { volt }}{(5) \text { volt }} *(0.1) \text { inH }_{2} \mathrm{O}=0.0465 \cdot \text { in }_{2} \mathrm{O}
$$

The pressure difference read by S-type pitot tube in $p s i$ :

$$
\begin{aligned}
& \Delta P=\rho_{\text {water }} * g * \Delta h \\
& \Delta P=(62.4) \frac{\mathrm{lb}}{f^{3}} *(32.174) \frac{f t}{\mathrm{sec}^{2}} *(0.0465) \mathrm{inH}_{2} \mathrm{O}=0.001679 \cdot \mathrm{psi} \\
& \Delta P_{\text {corr }}=\frac{\Delta P}{1.5}=\frac{(0.001679) \mathrm{psi}}{1.5}=0.001119 \cdot \mathrm{psi}
\end{aligned}
$$

Using pitot tube equation, velocity in inlet duct:

$$
V_{\text {pitot }}=\sqrt{\frac{2 * \Delta P_{\text {corr }}}{\rho_{\text {in }}}}
$$

where $\rho_{\text {in }}=\frac{\text { Pabs }_{\text {in }}}{R^{*} \text { Temp }}=\frac{(21.3) p s i}{(53.5714) \frac{f t \cdot l b f}{l b \cdot R} *(72.5+459.69) R}=0.108 \cdot \frac{l b}{f t^{3}}$ 
so, $V_{\text {pitot }}=\sqrt{\frac{2 *(0.001119) p s i}{(0.108) \frac{l b}{f t^{3}}}}=9.819 \cdot \frac{f t}{\mathrm{sec}}$

Volumetric flow rate through sampling probe:

$Q_{s p}=V_{p i t o t} * \frac{\pi}{4} * d^{2}$

$Q_{s p}=(9.819) \frac{f t}{\sec } * \frac{\pi}{4} *(0.08625)^{2} i^{2}=0.0003984 \cdot \frac{f t^{3}}{\mathrm{sec}}$

Finally, small rotameter setting for isokinetic sampling:

$$
\begin{aligned}
Q_{S C F H} & =Q_{s p} * \frac{P a b s_{\text {in }}}{P s t d} \\
Q_{S C F H} & =(0.0003984) \frac{f t^{3}}{\sec } * \frac{(21.3) p s i}{(14.7) p s i}=2.078 \cdot \frac{f t^{3}}{h r}
\end{aligned}
$$




\section{APPENDIX B. PARTICLE SIZE ANALYSIS}

Table B.1. Particle mean diameter calculation

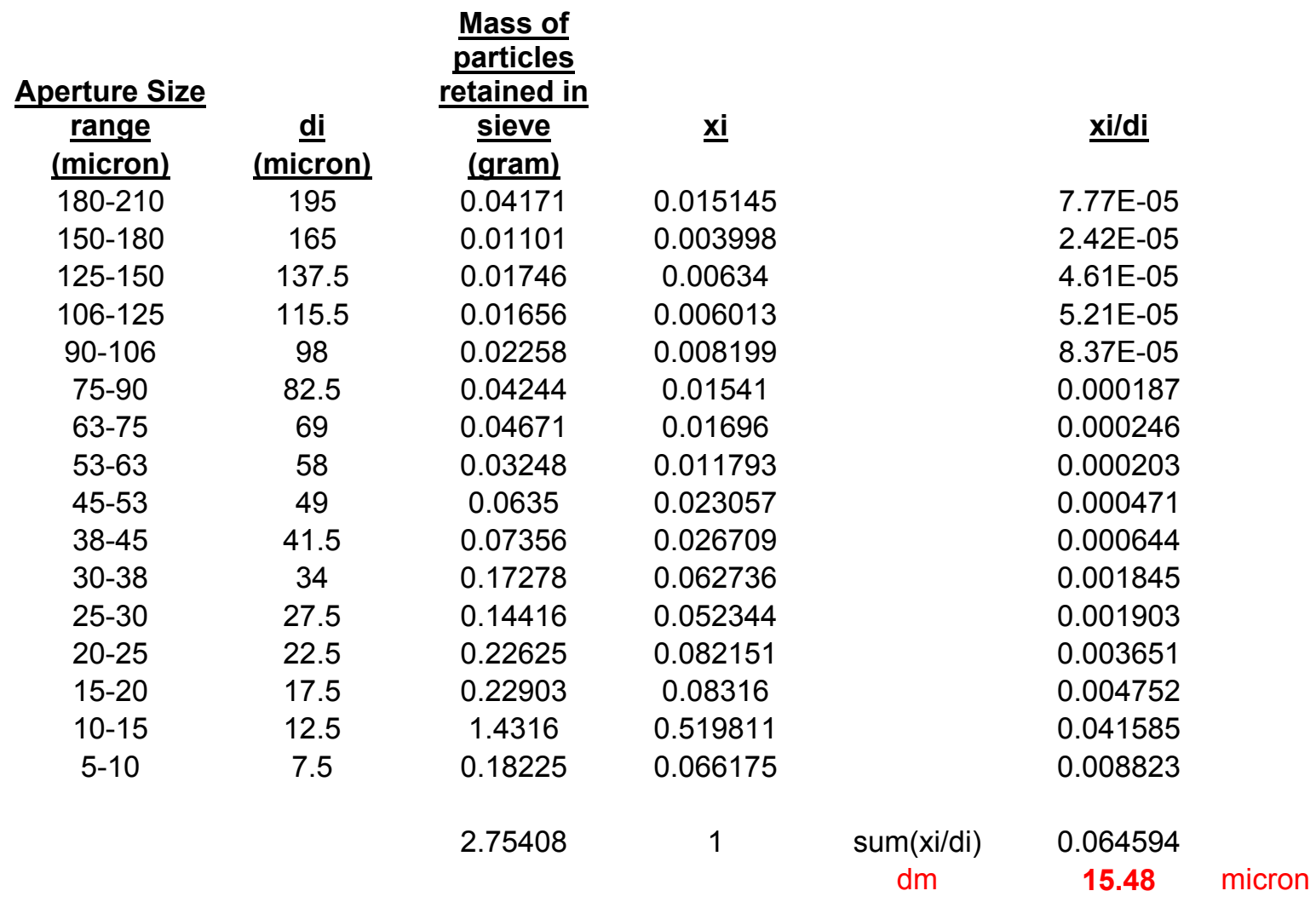




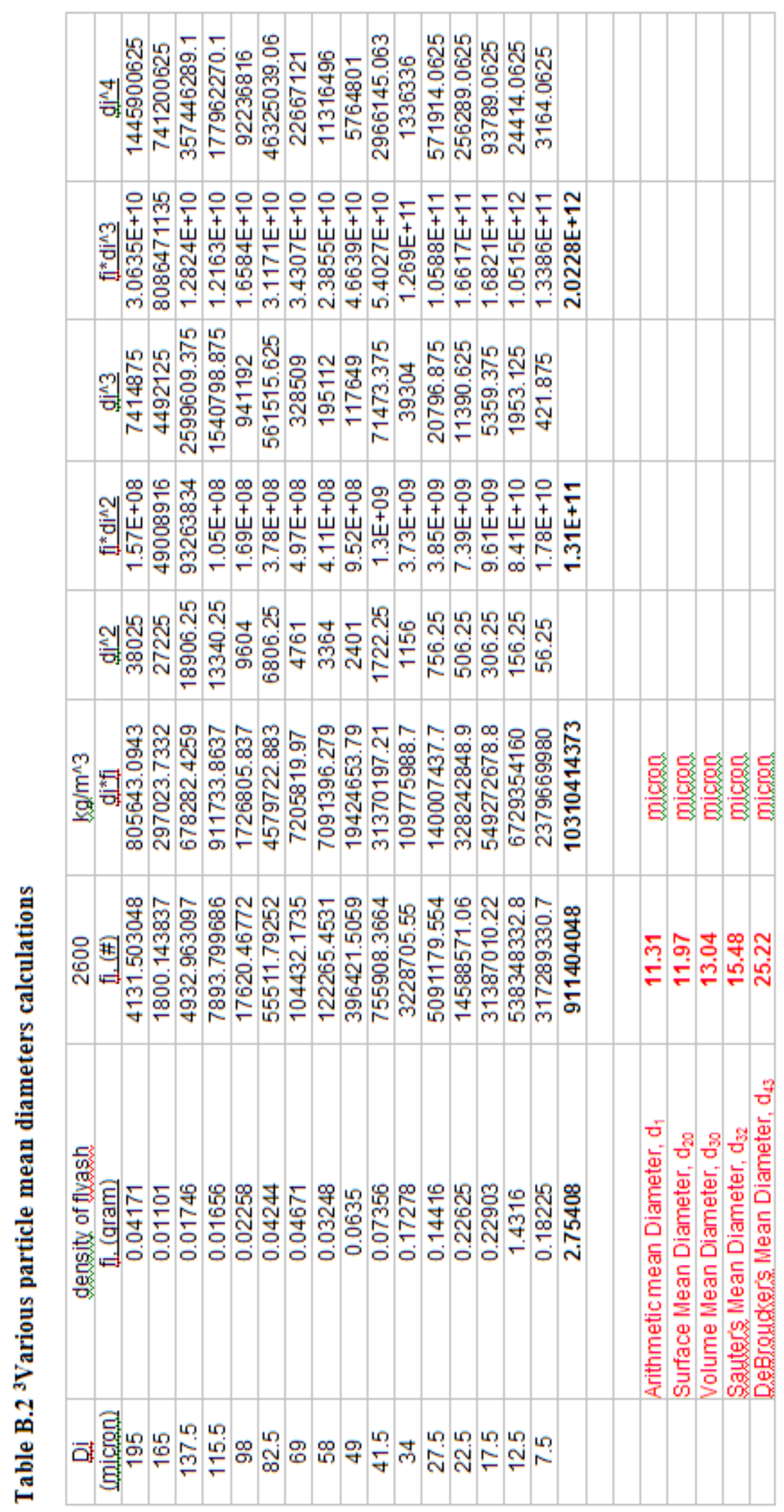

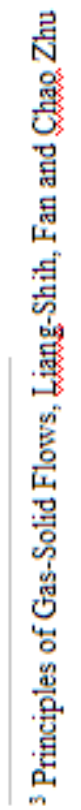




\section{APPENDIX C: FILTER BODY MECHANICAL DRAWING AND PHOTO}

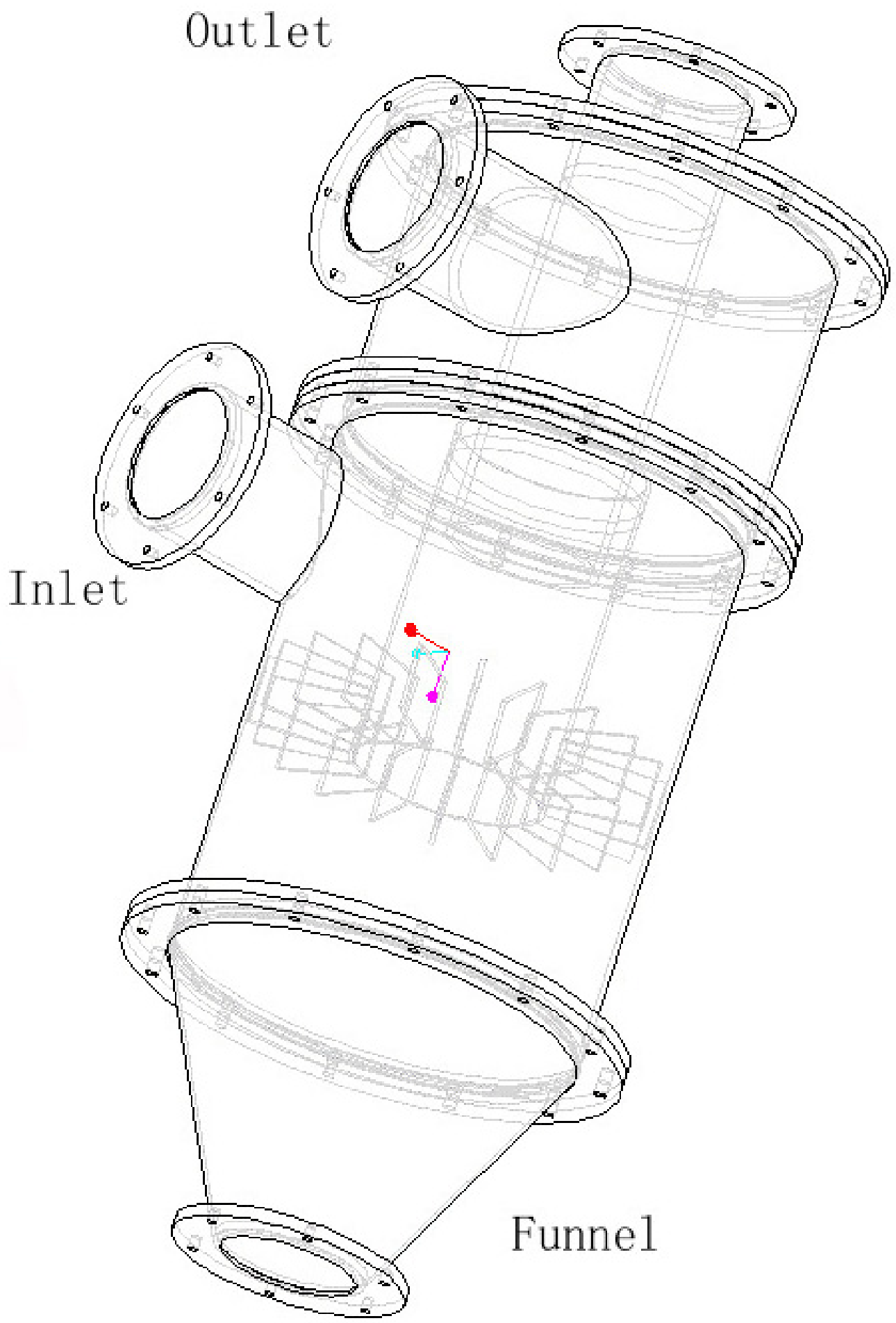

Figure C.1 Mechanical drawing of the filter body 


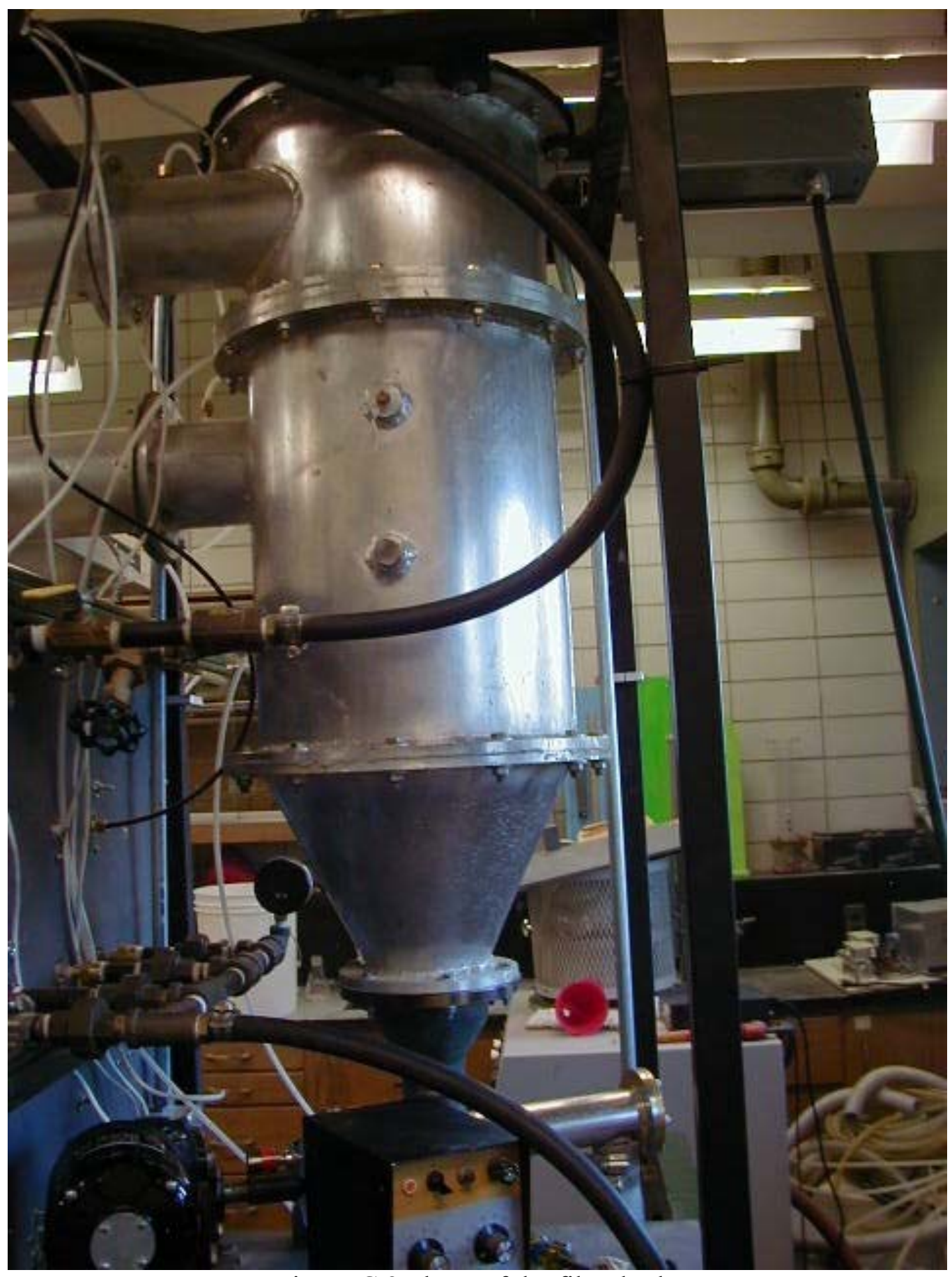

Figure C.2 Photo of the filter body 


\section{APPENDIX D. PARTICLE CONCENTRATION CALCULATION}

A run is assumed having the following parameters:

Ash sampled through sampling probe $=0.0005 \mathrm{~kg} / \mathrm{hr}$

${ }^{4}$ Volumetric air flow rate through sampling probe $=1.183 \times 10^{-5} \mathrm{~m}^{3} / \mathrm{sec}$

Temperature of the air $=73.3 \mathrm{~F}$

Density of fly ash $=2600 \mathrm{~kg} / \mathrm{m}^{3}$

${ }^{5}$ Diameter of ash particle $=17$ micron

Pressure drop across pitot tube $=0.049669$ inch of $\mathrm{H}_{2} \mathrm{O}$

Inlet duct pressure $=20.735 \mathrm{psia}$

Particle concentration in number of particle per cubic meter, $\# / \mathrm{m}^{3}$ is calculated to be $1,760,000,000$ as follow:

$\left(\frac{0.0005 \cdot \mathrm{kg} \cdot \mathrm{ash}}{1 \cdot \mathrm{hr}}\right) \times\left(\frac{1}{2600 \cdot \frac{\mathrm{kg} \cdot \mathrm{ash}}{\mathrm{m}^{3} \cdot a \mathrm{sh}}}\right) \times\left(\frac{\# \cdot \text { article }}{\frac{\pi}{6} \times\left(17 \times 10^{-6}\right)^{3} \cdot \mathrm{m}^{3} \cdot a \mathrm{sh}}\right) \times\left(\frac{1}{1.183 \times 10^{-5} \cdot \frac{\mathrm{m}^{3} \cdot \mathrm{air}}{\mathrm{sec}}}\right) \times\left(\frac{1 \cdot \mathrm{hr}}{3600 \cdot \mathrm{sec}}\right)$

Particle concentration in gram of particle per cubic meter of air, $\mathrm{g} / \mathrm{m}^{3}$ is calculated to be

11.74 as follow:

$\left(\frac{0.0005 \cdot \mathrm{kg} \cdot \mathrm{ash}}{1 \cdot \mathrm{hr}}\right) \times\left(\frac{1000 \cdot \mathrm{g} \cdot \mathrm{ash}}{1 \cdot \mathrm{kg} \cdot \mathrm{ash}}\right) \times\left(\frac{1}{1.183 \times 10^{-5} \cdot \frac{\mathrm{m}^{3} \cdot a i r}{\mathrm{sec}}}\right) \times\left(\frac{1 \cdot \mathrm{hr}}{3600 \cdot \mathrm{sec}}\right)$

${ }^{4}$ See Appendix A

${ }^{5}$ See Appendix B 


\section{APPENDIX E. SUPERFICIAL VELOCITY CALCULATION}

\section{Given:}

$$
\begin{aligned}
& \text { Qstd }_{\text {rot }}:=17.5 \cdot \frac{\mathrm{ft}^{3}}{\min } \quad \text { (Rotameter setting) } \quad \mathrm{P}_{\mathrm{std}}:=14.7 \cdot \frac{\mathrm{lbf}}{\mathrm{in}^{2}} \quad \text { (Atmospheric pressure) } \\
& \operatorname{Pabs}_{\mathrm{rot}}:=83.7 \cdot \frac{\mathrm{lbf}}{\mathrm{in}^{2}} \quad \begin{array}{l}
\text { (Abs. pressure at } \\
\text { inlet rotameter) }
\end{array} \quad \mathrm{Pabs}_{\text {in }}:=18.77259803 \frac{\mathrm{lbf}}{\mathrm{in}^{2}} \quad \begin{array}{l}
\text { (Abs. inlet bed } \\
\text { pressure) }
\end{array} \\
& \text { Temp }:=(69.9+459.69) \cdot \mathrm{R} \quad \text { (Air temperature) } \quad \mathrm{R}:=53.5714 \frac{\mathrm{ft} \cdot \mathrm{lbf}}{\mathrm{lb} \cdot \mathrm{R}} \quad \begin{array}{l}
\text { (Universal Gas } \\
\text { Constant) }
\end{array} \\
& \rho:=\frac{\text { Pabs }_{\text {in }}}{\mathrm{R} \cdot \mathrm{Temp}} \quad \text { (Air density) } \mathrm{d}:=0.08625 \mathrm{in} \quad \begin{array}{l}
\text { (Sampling proble } \\
\text { inner diameter) }
\end{array} \\
& \rho=1.526 \frac{\mathrm{kg}}{\mathrm{m}^{3}} \quad \rho=0.095 \frac{\mathrm{lb}}{\mathrm{ft}^{3}} \quad \mathrm{D}:=4 \cdot \mathrm{in} \quad \text { (Inlet duct inner diameter) }
\end{aligned}
$$

Real volumetric flow rate @ 1 atm of rotameter:

$$
\mathrm{Q}:=\operatorname{Qstd}_{\text {rot }} \cdot\left(\frac{\text { Pabs }_{\text {rot }}}{\mathrm{P}_{\text {std }}}\right)^{\frac{1}{2}} \quad \mathrm{Q}=0.696 \frac{\mathrm{ft}^{3}}{\mathrm{sec}}
$$

Real volumetric flow rate @ inlet duct pressure:

$$
\mathrm{Q}_{\text {in }}:=\mathrm{Q} \cdot \frac{\mathrm{P}_{\text {std }}}{\mathrm{Pabs}_{\text {in }}} \quad \mathrm{Q}_{\text {in }}=0.545 \frac{\mathrm{ft}^{3}}{\mathrm{sec}}
$$

$\underline{\text { Real air velocity in inlet duct: }}$

$$
\mathrm{V}_{\text {in }}:=\frac{\mathrm{Q}_{\text {in }}}{\frac{\pi}{4} \cdot \mathrm{D}^{2}} \quad \mathrm{~V}_{\text {in }}=6.245 \frac{\mathrm{ft}}{\mathrm{sec}} \quad \mathrm{V}_{\text {in }}=1.903 \frac{\mathrm{m}}{\mathrm{sec}}
$$




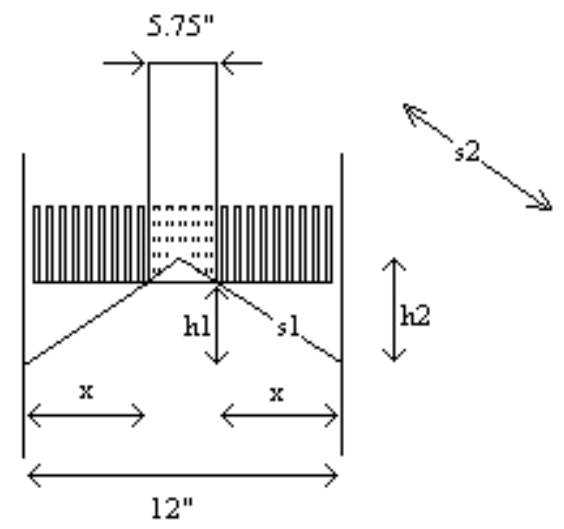

Figure E.1 Dimensions for superficial velocity calculation

$$
\begin{aligned}
& \mathrm{x}:=\frac{(12-5.75)}{2} \\
& \theta:=52 \quad \text { (Angle of repose) } \\
& \mathrm{h}_{1}:=\mathrm{x} \cdot \tan \left(\frac{\theta}{180} \cdot 3.1416\right) \quad \mathrm{h}_{1}=4 \\
& \mathrm{~h}_{2}:=\frac{12}{2} \cdot \tan \left(\frac{\theta}{180} \cdot 3.1416\right) \quad \mathrm{h}_{2}=7.68 \\
& \mathrm{~s}_{1}:=\left[(\mathrm{x})^{2}+\mathrm{h}_{1}{ }^{2}\right]^{\frac{1}{2}} \quad \mathrm{~s}_{1}=5.076 \\
& \mathrm{~s}_{2}:=\left(6^{2}+\mathrm{h}_{2}{ }^{2}\right)^{\frac{1}{2}} \quad \mathrm{~s}_{2}=9.746 \\
& \mathrm{~S}:=3.1416(6) \cdot \mathrm{s}_{2}-3.1416(3.125) \cdot \mathrm{s}_{1}
\end{aligned}
$$$$
\text { surface area in inch^2) }
$$

\section{CALCULATION OF SUPERFICIAL VELOCITY:}

$$
\begin{aligned}
& \text { Area }:=\mathrm{S} \cdot \text { in }^{2} \\
& \mathrm{~S}_{\mathrm{vel}}:=\frac{\mathrm{Q}_{\text {in }}}{\text { Area }} \quad \mathrm{S}_{\mathrm{vel}}=0.179 \frac{\mathrm{m}}{\mathrm{sec}}
\end{aligned}
$$




\section{APPENDIX F: APD FULL-QUADRATIC MODEL}

Table F.1 shows a full-quadratic model obtained with its analysis. Under the section of 'Effect Tests' in Table F.1, the coefficient of determination $\left(\mathrm{R}^{2}\right)$ for this model is 0.821275 , implying that about $82 \%$ of the variability in APD is explained by the quadratic relationship between these nine variables. However, all but DL*GF has p-value greater than $0.05(\alpha)$, which indicates that all variables but $\mathrm{DL} * \mathrm{GF}$ are not important in predicting average pressure drop in this model.

\section{Table F.1: Regression analysis of a full-quadratic APD model.}

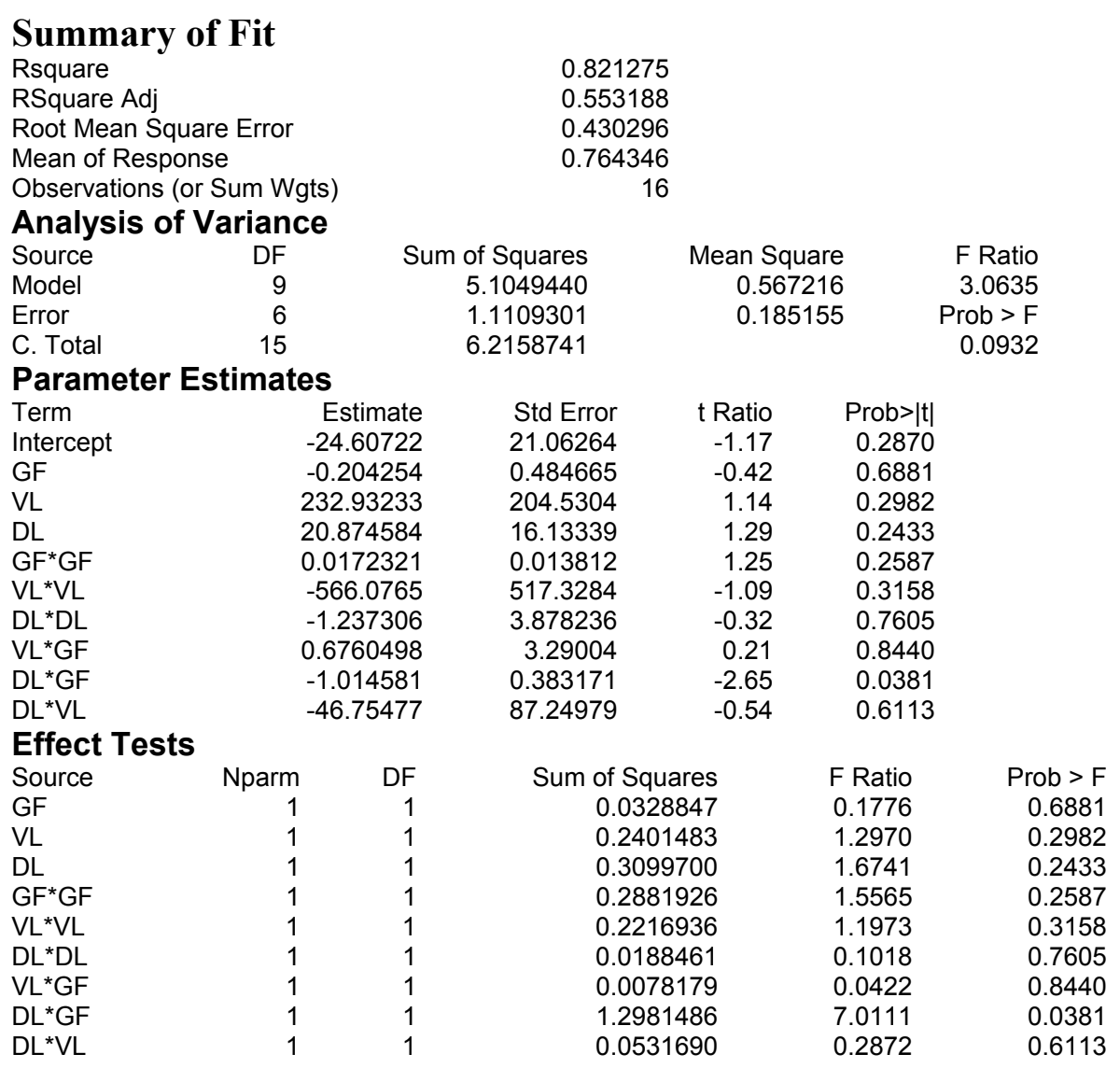




\section{APPENDIX G: AE FULL-QUADRATIC MODEL}

Table G.1 shows a full-quadratic model obtained with its analysis. Under the section of 'Effect Tests' in Table G.1, the coefficient of determination $\left(\mathrm{R}^{2}\right)$ for this model is 0.858034 , implying that about $86 \%$ of the variability in $\mathrm{AE}$ is explained by the quadratic relationship between these nine variables. However, all but GF*DL has p-value greater than 0.05 significant level $(\alpha)$, which indicates that all variables but GF* DL are not important in predicting average pressure drop in this model.

\section{Table G.1: Regression analysis of a full-quadratic AE model.}

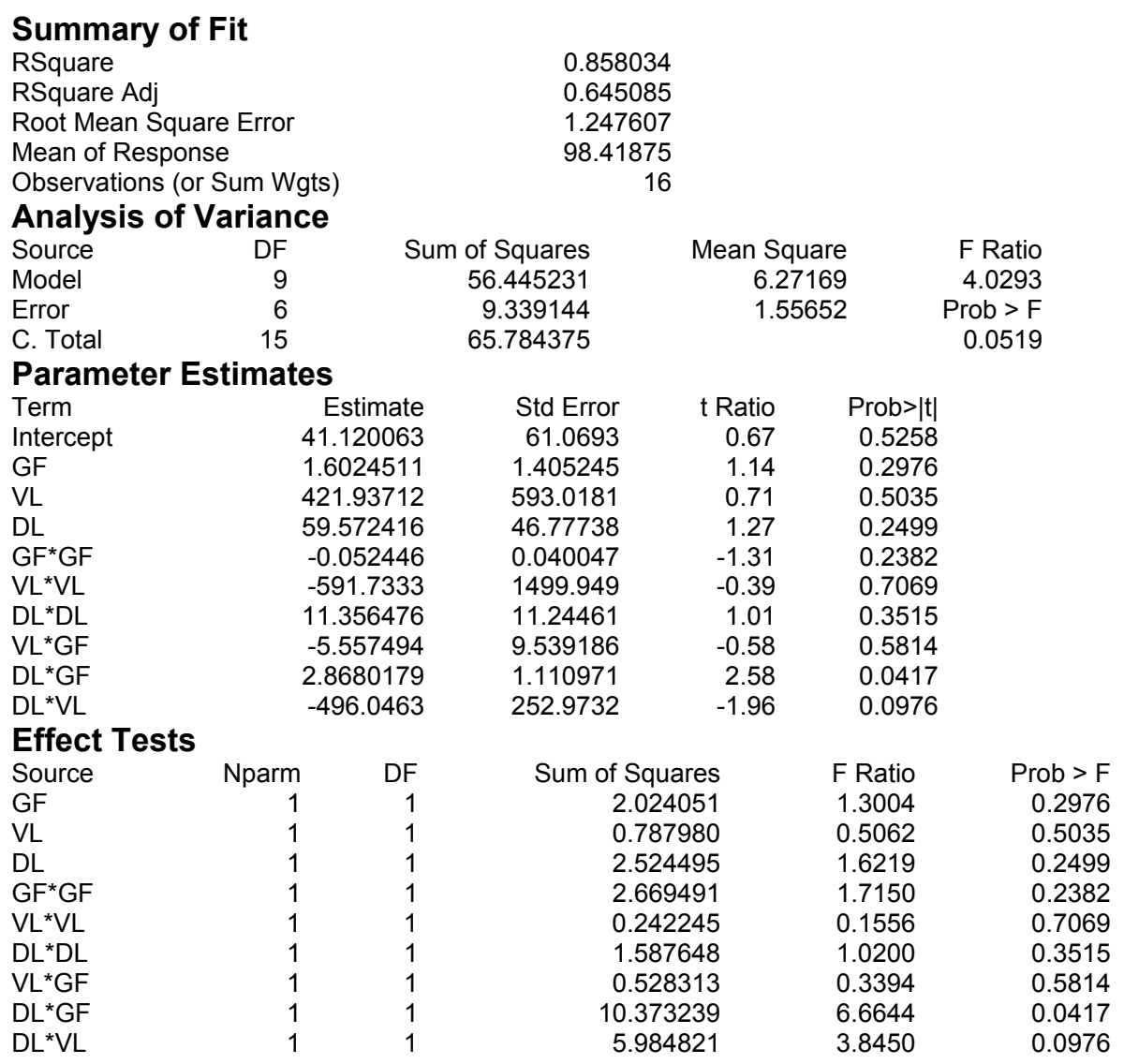




\section{APPENDIX H. CONTOUR PLOTS GENERATION}

In order to generate contour plots, the quadratic Equation 4.1 for APD and Equation 4.2 for $\mathrm{AE}$ are rearranged in the following forms:

$0.0427808 \cdot G F^{2}+(-0.570481-1.16844 \cdot D L) \cdot G F+(12.67477 \cdot D L+1.3914325-A P D)=0$

$-0.077787 \cdot G F^{2}+(1.1247304+2.2987478 \cdot D L) \cdot G F+(-23.97655 \cdot D L+96.321416-A E)=0$

Equation C. 1 and C. 2 can be further rearranged into Equation C. 3 and C.4 respectively. The decimal place presented in following equations is limited to two for simplicity. In actual plotting, every decimal place of coefficient (under Parameter Estimates section) as presented in Table 4.1 and Table 4.3 is used. These equations listed below can then used to generate contour plots.

$G F=\frac{(0.16+1.00 \cdot D L) \pm \sqrt{(-0.16-1.00 \cdot D L)^{2}-4(0.02)(-1.96+8.75 \cdot V L+10.75-A P D)}}{2(0.02)}$

$G F=\frac{(-1.12-2.30 \cdot D L) \pm \sqrt{(1.12+2.30)^{2}-4(-0.08)(-23.98 \cdot D L+96.32-A E)}}{2(-0.08)}$

For example, Equation C.3 can be used to generate contour lines (various APD) with respect to a set VL and a range of DL as presented in Figures 4.1 - 4.4. By the same token, Equation 
C.4 is used to produce contour lines (various AE) with respect to a range of DL. VL is not in the equation for AE model.

The figures below illustrate the command entered in MathCad worksheet for APD and $\mathrm{AE}$ model. In these figures, $\mathrm{x}_{1}$ is $\mathrm{GF}, \mathrm{x}_{2}$ is VL, and $\mathrm{x}_{3}$ is DL. 
Table H.1 Mathcad commands for APD contours at $V L=0.16 \mathrm{~m} / \mathrm{s}$.

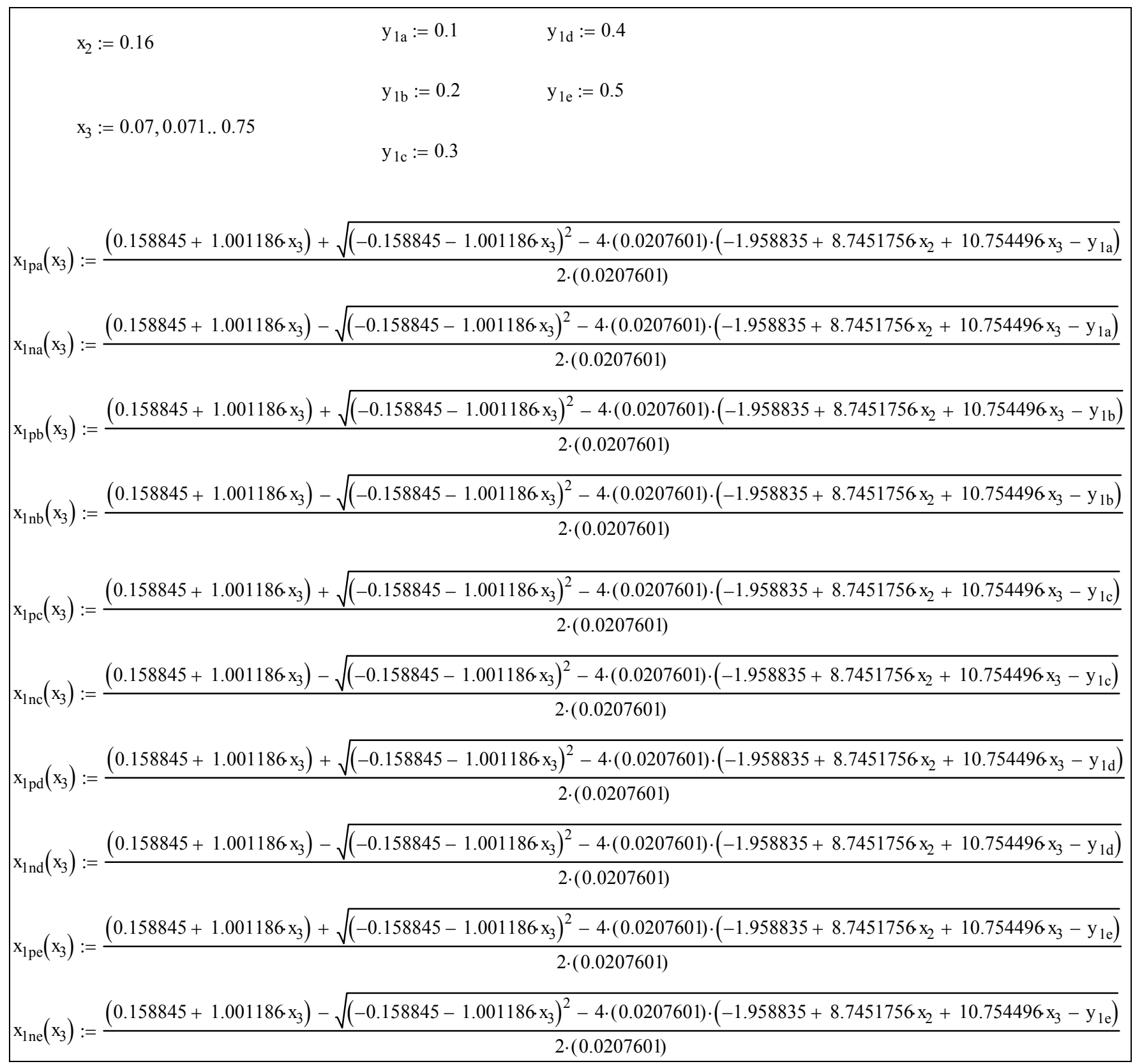


Table H.2 Mathcad commands for AE model.

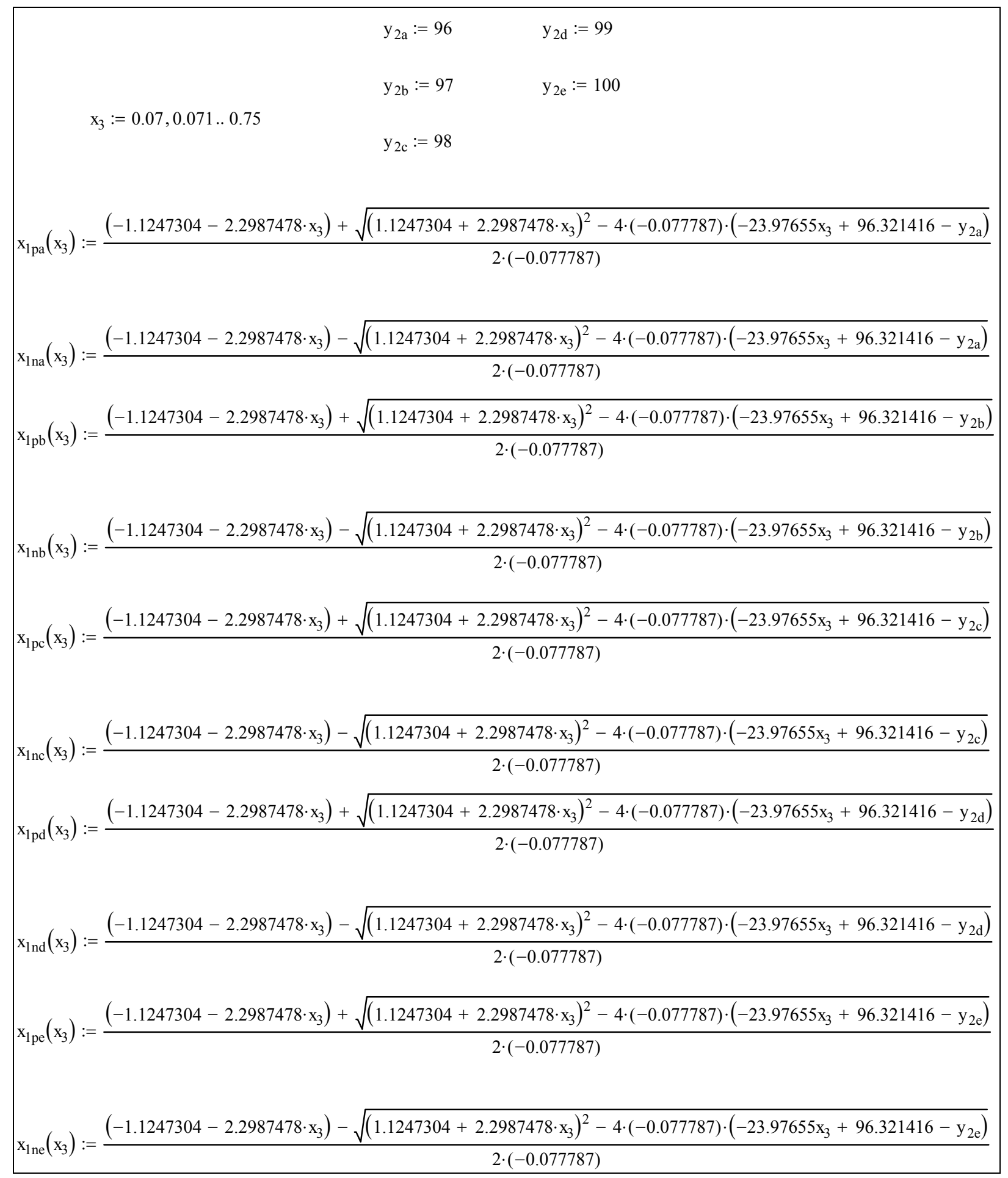




\section{APPENDIX I. UNCERTAINTY ANALYSIS FOR EFFICIENCY}

The efficiency of the filter system is calculated as:

$$
\varepsilon=1-\frac{m_{\text {out }}}{m_{\text {in }}}
$$

where mout and min are the ash sampled via isokinetic sampling probe at outlet and inlet duct respectively. Using the standard deviation of scale to be $0.000184 \mathrm{~g}$ and results from an illustrative experiment where $\mathrm{m}_{\text {out }}$ is $0.03668 \mathrm{~g}$ and $\mathrm{m}_{\text {in }}$ is $0.16679 \mathrm{~g}$, the following calculation can be done to estimate how good the final efficiency can be reported.

From Vardeman \& Jobe (1999) on propagation of error:

$$
\begin{aligned}
& \frac{\partial \varepsilon}{\partial m_{\text {out }}}=-\frac{1}{m_{\text {in }}} \\
& \frac{\partial \varepsilon}{\partial m_{\text {in }}}=\frac{m_{\text {out }}}{m_{\text {in }}^{2}} \\
& \Delta \varepsilon=\sqrt{\left(-\frac{1}{m_{\text {in }}}\right)^{2} \times V a r_{m_{\text {out }}}+\left(\frac{\left.m_{\text {out }}\right)^{2} \times{ }_{\text {in }}^{2}}{{ }^{2}} \times \operatorname{Var}_{m_{\text {in }}}\right.} \\
& \Delta \varepsilon=\sqrt{\left(-\frac{1}{0.16679}\right)^{2} \times 0.000184^{2}+\left(\frac{0.03668}{0.16679^{2}}\right)^{2} \times 0.000184^{2}}=0.00113 \\
& \varepsilon=1-\frac{0.03668}{0.16679}=0.78008 \\
& \frac{\Delta \varepsilon}{\varepsilon}=\frac{0.00113}{0.78008}=0.145 \%
\end{aligned}
$$

Since $\Delta \varepsilon=0.113 \%$, the reported efficiency has a standard deviation of $0.113 \%$. 


\section{APPENDIX J: STATISTICAL REGRESSION ANALYSIS}

1. Straight-line regression model gives the relationships between, time and filter collection efficiency, and, mass dust ratio and filter collection efficiency for four similitude experiments.

\section{a. Regression analysis on filter collection efficiency with time}

The straight-line model of $\mathrm{Y}($ Efficiency $)=\mathrm{B}_{0}+\mathrm{B}_{1} \mathrm{X}$ (Time) is applied to efficiency data points for each mass dust ratio value. Statistical software JMP was used to do the statistical analysis. All the figures and tables used below are based on the outputs and results of JMP's analysis. P-value is the statistical number for testing the null hypothesis of $B_{1}=0$, i.e. whether the slope is statistically significant. The significance level is 0.1 . When $\mathrm{P}>=0.1$, we cannot reject the null hypothesis, i.e. $\mathrm{X}$ does not help to predict $\mathrm{Y}$, or $\mathrm{X}$ has no significant linear relationship with $\mathrm{Y}$ at significance level of 0.1 . When $\mathrm{P}<0.1$, we can reject the null hypothesis, i.e. $\mathrm{X}$ does help to predict $\mathrm{Y}$, or $\mathrm{X}$ has a relationship with $\mathrm{Y}$ at significance level of 0.1 .

Figure J.1 gives the regression regression equations and P-values for various mass ratios. Since P-values are much larger than the significance level of 0.1 for all four experiments, we cannot reject the hypothesis that $\mathrm{B}_{1}=0$. In other words, time does not help to predict the filter collection efficiency; ie. efficiency is almost constant as time.

\section{b. Regression analysis on filter collection efficiency by mass dust ratio}

The straight-line model of $\mathrm{Y}($ Efficiency $)=\mathrm{B}_{0}+\mathrm{B}_{1} \mathrm{X}$ (Mass dust ratio) was applied to collection efficiency data points for four similitude experiments (Figure J.2). The Pvalue was 0.37. It is concluded that we cannot reject the hypothesis of $B_{1}=0$, i.e. mass dust ratio does not help to predict the filter collection efficiency. There is no significant linear relationship between mass dust ratio and filter collection efficiency. This means the present filter is robust for mass dust ratio within the range of $3.33 \%$ to $11.04 \%$ for similitude conditions. 


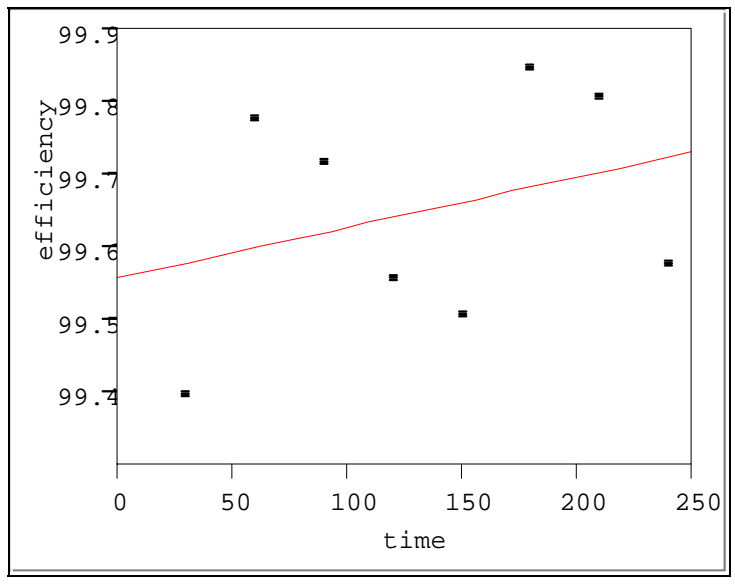

Mass dust ratio $=11.04 \%$

efficiency $=99.56+6.94 \mathrm{E}-4$ time, $\mathrm{P}=0.45$

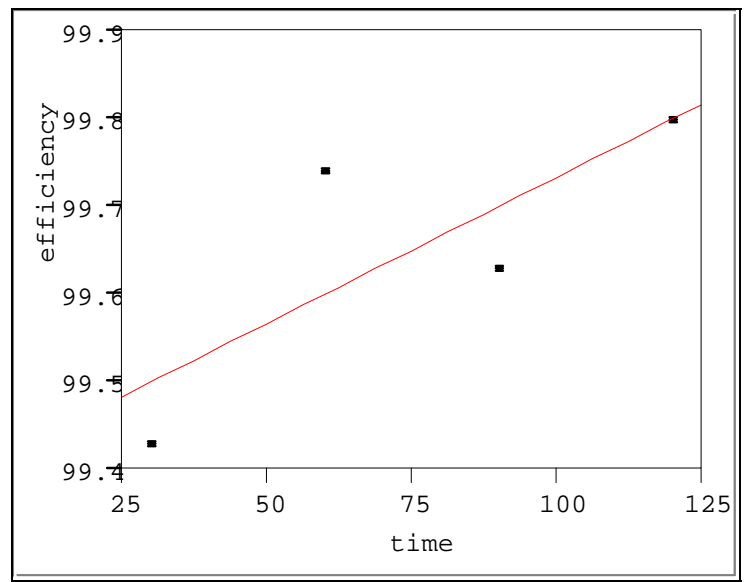

Mass dust ratio $=5.08 \%$

efficiency $=99.40+3.33 \mathrm{E}-3$ time, $\mathrm{P}=0.21$

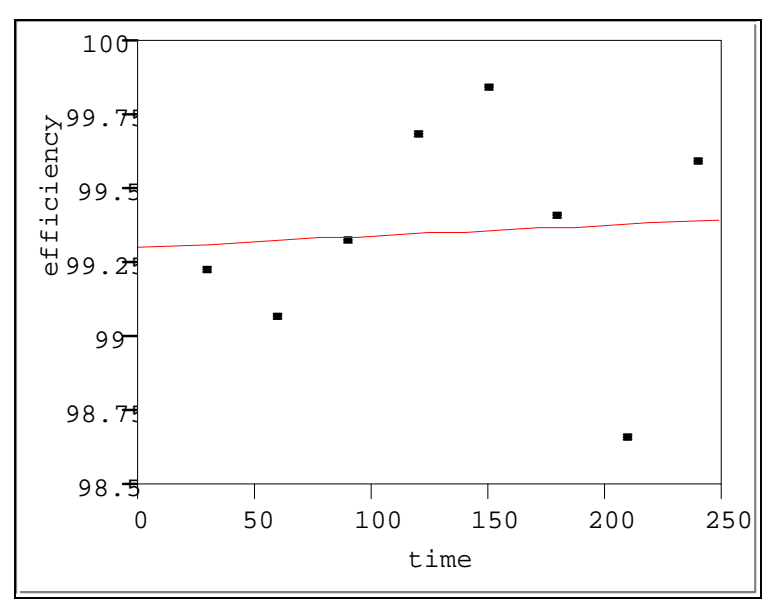

Mass dust ratio $=6.89 \%$

efficiency $=99.30+3.73 \mathrm{E}-4$ time, $\mathrm{P}=0.86$

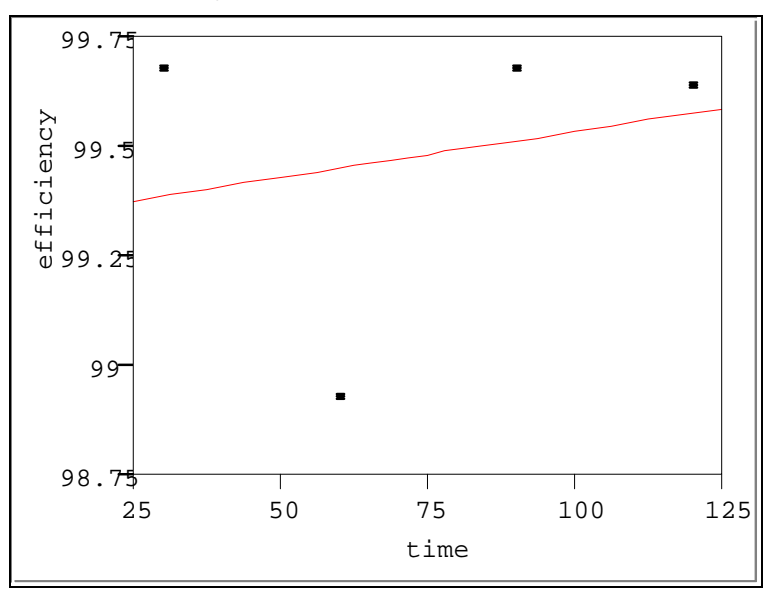

Mass dust ratio $=6.89 \%$

efficiency $=99.33+2.10 \mathrm{E}-3$ time, $\mathrm{P}=0.78$

Figure J.1 Fit of efficiency versus time with mass dust ratio 
100

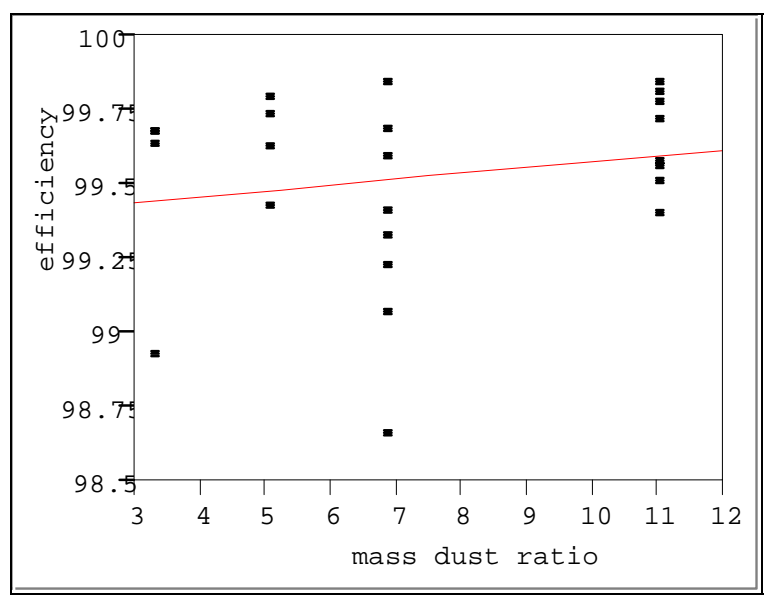

efficiency $=99.377189+0.0199201$ mass dust ratio, $\mathrm{P}=0.37$

Figure J.2 Fit of efficiency by dust-to-granule ratio

\section{Straight-line regression analysis to investigate the effect of granule size}

Figure J.3 indicates that time has no statistically significant linear relationship with filter collection efficiency for the $4 \mathrm{~mm}$ granule experiment $(\mathrm{P}$-value $=0.35>0.1)$. However, $2 \mathrm{~mm}$ granule experiment indicate a statistically significant negative linear relationship with filter collection efficiency $(\mathrm{P}$-value $=0.084<0.2)$, i.e. for the $2 \mathrm{~mm}$ granule particles, the filter collection efficiency has a decreasing trend with time.

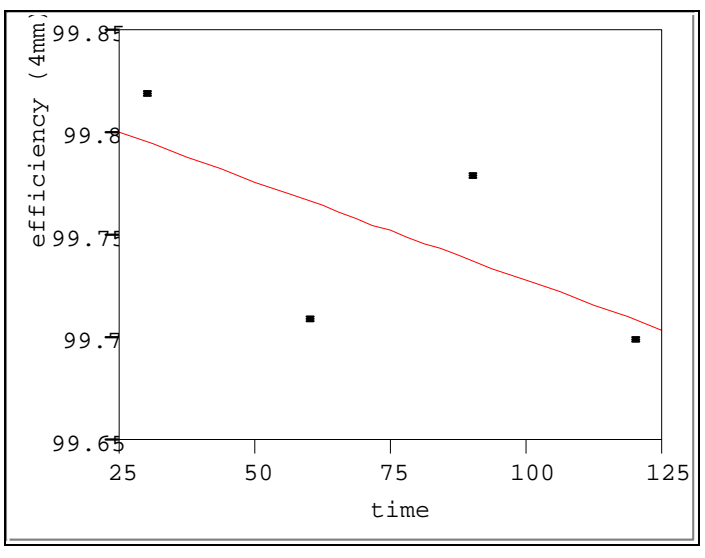

$4 \mathrm{~mm}$ granule test

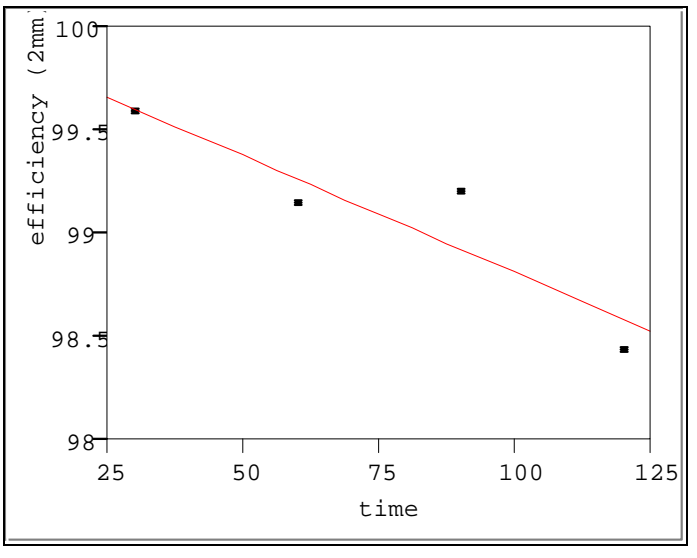

$2 \mathrm{~mm}$ granule test

efficiency $(4 \mathrm{~mm})=99.83-9.67 \mathrm{E}-4$ time, $\mathrm{P}=0.35 \quad$ efficiency $(2 \mathrm{~mm})=99.95-1.13 \mathrm{E}-2$ time, $\mathrm{P}=0.084$

Figure J.3 Fit of efficiency versus time for $4 \mathrm{~mm}$ and $2 \mathrm{~mm}$ granule experiments 
101

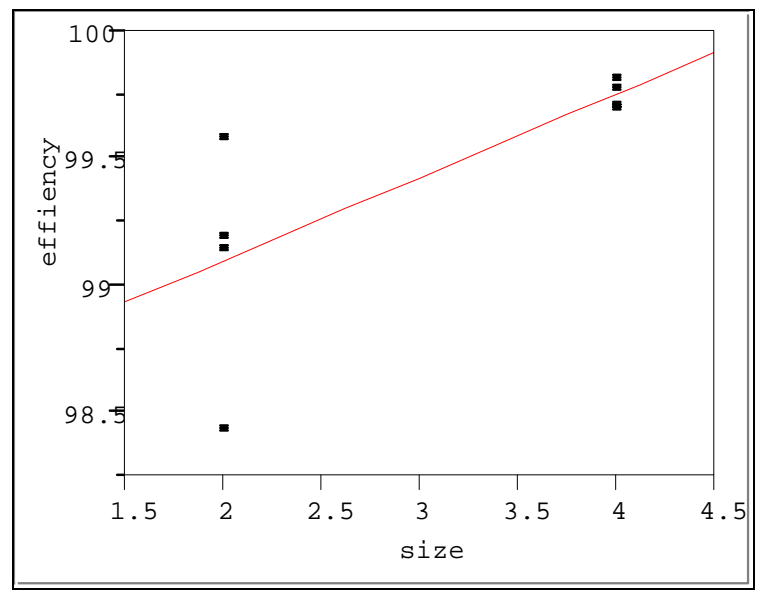

Collection Efficiency $=98.4375+0.32875$ size, $\mathrm{P}=0.034$

Figure J.4 Fit of efficiency versus granule size

Figure J.4 indicates that granule size has a statistically significant negative linear relationship with filter collection efficiency (P-value $=0.034$ ). This means that $2 \mathrm{~mm}$ granules will have lower collection efficiency statistically than $4 \mathrm{~mm}$ granules.

\section{Straight-line regression analysis to investigate the effect of bed pressure}

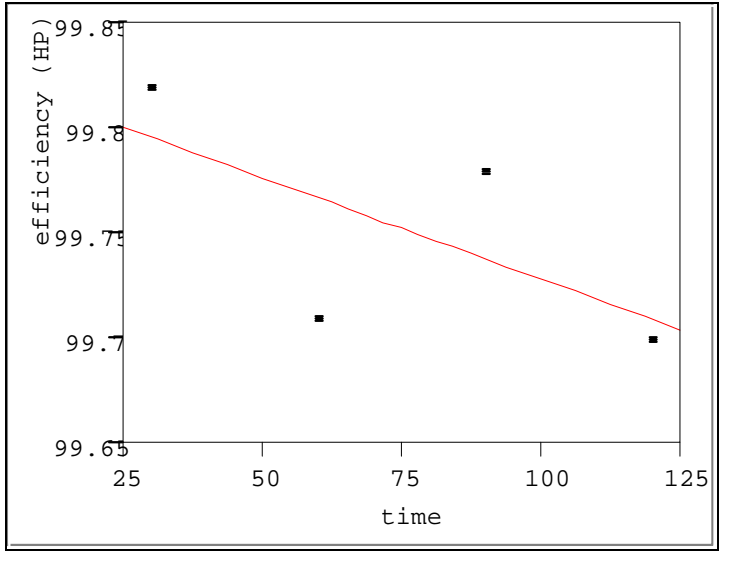

High pressure (around 23 psig) efficiency $(\mathrm{HP})=99.83-9.67 \mathrm{E}-4$ time, $\mathrm{P}=0.26$

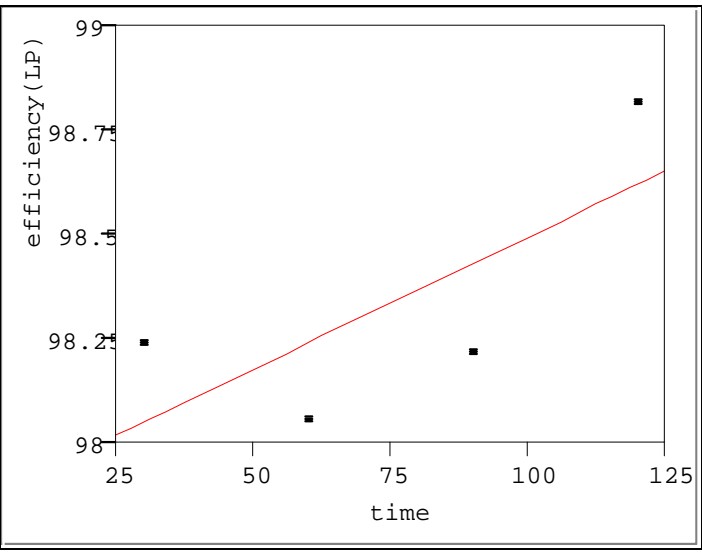

Low pressure (around $23 \mathrm{psig}$ ) efficiency $(\mathrm{LP})=97.86+6.33 \mathrm{E}-3$ time, $\mathrm{P}=0.35$

Figure J.5 Fit of efficiency versus time for high and low pressure experiments

Figure J.5 indicates that time has no statistically significant linear relationship with filter collection efficiency for both low $(\mathrm{P}$-value $=0.26)$ and high pressure $(\mathrm{P}$-value $=0.35)$ experiments. 
To do the regression analysis on the relationship between the pressure and collection efficiency, dummy variables were introduced to represent bed pressure. 1 represents high pressure, which is around 23 psig in experiment, and low pressure, which is around 5 psig, is represented by 0 . Figure J.6 indicates that pressure has a statistically significant negative linear relationship with filter collection efficiency (P-value=0.0002, much less than 0.1 ), i.e. we can reject the null hypothesis of $B_{1}=0$ with the significance level of 0.1 . The filter operated under lower pressure will have poorer collection efficiency statistically.

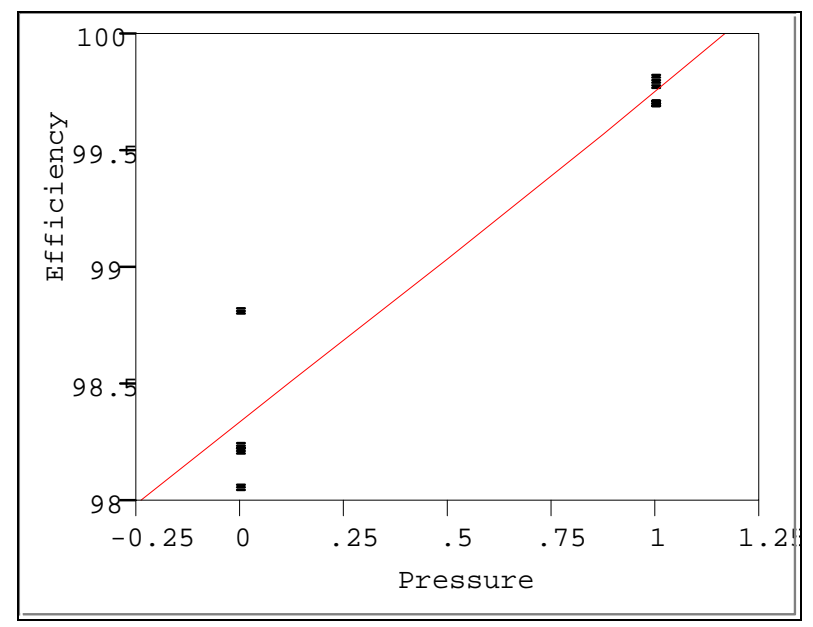

Efficiency $=98.335+1.4175$ Pressure, $\mathrm{P}=0.0002$

Figure J.6 Fit of efficiency versus pressure

\section{Straight-line regression analysis to investigate the effect of superficial velocity}

Figure J.7 indicates that time has no statistically significant linear relationship with filter collection efficiency for the low superficial velocity experiment (LSV) (P-value=0.26), but has a statistically significant linear relationship with filter collection efficiency (P-value $=0.0006)$ for the high superficial velocity (HSV) experiment, i.e. in high superficial velocity experiment, filter collection efficiency has decreasing trend as time. 
103

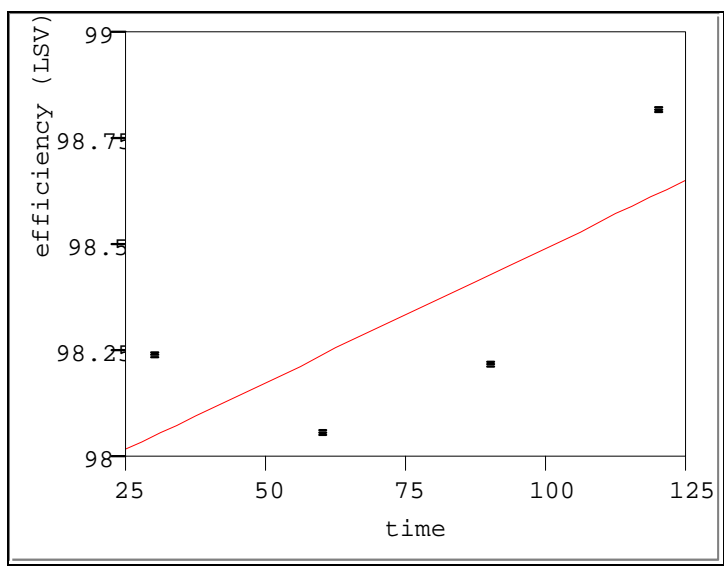

Low superficial velocity, around $0.2 \mathrm{~m} / \mathrm{s}$ efficiency $(\mathrm{LSV})=97.86+6.33 \mathrm{E}-3$ time, $\mathrm{P}=0.26$

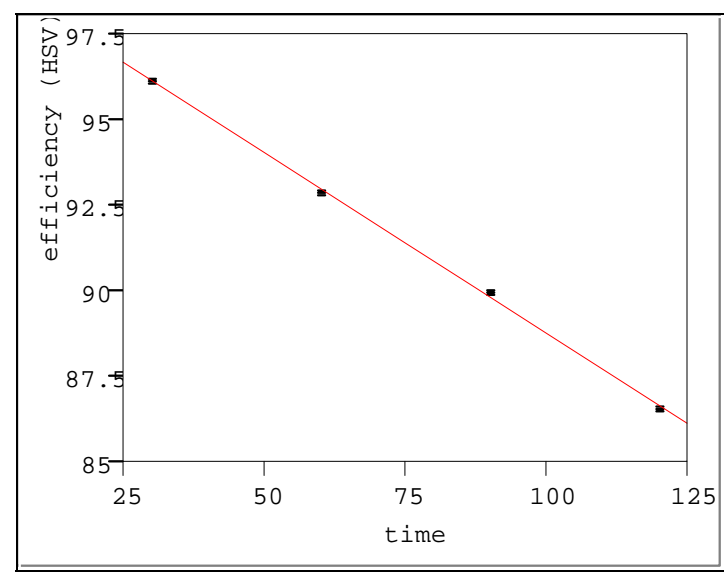

High superficial velocity, around $0.42 \mathrm{~m} / \mathrm{s}$ efficiency $(\mathrm{HSV})=99.32-0.11$ time, $\mathrm{P}=0.0006$

Figure J.7 Fit of efficiency versus time for high and low superficial velocity experiments

A dummy variable is also introduced here to represent superficial velocity: the high superficial velocity, which is around $0.42 \mathrm{~m} / \mathrm{s}$ experimentally, is represented by 1 and the low superficial velocity, which is around $0.2 \mathrm{~m} / \mathrm{s}$, is represented by 0 .

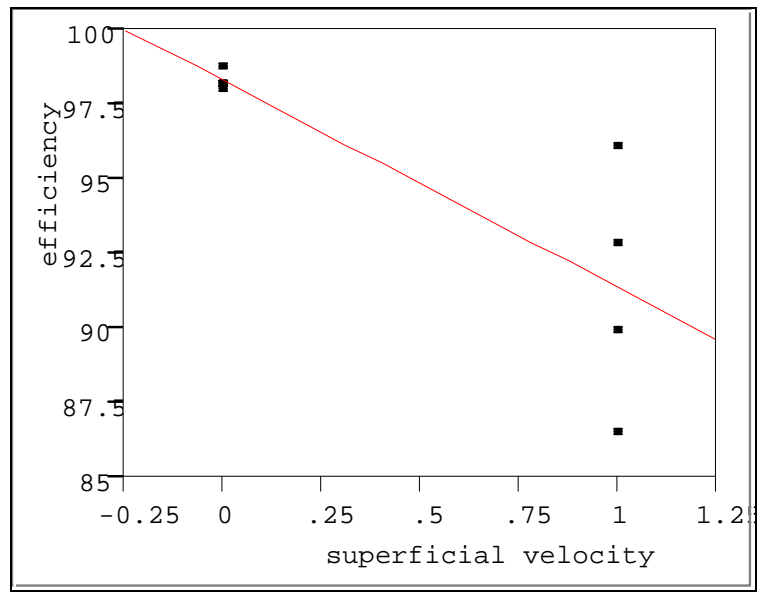

Efficiency $=98.335-6.94$ superficial velocity, Pressure, $\mathrm{P}=0.015$

Figure J.8 Fit of efficiency versus superficial velocity

Figure J.8 indicates that superficial velocity has a statistically significant negative linear relationship with filter collection efficiency (P-value $=0.015$, less than 0.1 ), i.e. the filter operated under higher superficial velocity will have the poorer collection efficiency statistically. 


\section{APPENDIX K: CALCULATIONS OF MINIMUM FLUIDIZATION VELOCITIES (4 MM AND 2 MM GRANULES)}

The concept and numbers of minimum fluidization velocities for both $4 \mathrm{~mm}$ and $2 \mathrm{~mm}$ granules are used to explain the filter collection performance.

Three equations are for calculating the minimum fluidization velocity [Kunii and Levenspiel, 1991].

$$
\begin{aligned}
& A r=\frac{\rho\left(\rho_{p}-\rho\right) g d_{p}^{3}}{\mu^{2}} \\
& \operatorname{Re}_{p m f}=\sqrt{(33.7)^{2}+0.0408 A r}-33.7 \\
& U_{m f}=\frac{\operatorname{Re}_{p m f} \mu}{d_{p} \rho} \\
& \text { Ar: Archimedes number } \\
& \rho: \text { air density } \\
& \rho_{p}: \text { granule density } \\
& d_{p}: \text { granule diamet } \\
& \operatorname{Re}_{p m f}: \text { Re number based on } U_{m f}
\end{aligned}
$$

Based on the equations above, we have the Table H.2.

Table K.1. Minimum fluidization velocities for $4 \mathrm{~mm}$ and $2 \mathrm{~mm}$ granules under 23 psig and 5 psig pressure

\begin{tabular}{|l|l|l|}
\hline Air pressure & $\begin{array}{l}23 \mathrm{psig} \text { (air density=3.10 } \\
\mathrm{kg} / \mathrm{m} 3)\end{array}$ & $\begin{array}{l}5 \mathrm{psig} \text { (air density=1.62 } \\
\mathrm{kgm} / \mathrm{m} 3)\end{array}$ \\
\hline $4 \mathrm{~mm}$ & $1.1 \mathrm{~m} / \mathrm{s}$ & $1.46 \mathrm{~m} / \mathrm{s}$ \\
\hline $2 \mathrm{~mm}$ & $0.7 \mathrm{~m} / \mathrm{s}$ & $0.93 \mathrm{~m} / \mathrm{s}$ \\
\hline
\end{tabular}

